NUREG/CR-4492

PNL-5737

\title{
Methodology for \\ Estimating Extreme Winds for \\ Probabilistic Risk Assessments
}

Prepared by J. V. Ramsdell, D. L. Elliott, C. G. Holladay, J. M. Hubbe

Pacific Northwest Laboratory

Operated by

Battelle Memorial Institute

Prepared for

U.S. Nuclear Regulatory

Commission 


\section{NOTICE}

This report was prepared as an account of work sponsored by an agency of the United States Government. Neither the United States Government nor any agency thereof, or any of their employees, makes any warranty, expressed or implied, or assumes any legal liability of responsibility for any third party's use, or the results of such use, of any information, apparatus, product or process disclosed in this report, or represents that its use by such third party would not infringe privately owned rights

\section{NOTICE}

\section{Availability of Reference Materials Cited in NRC Publications}

Most documents cited in NRC publications will be available from one of the following sources:

1. The NRC Public Document Room, 1717 H Street, N.W Washington, DC 20555

2. The Superintendent of Documents. U.S. Government Printıng Office. Post Office Box 37082, Washington, DC 20013-7082

3. The Naticna! Technical Information Service, Springfield, VA 22161

Although the listing that follows represents the majority of documents cited in NRC publications, it is not intended to be exhaustive.

Referenced documents available for inspection and copying for a fee from the NRC Public Docu ment Room include NRC correspondence and internal NRC memoranda: NRC Office of Inspection and Enforcement bulletins, circulars, information notices, inspection and investigation notices; Licensee Event Reports; vendor reports and correspondence; Commission papers: and applicant and licensee documents and correspondence.

The following documents in the NUREG series are available for purchase from the GPO Sales Program: formal NRC staff and contractor reports, NRC-sponsored conference proceedings, and NRC booklets and brochures. Also available are Regulatory Guides, NRC regulations in the Code of Federal Regulations, and Nuclear Regulatory Commission Issuances.

Documents ava lablefrom the National Technical Information Service include NUREG series reports and technical reports prepared by other federal agencies and reports prepared by the Atomic Energy Commission, forerunner agency to the Nuclear Regulatory Commission

Documents ava lablefrom public and special technical libraries include all open literature Items, such as books, journal and periodical articles, and transactıons Federal Register notıces, federal and state legislation, and congressional reports can usually be obtained from these libraries

Documents such as theses, dissertations, foreign reports and translations, and non NRC conference proceedings are available for purchase from the organization sponsorıng the publication cited

Single copies of NRC draft reports are ava lablefree to the extent of supply upon written request to the Division of Technical information and Document Control U S Nuclear Requlatory Com mission, Washington, DC 20555

Copies of industry codes and standards used in a substantive manner in the NRC regulatory process are maintained at the NRC Library, 7920 Norfolk Avenue, Bethesda, Maryland, and are ava lable there for reference use by the public Codes and standards are usually copyrighted and may be purchased from the orıginatıng organızation or, if they are American National Standards, from the American National Standards Institute, 1430 Broadway, New York, NY 10018 
NUREG/CR-4492

PNL-5737

\section{Methodoloay for Estimating Extreme Winds for Probabilistic Risk Assessments}

Manuscript Completed: September 1986

Date Published: October 1986

Prepared by

J. V. Ramsdell, D. L. Elliott, C. G. Holladay, J. M. Hubbe

Pacific Northwest Laboratory

Richland, WA 99352

Prepared for

Division of Pressurized Water Reactor Licensing-B

Office of Nuclear Reactor Regulation

U.S. Nuclear Regulatory Commission

Washington, DC 20555

NRC FIN B2959 
EXECUTIVE SUMMARY

The U.S. Nuclear Regulatory Commission (NRC) assesses the risks associated with nuclear facilities using techniques that fall under a generic name of Probabilistic Risk Assessment. In these assessments, potential accident sequences are traced from initiating event to final outcome. At each step of the sequence, a probability of occurrence is assigned to each available alternative. Ufitimately, the probability of occurrence of each possible outcome is determined from the probabilities assigned to the initiating events and the alternative paths. Extreme winds are considered in these sequences. As a result, it is necessary to estimate extreme wind probabilities as low as $10^{-7}$ $\mathrm{yr}^{-1}$.

When the NRC staff is called on to provide extreme wind estimates, the staff is likely to be subjected to external time and funding constraints. These constraints dictate that the estimates be based on readily available wind data. In general, readily available data will be limited to the data provided by the facility applicant or licensee and the data archived at the National Climatic Data Center in Asheville, North Carolina.

This report describes readily available data that can be used in estimating extreme wind probabilities, procedures for screening the data to eliminate erroneous values and for adjusting data to compensate for differences in data collection methods, and statistical methods for making extreme wind estimates. Supporting technical details are presented in several appendices.

Estimation of extreme wind probabilities at a given location involves many subjective decisions. The procedures described do not eliminate all of the subjectivity, but they do increase the reproducibility of the analysis. They provide consistent methods for determining probabilities given a set of subjective decisions. By following these procedures, subjective decisions can be identified and documented. 


\section{CONTENTS}

EXECUTIVE SUMMARY $\quad$ • ACKNOWLEDGMENTS • • • • • • • • • • • • • • • • • • • INTRODUCTION

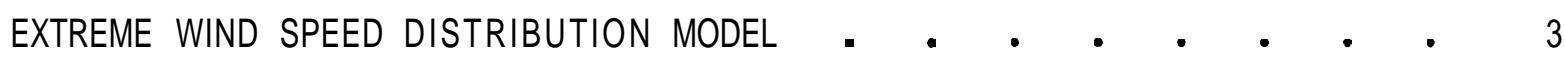
THE DISTRIBUTION OF OBSERVED EXTREME WINDS • . • • • •

The Fisher-Tippett Type I Distribution . . . . . 4

Type Distribution Parameter Estimation . • • . 5 TORNADO WINDS • • • • • • • • • • • • • • • RETURN PERIODS • • • • • • • • • • • • • • 11 DATA ACQUISITION OBSERVED EXTREME WIND DATA • • • • • • • • • • 13

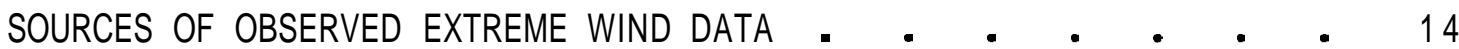
TORNADO DATA $\quad$ •

DATA BASE PREPARATION • • • • • • • • • • • • • • 17 DATA SCREENING • • • • • • • • • • • • • • • 17 ADJUSTMENT OF OBSERVED EXTREME WINDS . • • • • • 18

Averaging Interval . . . . . . . . 19

Measurement Height • • • • • • • • 21

SINGLE STATION ANALYSIS • • • • • • • • • • • • • 25 ANALYSIS OF OBSERVED WINDS • • • • • • • • • $\quad 25$ STATISTICAL TESTS • • • • • • • • • • • • • 30

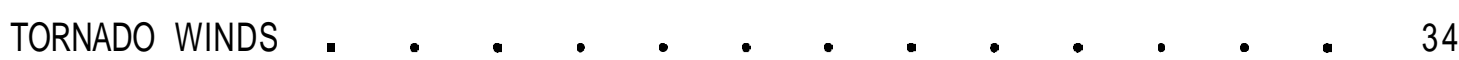
FINAL ANALYSIS • • • • • • • • • • • • • • • 
MULTIPLE STATION ANALYSIS • • • • • • • • • • • • • 39

ATLANTIC COAST EXAMPLE . • • • • • • • • • • 40

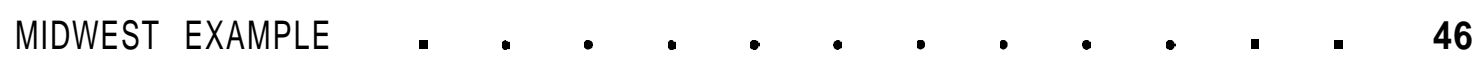

DISCUSSION • • • • • • • • • • • • • • • • 51

REFERENCES • • • • • • • • • • • • • • • • • •

APPENDIX A - MAXIMUM-LIKELIHOOD ESTIMATION OF EXTREME VALUE

DISTRIBUTION PARAMETERS $\bullet \cdot \cdot$ •

APPENDIX B - VARIATION OF EXTREME WINDS WITH AVERAGING INTERVAL . • B.I

APPENDIX C - VARIATION OF EXTREME WINDS WITH HEIGHT .

APPENDIX D - BASIC PROGRAM FOR EVALUATING EXTREME WIND

PROBABILITIES • • • • • 


\section{FIGURES}

Tornado Wind Speed Intensity Distributions for the Contiguous

United States

Tornado Point-Strike Probabilities for the Contiguous United

States Based on Tornadoes Reported from 1954 Through 1983 .

Final Extreme Wind Analysis for Jacksonville, Grand Rapids, and La Crosse . . . . . • . . . . . . . .

Synopsis of Coastal Extreme Wind Data Between Jacksonville and Cape Henry

Map of the Coastal Region Between Jacksonville and Cape Henry Showing Extreme Wind Distribution Parameters and Location for Which Extreme Wind are to be Estimated.

Distribution of Coastal Extreme Winds for Stations From Jacksonville Through Wilmington $\quad$. . .

Final Extreme Wind Analysis for the Hypothetical Atlantic Coast Location

Map of the Region for the Midwest Example Showing Extreme Wind Distribution Parameters and Location for Which Extreme Winds are to be Estimated

Distribution of Combined Extreme Winds from Escanaba, Green Bay, and Milwaukee

10 Final Extreme Wind Analysis for the Hypothetical Midwest Location

A.1 A Simplex Used in Maximum-Likelihood Estimation . . . . A.3

A.2 Distribution of Observed Coastal Extreme Winds for Stations From Jacksonville Through Wilmington Showing a Type I Distribution with Maximum-Likelihood Parameter Estimates

B.1 Ratio of a T-s Gust to a 60-s Gust . . . . . . . . B.3

C.1 Vertical Variation of Extreme Wind Distribution Parameters at Hanford, Washington

C.2 Vertical Variation of Extreme Wind Distribution Parameters at the Kennedy Space Center, Florida 


\section{$\underline{\text { TABLES }}$}

1 Relationship Between Standardized Extremes and Probability . $\quad 5$

2 Tornado Intensities and Corresponding Wind Speed Ranges $\quad 7$

3 Weibull Distribution Parameters for Regional Probability

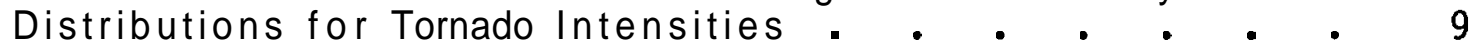

Probability of One or More Occurrences of the 50-year Wind in

Observation Periods of Various Lengths . . . . . . . 12

5 Effect of Wind Speed Adjustment Factors on Extreme Wind Values . 21

6 Extreme Winds for Jacksonville, Florida . . . . . . 26

7 Statistics of Jacksonville Extreme Winds at Each Anemometer

Location . • • • • • • • • • • • 27

8 Extreme Winds for Grand Rapids, Michigan . . . • . . 29

9 Statistics of the Grand Rapids Airport Extreme Winds at Each

Anemometer Location . • . • • • • • • . . 29

10 Extreme Winds for La Crosse, Wisconsin . • . . . . . 31

11 Statistics of La Crosse Extreme Winds at Each Anemometer

Location . • • • • • • • • • • • • • 32

12 Effect of Excluding the 49-ft Data From the La Crosse, Wisconsin Extreme Wind Data Base . • • • • . • . • . 32

13 Extreme Wind Parameter Estimates for Jacksonville, Florida; the Grand Rapids, Michigan Airport; and La Crosse, Wisconsin .

14 Extreme Wind Estimates for Jacksonville, Florida; the Grand Rapids, Michigan Airport; and La Crosse, Wisconsin Based on Observed Wind Data . • • • • • • • • • • 37

15 Tornado Wind Speed Estimates for Jacksonville, Florida; the Grand Rapids, Michigan Airport; and La Crosse, Wisconsin .

16 Data Base For The Atlantic Coast Multiple-Station Extreme Wind Analysis Example . . • • • . • . • • • •

17 Data Base For The Midwest Multiple-Station Extreme Wind Analysis Example 
A.I Comparison of Method-of-Moments and Maximum-Likelihood Estimates of Extreme Wind Distribution Parameters and Their Standard Deviations . • • • • • • • • • • • • . A.6

B.I Coefficient Values for Deacon's Wind Speed Ratio Model . . B.I

C.I Hanford Site, Washington Extreme Winds . . . • . . . C.3

C.2 Peak Gusts at the Kennedy Space Center . . . . . . . C.4

C.3. Parameter Estimates for Extreme Wind Distributions at Hanford and the Kennedy Space Center Based on Peak Gust Data . . C.4

C.4 Comparison of Factors for Use in Reducing Extreme Wind Speed Measurements Made at Height $\mathrm{z}$ to Speeds at $10 \mathrm{~m}(33 \mathrm{ft})$. . C.7 


\section{ACKNOWLEDGMENTS}

The authors wish to thank the staff of the Meteorology and Effluent Treatment Branch of the U.S. Nuclear Regulatory Commission (NRC) Division of Systems Integration for their guidance and assistance in development of the procedure for estimating extreme wind probabilities. Frequent discussions with the NRC Project Monitors Earl Markee, James Fairobent, and Irwin Spickler helped to make the procedure both practical and realistic. Reviews of the procedure and manuscript by Mr. Michael Changery and Dr. Lawrence Nicodemus, National Climatic Data Center; Dr. Oskar Essenwanger, U.S. Army Missile Command, Redstone Arsenal; Professor Arnold Court, California State University, Northridge; and Professor Allen Murphy, Oregon State University resulted in numerous suggestions that have led to improvements in the procedure and manuscript. Their assistance is greatly appreciated. 


\section{INIRODUCTION}

The U.S. Nuclear Regulatory Commission (NRC) assesses the risks associated with nuclear facilities using techniques that fall under a generic name of Probabi 1istic Risk Assessment (PRA). In these assessments, potential accident sequences are traced from initiating event to final outcome. The probability of occurrence of the sequence is determined from the probabilities assigned to the initiating event and the events in the sequence. Extreme winds may be included in potential accident sequences as initiating events or events that affect the sequence. The probabilities of the extreme winds of interest are as low as $10^{-7} \mathrm{yr}^{-1}$.

When the NRC staff is called on to provide extreme wind probability estimates, the staff is likely to be subjected to external time and funding constraints. These constraints dictate that the estimates be based on readily avai lable wind data. In general, readily available data will be limited to the data provided by the facility applicant or licensee and the data archived at the National Climatic Data Center (NODC) in Asheville, North Carolina. There will not be time for special measurements to obtain data for extreme wind estimates.

This report describes readily available data, procedures for screening and adjusting data, and procedures for making extreme wind estimates. The procedures do not eliminate all of the subjective decisions from the analysis, but they do increase the reproducibility of the analysis. By following the procedures, subjective decisions can be readily identified and documented. Supporting technical details are presented in the Appendices.

The first stage of the procedure is acquisition of available extreme wind data for use in estimating the magnitudes of low probability events. As is shown in the next section, the uncertainty in the estimates of the parameters of the extreme value distribution are inversely proportional to the square root of the number of data. Therefore, the goal of the data acquisition phase is to accumulate all readily avai lable extreme data that might be representative of atmospheric conditions at the facility for which the PRA is being conducted. Data should be obtained for nearby National Weather Service (Weather Bureau), Federal Aviation Administration, and military installations. The NCDC is the repository for meteorological data for all of these organizations.

The second stage of the procedur is preparation of an extreme wind data base using the available data. Extreme wind data archived at the NCDC are not likely to be as consistent as if the measurements had been made expressly for estimation of extreme winds. As a result, it may be necessary to adjust some or all of the archived data prior to estimation of the extreme value distribution parameters to minimize variability in the data resulting from differences related to anemometers and their exposure. In data base preparation, the avai lable wind speed data are screened for obvious problems, converted to units of miles per hour, adjusted to a standard averaging time, and standard height. When all adjustments have been made, the data are combined 
into a consistent data set in which the variability related to measurement techniques has been minimized.

The third stage of the procedure is the extreme value analysis. The data in the data base are used to estimate parameters of the extreme wind distribution and the extreme wind probabilities. Confidence intervals for the extreme winds based on the uncertainties of the parameter estimates are also estimated. Extreme winds for tornadoes, which are not likely to be adequately represented in the data base, are also considered in this stage of the procedure.

The next section of the report describes the basis for estimating extreme winds. It is followed by sections describing the sources of extreme wind data and the procedures used to adjust the wind data. These sections are followed by a section on the analysis of data for a single location and a section on the consolidation and analysis of data from several locations. Appendices contain details of several aspects of extreme winds that are related to, but not part of the procedure. Specific topics covered include: variation of extreme winds with averaging time, vertical variation of extreme winds, and maximum likelihood techniques for refining parameter estimates. Finally, Appendix D contains a listing of a program that computes extreme wind probabilities using the parameter estimates. 


\section{EXIREME WIND SPEED DISTRIBUTION MODE}

Extreme winds are associated with several meteorological phenomena. If sufficient extreme wind data and analysis time were available, it might be appropriate to attempt to estimate an extreme wind probability for each phenomenon and to estimate the overall extreme wind probability at a site as a weighted average of the individual phenomenon probabilities. This approach, called a mixed distribution model, has been suggested implicitly by Thom (1968) and Simiu and Scanlan (1978), and has been partially followed by Changery (1982a).

However, the identification of the cause of each extreme wind is an involved process because the meteorological conditions associated with the observed extremes are not recorded along with the extremes. As a result, it is necessary to determine the time of occurrence of each extreme and then evaluate the synoptic situation at that time. In general, the time available for extreme wind analyses for probabilistic risk assessments will not permit the research required by the mixed distribution approach.

The following sections describe the recommended methods for estimating extreme winds. As an alternative to the mixed distribution model, it is suggested that a single distribution be used to describe the observed extreme winds. If the data base used to evaluate distribution parameters is adequate, the meteorological conditions causing extreme winds, with the exception of tornadoes, should be represented in about the proper proportion. Observed winds are not likely to adequately describe the extremes due to tornadoes because the area affected by tornadoes is small and the winds are likely to destroy any wind instruments that are encountered. Consequently, extreme winds associated with tornadoes should be estimated separately using indirect methods.

\section{THE DISTRIBUTION OF OBSERVED EXTREME WINDS}

If the form of the frequency distribution of a population of random variables such as wind speeds were known, and if the distribution were from one of the common distribution families, that information could be used to determine the distribution of extreme winds. However, no single theoretical distribution has been found to describe wind speeds. Therefore, it is not possible to make an a priori determination of a distribution form for extreme winds, although Davenport (1960) makes a heuristic argument related to the parent wind distributions to support the selection of a distribution for regions not affected by hurricanes.

Formal discussions of extreme value distributions are found in Fisher and Tippett (1928), Gumbel (1958), and Galambos (1978). Several extreme value models have been used to describe the distribution of annual maximum wind speeds. These models include Fisher-Tippett Type I (Gumbel), Type II (Frechet), and Type III (Weibull) distributions. The Fisher-Tippett Type I distribution is most frequently used to estimate extreme wind probabilities, although the Type II and Type III asymptotic distributions have also been used. The 
selection of one distribution over the others has generally been made on the basis of fitting a distribution form to observed extreme values.

Simiu and Filliben (1976), Simiu et al. (1978), Simiu and Filliben (1980), and Tabony (1983) all discuss the problems of selecting a "best-fitting" extreme value distribution on the basis of a limited number of observations. When a set of extremes is drawn from a population with a known distribution, there is a reasonably large probability that the extreme value distribution that best fits the data in the set will not be the correct extreme value distribution (i.e., the extreme distribution that is appropriate for the underlying population distribution).

Recent guidance on estimation of extreme winds--for example, American National Standard Institute Standard A58.1-1982 (ANSI 1982), American Nuclear Society Standard (ANS 1983), and International Atomic Energy Agency Safety Series No. 50-SG-S11A (IAEA 1981)--has tended toward use of the Type I distribution. However, Changery (1982a), who us'ed a Type I distribution for extreme winds not associated with tropical storms, chose to use a Weibull distribution for extreme winds associated with tropical storms. His use of the Weibull distribution for tropical storm winds was based on numerical simulation of winds in tropical storms (Batts et al. 1980).

The assumptions made in the numerical simulations included limiting the ranges of several variables. These limitations effectively placed an upper bound on the maximum hurricane wind speeds, and thereby biased the results of the simulation. The conclusion that the hurricane winds are better $\mathrm{fit}$ by a Weibull distribution than Type I distributions is likely to be no more than a reflection of the assumptions made in the simulation because Weibull distributions are commonly used to describe the probabilities of events that have limited ranges.

After considering this information, the Type I distribution has been selected for use in modeling straight-line extreme winds.

The Fisher-Tippett Type I Distribution

The Fisher-Tippett Type I distribution, as applied to extreme winds, is

$$
F(u)=1-\exp \{-\exp [-(u-m) / s]\}
$$

where $F(u)$ is the probability that an observed annual extreme wind, $U$, will have a value of $u$ or greater. The $m$ and $s$ are parameters of the distribution. The location parameter is $\mathrm{m}$, the mode of the distribution. It serves the same function for the Type I distribution as the mean serves for the Gaussian distribution. The $s$ (more properly $1 / s$ ) is a scale parameter that characterizes the spread of the distribution. It serves the same function as the standard deviation serves in the Gaussian distribution. Estimation of parameter values is discussed shortly. 

$y_{1}$ as

Equation (1) can be simplified by defining a standardized extreme value,

$$
y=(u-m) / s
$$

The standardized extreme value, y, is analogous to the standardized normal deviate, $z$. The distribution of values of $y$ has a mode of zero and a standard deviation of $\pi / \sqrt{ } 6$. Substitution of the standard extreme into Equation (1) results in

$$
F(u)=1-\exp [-\exp (-y)]
$$

If $F(u)$ is known, the corresponding y can be found from

$$
y=-\ln \{-\ln [F(u)]\}
$$

Corresponding values of the standardized extreme and probability of occurrence are given in Table 1.

Type I Distribution Parameter Estimation

There are several methods for estimating the parameters of a Type I distribution. Among these methods are graphical techniques, linear regression, the method of moments, and the maximum likelihood method, which are described by Kinnison (1985). Another method, which uses order statistics, has been proposed by Lieblein $(1954,1974 a$, and 1974b). Simiu et al. (1979) used linear regression to estimate location and scale parameters, and Changery

TABLE 1. Relationship Between Standardized Extremes and Probability

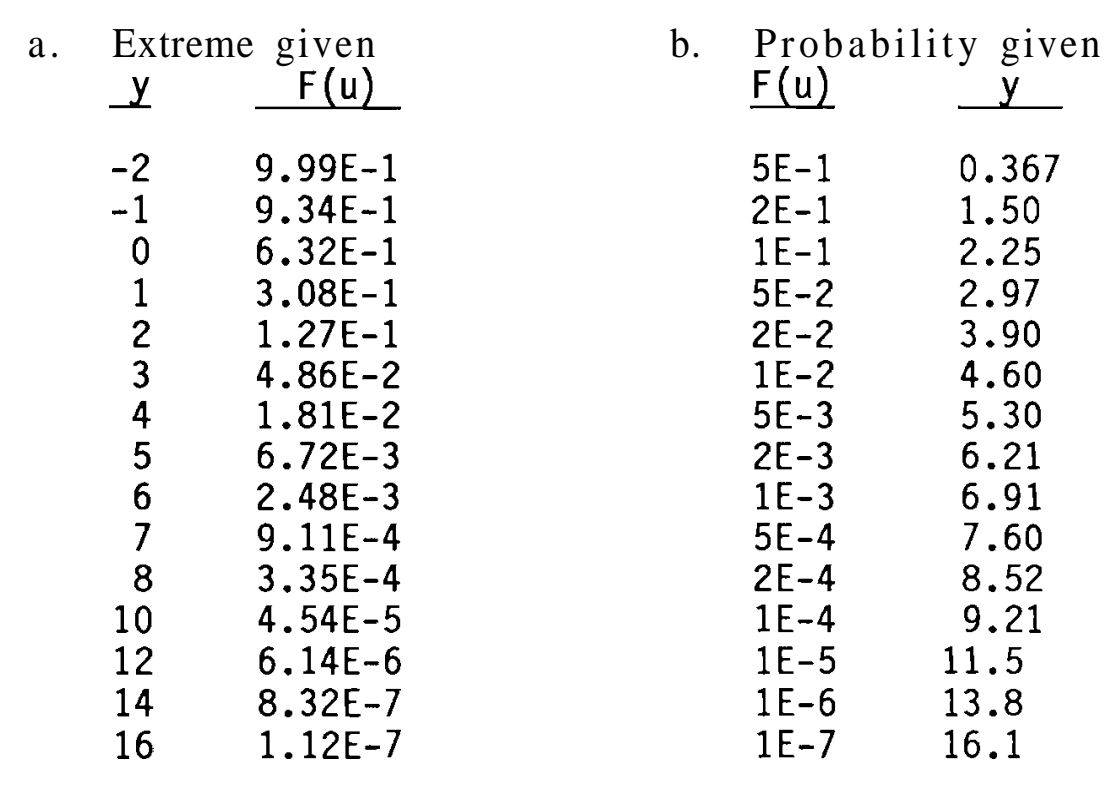


(1982a, 1982b) used Lieblein's approach. Knnison (1985) indicates that parameter values estimated graphically or by linear regression may be biased. The maximum likelihood method is a numerical technique that may be used to refine initial parameter estimates and estimates that may be biased.

In the method of moments, the Type I distribution parameter values are estimated from the mean and standard deviation of the observed extreme winds. The method of moments will be used to estimate parameter values for the Type I distribution because of the ease of computing the mean and standard deviations of observed extreme winds. In this method, the scale parameter of the distribution is estimated from the standard deviation of the extreme values using

$$
s=0.7797 \mathrm{~S}[\mathrm{U}]
$$

where 0.7797 is equal to $\sqrt{ } 6 / \pi$, and $S[U]$ is the standard deviation of the extremes.

The mode of the Type I distribution is estimated from the mean and standard deviation of the annual extremes by

$$
m=E[U]-0.5772 \mathrm{~s}
$$

where $E[U]$ is the expected (mean) value of the extremes, and 0.5772 is Euler's constant.

Parameter values estimated by the method of moments are subject to random error because $\mathbf{E}[\mathrm{U}]$ and $\mathbf{S}[\mathrm{U}]$ are computed from observed values rather than being true population statistics. According to Johnson and Kotz (1970) the variances of Type I parameter estimates based on sample moments (mean and standard deviation) are approximately

$$
V[\mathrm{~m}]=1.1678 \mathrm{~s}^{2} / \mathrm{n}
$$

and

$$
V[\mathrm{~s}]=1.1 \mathrm{~s}^{2} / \mathrm{n}
$$

where $V[]$ denotes the variance of the indicated parameter estimate.

When extreme winds are estimated to correspond with some probability level, the uncertainty in the estimated speed is related to the probability level and the variances of the estimated values of the extreme wind distribution parameters. This relationship is expressed as

$$
\mathrm{V}[\mathrm{U}]=\mathrm{V}[\mathrm{m}]+\mathrm{y}^{2} \mathrm{~V}[\mathrm{~s}]
$$

The variance of the extreme wind estimate given by Equation (9) is approximately the same as the variance computed using an expression given by Gumbel (1958) 
and somewhat larger than the Cramer-Rao lower bound (Downton 1966), which were used by Simiu et a1. (1979) as measures of the sampl ing error in extreme wind estimates.

Assuming that the errors in the estimate of the extreme wind are normally distributed, a confidence interval for the speed estimate can be established using standard statistics techniques (e.g., Brownlee 1965; Meyer 1975). This interval may be expressed as

$$
\text { Confidence interval }=U \bullet t_{n, \alpha} S[U]
$$

where $t_{n}$ is a percentage point of the $t$-distribution with $n$ degrees of freedom and confidence level a. The number of degrees of freedom used for $t_{n_{1} \alpha}$ is two less than the number of observations used to obtain the parameter estimates. The appropriate value of $t_{n, \alpha}$, obtained from a statistical table should be used when the extreme wind estimate is based on a small number of observations or when an accurate estimate of the confidence interval is needed. If the number of observations is large, an approximate $90 \%$ confidence interval can be estimated using $t_{n, \alpha}=1.645$.

The method of moments is an efficient estimator of the mode, but it is a relatively inefficient estimator of the scale parameter compared with the maximum likel i hood technique. Kinnison (1985) gives the relative efficiencies of the method of moments as about $95 \%$ for the mode and $55 \%$ for the scale parameter. Equations (7) and (8) indicate that the variance (uncertainty) of the parameter estimates is related to the square of the scale parameter. Therefore, refined estimates of the parameter values may occasionally be required. If refined parameter value estimates are required, the method-of-moment estimates will be refined using maximum likelihood techniques. Appendix A describes the Nelder-Mead Simplex maximum likelihood algorithm using initial parameter estimates provided by the method-of-moments.

\section{TORNADO WNDS}

Tornado wind speed measurements are rare. Consequently, it is necessary to estimate these speeds indirectly. Tornado intensities, which are related to wind speeds, may be estimated from the area affected by and the damage caused by tornadoes. The most common method of rating tornado intensities is a scale (F-scale) developed by Fujita (1970). In this scale, tornado intensities range from FO through F5 in order of increasing intensity. The tornado speed range associated with each intensity is shown in Table 2.

TABLE 2. Tornado Intensities and Corresponding Wind Speed Ranges

\begin{tabular}{cc} 
F-Scale & Speed $(\mathrm{mph})$ \\
\cline { 2 - 2 } 0 & $40-72$ \\
1 & $73-112$ \\
2 & $113-157$ \\
3 & $158-206$ \\
4 & $207-260$ \\
5 & $>261$
\end{tabular}


Estimation of the extreme wind probabilities associated with tornado strikes has been separated into two parts: estimation of the probability that a tornado will strike a point, and estimation that of the probable maximum wind speed assuming that a tornado strike occurs (e.g., Markee et al. 1974, Ramsdell and Andrews 1986). Mathematically, this approach may be represented as

$$
F_{t}(u)=P_{s} \cdot P(U \geq u \mid s)
$$

where $\mathrm{P}(\mathrm{U}>\mathrm{u})=$ the probability that a tornado with a wind speed equal to or greater than u will strike a point

$P_{\mathbf{s}}=$ the probability of a tornado striking the point

$\mathrm{P}(\mathrm{U}>\mathrm{u} \mid \mathrm{s})=$ the conditional probability that the maximum wind speed in a tornado will equal or exceed $u$ assuming that a tornado strike occurs.

Tornado strike probabilities are typically evaluated on the basis of tornado data in the vicinity of the site for which the wind speed estimates are required while a much larger data base is used to evaluate the conditional probability. Thom (1963) describes a geometrical method of estimating strike probabilities that is in common use. In this method, the probability of a tornado striking a point is estimated as

$$
P_{s}=\frac{n A_{t}}{N A_{r}}
$$

where $\mathrm{A},=$ the average (expected) area affected by a tornado in a region

$A=$ the area of the region for which tornado statistics have been accumulated

$\mathbf{N}=$ the number of years for which tornado data are available

$\mathrm{n}=$ the number of tornadoes occurring during the $\mathbf{N}$ years.

For this approach to provide a good estimate of the strike probability, $\mathrm{A}$, and $\mathbf{N}$ must be large enough to yield a good estimate of the average tornado area. The distribution of tornado areas is skewed with small areas occurring more frequently than large areas. As a result, if the average tornado area is based on data from a small number of tornadoes, it is likely that the area will be underestimated. To minimize this likelihood, the distribution of areas is frequently assumed to be lognormal (Thom 1963; Markee et al. 1974; Ramsdell and Andrews 1986), and expected tornado areas computed from observed areas using this assumption are used to estimate strike probabilities. If the lognormal assumption is correct, which is open to question (e.g., Ramsdell and Andrews 1986), the expected area and the arithmetic average area computed 
from observed tornado tracks will converge to the true mean area as the number of tornado tracks increases. However, the expected area will converge faster.

The conditional probability of exceeding a given wind speed in a tornado can be estimated from the distribution of tornado intensities. After examining the spatial variation of tornado statistics, including the number of occurrences of F4 and F5 tornadoes, Ramsdell and Andrews (1986) divided the contiguous United States into two regions for the purpose of specifying intensity distributions. The division between the regions is $105^{\circ}$ west longitude. This division generally falls along the eastern edge of the Rocky Mountains.

The probability of a tornado equaling or exceeding a given intensity in each region was estimated using the total area associated with tornadoes of each intensity, and intensities were converted to wind speeds using the wind speed ranges in Table 2 . The conditional probabilities were assumed to be represented by a Weibull. With this distribution, the probability of exceeding a wind speed u in a tornado is estimated from

$$
P(U \geq u \mid t)=\exp \left\{-[(u-40) / a]^{b}\right\}
$$

where 40 is the minimum wind speed (mph) for an Ю tornado, and a, $b$ are the parameters of the Weibull distribution.

The parameter a is dimensional, in this case having dimensions of miles per hour, and $b$ is non-dimensional. Figure 1 shows the distributions for the two regions. Parameter values for the curves shown in Figure 1 are listed in Table 3.

Tornado winds are not measured; therefore, the averaging interval associated with them is not explicit. However, there is an averaging interval implicitly associated with tornadoes because the winds are estimated from damage. Typical values for the duration of the winds associated with tornadoes can be estimated using the data presented by Ramsdell and Andrews (1986) for average widths of tornadoes and the algorithm in the TORNADO computer code (Schreck and Sandusky 1982) to compute the translational speed of tornadoes.

TABLE 3. Weibull Distribution Parameters for Regional Probability Distributions for Tornado Intensities

\begin{tabular}{|c|c|}
\hline Region & $(\mathrm{mph})$ \\
\hline Western United States & 78.29 \\
\hline Eastern United States & 136.1 \\
\hline Contiguous United States & 135.6 \\
\hline
\end{tabular}




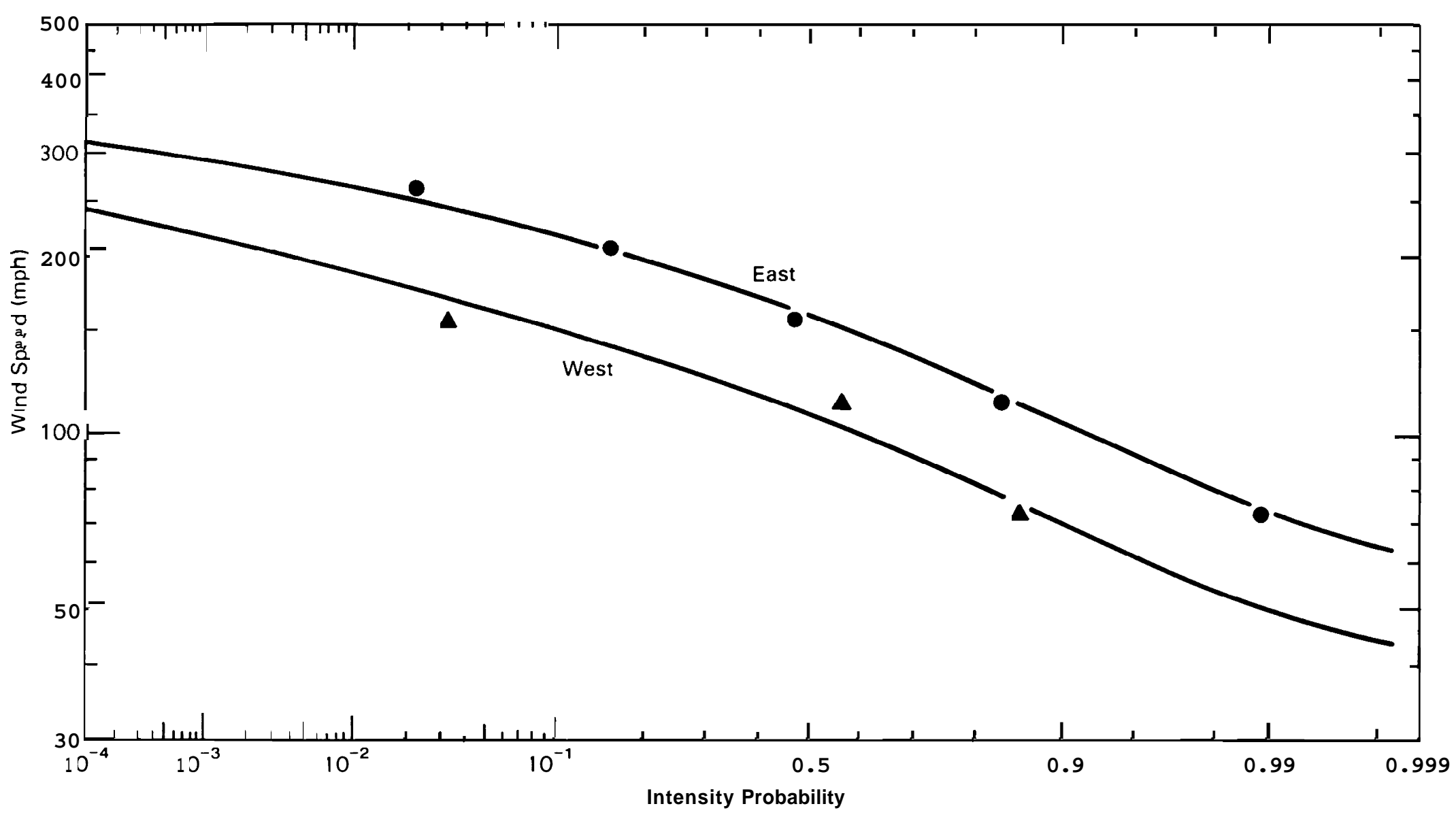

FIGURE 1. Tornado Wind Speed Intensity Distributions for the Contiguous United States. Based on Data for Tornadoes Report From 1954 Through 1983.

From Ramsdel1 and Andrews (1986). 
These durations range from about $8 \mathrm{~s}$ for minimal tornadoes to over $30 \mathrm{~s}$ for violent tornadoes.

There is no basis for adjusting tornado wind speeds to a standard averaging interval or to a standard $10 \mathrm{~m}$ height. Consequently, it is inappropriate to combine tornado wind speed probabilities with probabilities estimated from observed wind data. However, the two sets of probabilities can be shown on the same figure or side-by-side in a table to indicate which is the more likely to be responsible for specific speeds.

\section{RETURN PERIODS}

Return periods are frequently used as alternative descriptions of the probabilities of extreme events. If $P(u)$ is the probability of an annual extreme wind equaling or exceeding $u$ in one year, the return period $T(u)$ is

$$
T(u)=1 / F(u)
$$

This values is the average number of years between years when $u$ is equaled or exceeded. $\quad \mathrm{o}$ other interpretation of return period is correct.

The probability of occurrence of a wind equaling or exceeding predetermined extreme at least once during an finite observation period can be estimated using the binomial distribution, which is discussed in texts on probability and statistics (e.g., Brownlee 1965). If an event is defined as the occurrence of a wind speed equaling or exceeding $u$, and the probability of this event occurring in a year is $P(u)$, then the probability of the event occurring at least once in $n$ years is given by

$$
P_{n}\left[N_{0} \geq 1\right]=1-[1-F(u)]^{n}
$$

Generalizing this relationship, the probability of occurrence the event in $m$ or more years in an $n$ year period is

$$
P_{n}\left[N_{0} \geq m\right]=1-\sum_{i=0}^{m-1}\left\{\frac{n !}{i !(n-i) !}[F(u)]^{i}[1-F(u)]^{n-i}\right.
$$

An example of the application of these equations is shown in Table 4, which shows the probability of observing winds that equal or exceed the 50 -yr wind. The probabilities shown in the table are also approximately correct for other observation and return periods having the ratios shown in the right column, provided the return period exceeds 10 years. 
TABLE 4. Probability of One or More Occurrences of the 50-yr Wind in Observation Periods of Various Lengths

\begin{tabular}{|c|c|c|c|c|c|c|}
\hline Observation & & Number $\mathrm{c}$ & f Occurr & ences & & \\
\hline Period (yr) & 1 & 2 & 3 & 4 & 5 & $\mathrm{n} / \mathrm{T}$ \\
\hline 5 & 0.0961 & 0.0039 & 0.0001 & $<0.0001$ & $<0.0001$ & 0.1 \\
\hline 10 & 0.1829 & 0.0162 & 0.0009 & $<0.0001$ & $<0.0001$ & 0.2 \\
\hline 25 & 0.3965 & 0.0886 & 0.0132 & 0.0014 & 0.0001 & 0.5 \\
\hline 50 & 0.6358 & 0.2642 & 0.0784 & 0.0178 & 0.0033 & 1. \\
\hline 100 & 0.8674 & 0.5967 & 0.3233 & 0.1410 & 0.0508 & . \\
\hline
\end{tabular}




\section{DATA ACQUISITION}

The first step in estimating the extreme winds for a nuclear facility is identification of the extreme wind data that are available for the general region of interest. Extreme wind data have been recorded at weather stations throughout the United States since the middle 1800's. Harrison (1963) and Changery $(1978,1982 a, 1982 b)$ briefly describe the history of the instruments used for wind measurements in the United States and the types of wind data that are generally avai lable. A11 avai lable extreme wind data should be considered in an extreme wind analysis. Methods for standardizing the different types of data are discussed in later sections.

OBSERVED EXTREME WND DATA

Four types of observed extreme wind data are commonly available in the United States:

- fastest-mile speeds

- peak gust speeds

- fastest 5-min speeds

- fastest 1-min observed speeds.

Historically, fastest-mile wind speeds are the most common form of extreme wind data. They regularly reported in climatological summaries of data from July 1887 through 1904 and from 1912 to the present. A fastest-mile wind speed is the wind speed computed from the shortest interval required for passage of one mile of wind during some longer period such as a day, month, or year. Mles of wind passage are measured consecutively. As a result, there is a high likelihood that a strong gust will be distributed between 2 miles of wind and that a reported fastest-mile wind speed is likely to be lower than the true fastest-mile speed.

Peak gust wind speeds are determined from dials or analog wind speed records. They represent wind speeds averaged over a short period of time because anemometer response characteristics do not permit measurement of truly instantaneous wind speeds. The averaging period for common wind instruments is of the order of one or two seconds. As a result, reported peak gust speeds may be slightly underestimated, but the underestimation of peak gusts should be less than the underestimation of fastest-mile speeds.

Although fastest-mile data tend to be more extensive and more readily available than peak gust data, peak gust data are common. Military airfields have generally reported peak gusts rather than fastest-mile speeds, and many of the major airport stations in the Florida and along the Gulf of Mexico Coast have long-term peak gust records rather than fastest-mile records. Further, in the late 1960's and 1970's, most National Weather Service locations were equipped with peak gust instrumentation. Consequently, there are regions where 
peak gust data are more plentiful than fastest-mile data. For example, Florida and the coastal area west to Louisiana have only two airfields with long-term (20 years or more) fastest-mile data, while 22 airfields in that area have long-term peak gust data. Similarly, California has a limited number of airfields with long-term fastest-mile date (4), and many more airfields (27) with long-term peak gust data.

Extreme wind data reported prior to June 1887 and from 1904 through 1911 are fastest 5-min speeds (Changery 1982a). Fastest 5-min speeds are determined from charts and should be reasonably accurate except for human errors in extracting data from the charts. If these data were more extensive, it would be advantageous to use them exclusively in extreme wind analysis because the averaging interval is defined and constant and because $i \mathrm{t}$ is long compared to the response time of common wind instruments. Both fastest-mile and fastest 5-min speeds are available for locations with proper instrumentation for the period 1887-1904 and from 1912 through September 1957.

Fastest 1-min speeds are general ly not obtained from charts. Typically, the 1-min averaging is done visually from a non-recording display. These averages are likely to reflect biases of the observers. The fastest 1-min observed winds are compiled from reported observations. These observations are made at scheduled times. It is unlikely that the actual fastest 1-min wind during any period would coincide with a scheduled observation time. As a result, fastest 1-min observed speeds should be considered to be underestimates and treated as lower bounds for extreme winds.

Although fastest 1-min observed data are not as suitable for evaluation of extreme winds as are peak gust and fastest-mile data, they may be very useful in extreme wind analyses for complex-terrain or data-sparse regions where fastest-mile and peak gust data are very limited. For example, Wantz and Sinclair (1981) used fastest 1-min observed data in a study of extreme winds in the Pacific Northwest. Similarly, the only extreme wind data that are available for many airfields in California are fastest 1-min observed speeds.

\section{SOURCES OF OBSERVED EXTREME WN DATA}

Identification of the extreme wind data available for a region and determination of the various types of extreme wind data recorded for each location are not easy. N single publication or index provides a comprehensive listing of stations in the United States for which observed extreme wind records are avai lable.

Three summaries of extreme wind data have been published for the United States: Simiu et al. (1979), and Changery (1982a, 1982b). Taking duplications into account, these documents contain data for about 200 locations. The data in the reports include measured wind speeds, wind speeds adjusted to common anemometer heights, and the results of extreme value analyses of the data for each location. 
Observed and 'estimated' fastest-mile data for 129 airports in the contiguous United States are contained in Simiu et al. (1979). The small fraction of these data that are 'estimated' fastest-mile speeds are based on fastest 1-min observed speeds. Changery (1982a) contains data for 53 airport and city locations along the Atlantic and Gulf of Mexico coastlines, and Changery (1982b) contains data for 70 locations in the Great Lakes area. Changery's reports contain fastest-mile data, even for the periods when other climatological summaries report only fastest 5 -min average speeds. The fastest-mile data for these periods were obtained by analysis of original wind records.

The NOC is the primary repository for meteorological data collected by or for United States government agencies. The Guide to Climatic Data Sources (Hatch 1983) is an index to the records maintained at the NCDC. It lists locations for which data have been archived and describes the forms in which data are available; for example, in publications, on microfiche, on magnetic tape. Changery (1978) published a specialized index to wind data available at the NCDC. This index describes the wind instruments in common usage and the forms on which the data have been recorded. More importantly, the index lists the locations for which archived data are available from the NCDC, provides a history of the anemometer heights at each location, and gives the status of the data. The index is arranged by state.

Daily maximum wind data are published by the NODC for approximately 284 airport stations in the contiguous United States in Local Climatological Data (LCD) monthly supplements. Daily maximum wind data are also available on the "Summary of Day - First Order" series magnetic tapes (TD-9750) available from the NCDC. The TD-9750 series tapes contain data from the National Weather Service and United States military installations. These tapes have daily peak gust data beginning as early as the late 1940's (if the stations were equipped with gust recorders) and fastest-mile or fastest 1-min observed data beginning in 1965. Most National Weather Service locations were equipped with gust recorders in the late 1960's and early 1970's. The peak gust data for Air Force stations are included on the TD-9750 data tapes only through 1970 . The Air Force peak gust data obtained since 1970 are available on separate data tapes.

\section{TORNADO DATA}

The National Severe Storms Forecast Center (NSSFC) operated by the National Weather Service in Kansas City, Missouri, maintains a data base that lists tornadoes reported in the contiguous United States since 1950. Tornadoes are tabulated by states and are described by position (latitude and longitude of the beginning and end), length, width, and intensity. A similar data base, called the DAPPL (Damage Area Per Path Length) data base, is maintained by Fujita at the University of Chicago. Grazulis (1984) reevaluated the intensity ratings of tornadoes listed as F4 and F5 in the NSSFC and DAPPL tornado data bases and reconciled the differences in the ratings of these tornadoes. 
A climatology of tornado occurrences in the contiguous United States from 1954 through 1983 has been prepared by Ramsdell and Andrews (1986) using the NSSFC data base containing the results of the reconciliation. Tornado strike probability estimates and intensity (wind speed) distributions are presented for the contiguous United States, the United States west and east of the Rocky Mountains, each state, and $5^{\circ}$ boxes of latitude and longitude. This information can be used to estimate the probabilities of extreme winds associated with tornadoes for probabilistic risk assessments. 


\section{DATA BASE PREPARATION}

Observed wind data acquired for evaluation of extremes for a probabilistic risk assessment will probably not be ready for analysis. It is likely that they will have been obtained at several measurement heights and will have been averaged over different intervals. The data may also contain obvious errors. The second stage of the procedure is to prepare the data base for the remainder of the analysis. The second stage starts with screening the data for problems. Next, the data are adjusted to put them into a consistent form. Then, the data for each measurement location are combined, and an initial extreme value analysis is performed for each location. The data for several sites may then be combined for a final extreme value analysis.

\section{DATA SCREENING}

Screening of the observed extreme wind data consists of 1) determining exactly what type of data have been obtained, 2) identifying the location and height of measurement for each speed, and 3) examining the data for spurious val ues and trends that may indicate unreported changes in anemometer exposure, location, or type. The importance of data screening can be illustrated by recounting some of the problems that have been encountered in the past.

Extreme wind data have been obtained from several sources, and in the process, duplicate data sets were obtained for several locations. The data in some of these sets were neither identical nor consistent. Discrepancies were found in specification of the measurement locations, in specification of the type of extreme wind data, and in the extremes reported. For example:

- fastest 1-min observed data and some peak gust data were labeled as fastest-mi le data

- data from city stations were occasionally listed for airport locations and vice versa

- historical maximum 5-min data were labeled as fastest-mile data

- changes from one type of data to another (such as fastest-mile to fastest 1-min observed) during a station's period of record were not identified.

Potential problems in a data set may be identified if the annual average and extreme speeds are plotted as a function of time. Long-term trends in averages or extreme values indicate potential problems associated with anemometer exposure, for example, increases in the surrounding vegetation or structures. Discontinuities in the averages and extremes may indicate changes in anemometer height, location or type.

Footnotes accompanying published wind data must be read before using any of the data, even though there may not be a reference to the footnotes. Despite this precaution, it is not always possible to identify the exact nature of wind data because the climatological summary forms and listings may not clearly or 
explicitly indicate the type of data reported or changes in the data type. Determining the measurement height for fastest-mile data poses a particular problem. Publications that contain both routine and fastest-mile wind data and list information on anemometer heights usually give the height and location of the anemometer used for the routine wind observations. The fastest-mile data may have been obtained using another anemometer at a different height and location.

The National Wind Data Index (Changery 1978), lists anemometer heights and locations for almost every station for which hourly wind data have been recorded. However, it does not list some stations that have historical fastest-mile data but did not report routine hourly observations. The index gives the height of the anemometer used for fastest-mile measurements as well as the height of the anemometer used for routine observations when these two anemometers heights are different.

When the available extreme wind data are examined, one or more individual extremes may stand out from the others sufficiently that their validity is questioned. These data should not be eliminated from the data base unless it can be established that they are, in fact, incorrect. Storm Data, published monthly by the NCDC, lists all major storms and describes the damage associated with them. It can be consulted to determine if a questionable extreme wind could have been associated with a major storm.

If questions about specific stations or wind observations arise that cannot be resolved using available information, the NCDC can be consulted. During preparation of data for use in evaluation of the extreme value analysis procedure, the staff of the NCDC was cooperative and helpful in resolving questions on data availability, anemometer locations, and suspect data.

\section{ADJUSTMENT OF OBSERVED EXTREME WINDS}

After the initial screening has been completed, the observed wind data base should be made internally consistent. In a typical situation, the extreme wind data will have been measured by different organizations and for different periods of time. As a result, the dimensional units in which the speeds are expressed may not be the same for all data, the data may not be of a common type, and the data are likely to have been obtained at different measurement heights. When this is the case, it is necessary to standardize the data to minimize any differences that may be due to measurement techniques.

Conversion of the data to common measurement units is the first step in adjusting the data. The unit conversion will not, in itself, alter the wind speed. However, it is the first step in which rounding and truncation errors wi 11 accumulate. The accumulation of errors can be minimized by carrying more significant figures in the converted speed than are justified by the precision of the original data. For example, in conversion of speeds from knots to miles-per-hour, 56 knots becomes 64 mph and 57 knots becomes 66 mph if the speeds are rounded to the closest integer value after the conversion process. It is recommended that wind speeds be carried to the closest tenth of a 
mile-per-hour once data adjustments have begun. After all conversions and adjustments have been made and the analysis has been completed, the final speeds can be rounded to the closest mile per hour.

$\underline{\text { Averaging Interval }}$

Every wind speed observation is, at least implicitly, associated with an interval over which the speed is averaged. Given a continuous wind record, the reported maximum speed will increase as the averaging interval decreases. The averaging intervals associated with extreme winds range from about $2 \mathrm{~s}$ for peak gusts to 5-min. However, the most common extreme wind, the fastest mile, is not associated with a fixed averaging interval. The fastest-mile wind speed averaging interval is a function of the wind speed. For any fastest-mile speed, the averaging interval, $t$ in seconds, is given by

$$
\mathrm{t}=3600 / \mathrm{U}
$$

where $U$ is the wind speed in miles per hour. Typical fastest-mile speeds are generally between $\mathbf{3 0}$ and $120 \mathrm{mph}$; thus the associated averaging intervals range from about 120 to $\mathbf{3 0} \mathrm{s}$.

Gust factors are frequently used to describe the relationship between wind speed and averaging interval. For example, if $U(T)$ is a wind speed averaged for time $T, U(t)$ is the maximum speed averaged for time $t$, and $t$ is less than and contained within $T$, then the gust factor, $G(t: T)$, is

$$
G(t: T)=U(t) / U(T)
$$

where $\mathbf{t}$ and $\mathrm{T}$ are in common units. Gust data summarized by Deacon (1965) show a variation of gust factors with surface roughness, measurement height and wind speed. For high winds (greater than $12 \mathrm{~m} / \mathrm{s}$ ), the $\mathrm{G}(2: 60)$ gust factors at $10 \mathrm{~m}$ range from about 1.25 over flat grass lands to 1.43 in the vicinity of numerous trees and buildings.

A mathematical technique for adjusting extreme winds to compensate for differences in averaging interval is developed in Appendix B. The basis for the technique is a relationship for average ratio between gusts averaged for a period $T$ and the maximum 2 s gusts within T given by Deacon (1965).

Additional justification for using gust factors as a basis for adjusting wind speed to a standard averaging period is provided by Changery (1982a), who shows that the annual fastest miles tend to occur during the period of the annual maximum 5-min average speeds.

N technique can be expected to provide an accurate adjustment for all conditions or every observation. Therefore, considering the range of averaging intervals associated with the fastest-mile speeds, $60 \mathrm{~s}$ has been selected as the standard averaging interval to all extreme winds will be adjusted. 
The $60 \mathrm{~s}$ average wind $\mathrm{U}(60)$ is estimated as

$$
U(60)=U(t) \cdot F(60: t)
$$

where $U(t)$ is the reported extreme wind speed, $t$ is the averaging interval associated with the reported speed, and $F(60: t)$ is an adjustment factor. The wind speed adjustment factor derived in Appendix B is

$$
F(60: t)=0.7819 /[1.095-0.0760 \ln (t+1.5)]
$$

The values of the constants in this relationship are based on an assumption that the terrain is generally open with scattered trees and buildings. If a smoother surface roughness is assumed, the adjustment factors are closer to 1.0 than those given by Equation (20).

The effect of the application of the adjustment factor to observed extreme winds is shown in Table 5 for three surface roughness assumptions. The first roughness assumption is that made for Equation (20); the second assumption is flat grass land, and the third assumption is for very smooth terrain. The upper portion of the table shows the effect of the adjustment factors on fastest-mile speeds, and the lower portion shows the effects on peak gusts. The significant features to be seen in the table are 1) the adjustments made to fastest-mile speeds are small, while the adjustments made to peak gusts are relatively large (of the order of $20 \%$ ), 2) the fastest-mile speeds less than 60 mph increase, while speeds greater than $60 \mathrm{mh}$ decrease, 3) the peak gust speeds always decrease, and 4) the effects of surface roughness on the adjustment are small compared to the magnitude of the adjustments.

The averaging periods associated with fastest-mile, peak gust and 5-min average speeds have been discussed. The averaging interval associated with fastest 1 -min observed speeds is nominally $60 \mathrm{~s}$, which means that these speeds do not require an averaging interval adjustment. However, the fastest observed speeds are maxima taken from speeds observed at fixed times. As a result, the fastest 1-min observed speeds are likely to significantly underestimate the annual true fastest 1-min speed. Based on an analysis of fastest-mile and fastest l-min data reported by Thom (1964), Simiu et al. (1979) recommend that $10 \mathrm{mph}$ be added to each fastest l-min observed speed before it is used in an extreme wind analysis.

A total of 95 pairs of annual peak gusts and annual fastest 1-min speeds were found for on the NCDC data tapes for 12 southern California locations. The mean difference between the peak gusts and the fastest 1-min speeds was $16.7 \mathrm{mph}$. Following adjustment of the peak gusts to $60 \mathrm{~s}$ averages by multiplying by 0.7819 , which is the adjustment factor given by Equation (20), the mean difference between observed fastest 1 -min speeds and the annual fastest $60 \mathrm{~s}$ average is estimated to be $13 \mathrm{mph}$. 
TABLE 5. Effect of Wind Speed Adjustment Factors on Extreme Wind Values. $\quad A=$ Terrain assumed in Equation 20, $B=f \mathrm{l}$ at grass land, $C=$ very smooth terrain. The numbers in parentheses following the fastest-mile speeds are the averaging periods in seconds associated with the speeds.

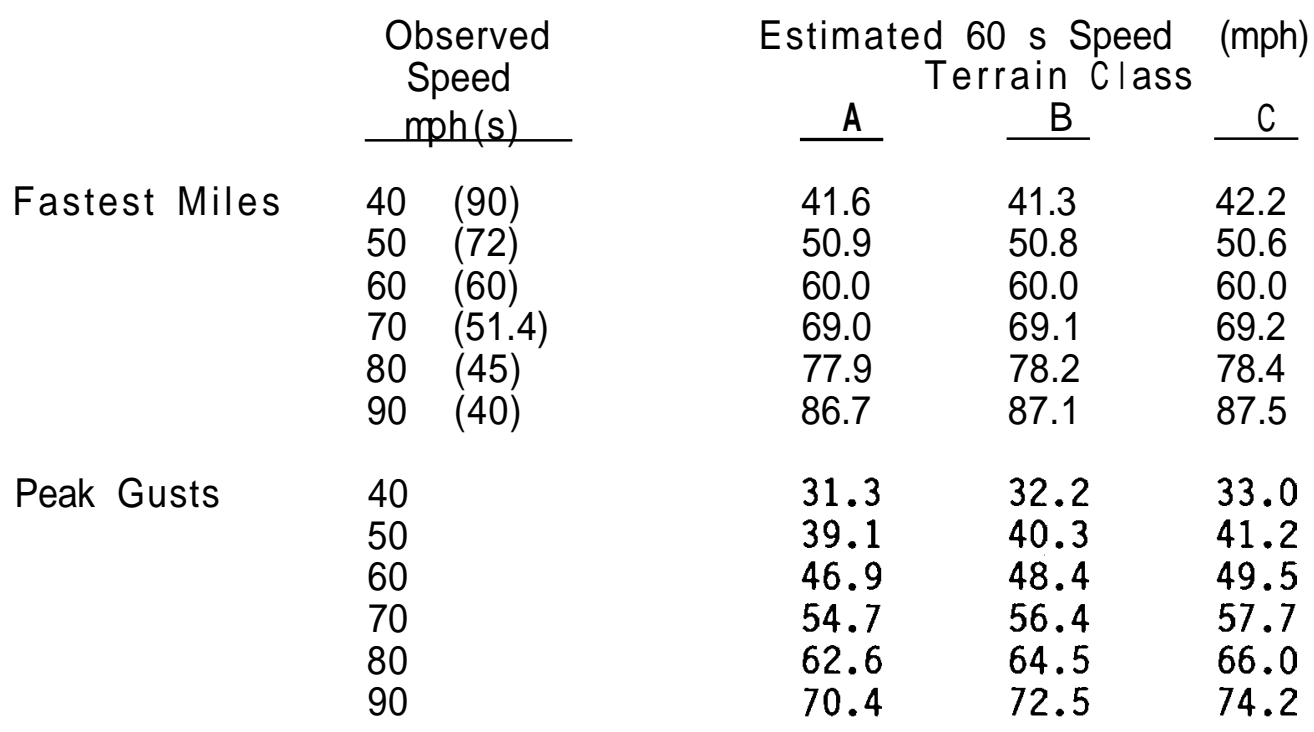

Linear regression between annual peak gusts and annual fastest 1-min speeds gave a relationship of

$$
U_{p}=1.31+1.10 U_{f}
$$

where $U_{p}$ is the peak-gust speed (mph) and $U_{f}$ is the fastest 1-min speed (mph). However, the slope of the regression is not significantly different from 1 at the $90 \%$ confidence level. This finding is consistent with the Thom's conclusion and the recommendation of Simiu et al. Therefore, it is reasonable to add a constant factor to the annual fastest 1-min observed speeds to estimate the true fastest $60 \mathrm{~s}$ average speed. It is recommended that a correction factor of 13 mph be used rather than 10 mph because it gives slightly higher speeds.

\section{Measurement Height}

Near the earth's surface, winds increase with height above ground. Therefore, it is reasonable to attempt to take the height of measurement into account in the analysis of extreme winds. However, theaform of variation of extreme winds with height has not been resolved.

It may be assumed that high winds near the surface are generally associated with neutral atmospheric stability. During these conditions, the variation of mean winds with height near the earth's surface can be described by a logarithmic profile that is derived from theory. Simiu et al. (1979) and Changery (1982a, 1982b) have used a height adjustment procedure that is based 
on the logarithmic profile for mean winds, corrected for turbulence. This approach is not satisfying because an assumption of steady-state conditions is inherent in the use of the logarithmic profile. There is no reason to assume that the gusts responsible for extreme winds are related to steady-state atmospheric conditions.

An alternative to the height adjustment procedure followed by Simiu et al. and Changery is developed in Appendix C. This procedure is not based on an assumption related to a mean wind profile. Instead, extreme winds are assumed to be random occurrences drawn from a distribution that has parameters that are functions of height. The adjustment of extreme winds is then based on the extreme wind distribution location parameter profile rather than the mean wind profile. In Appendix C, extreme wind data for Hanford, Washington and the Kennedy Space Center in Florida are used to evaluate the procedure. No other readily available data were found for use in additional tests of the procedure.

The Hanford and Kennedy Space Center data indicate that the height variation of the mode (location parameter) of the distributions is adequately described by a logarithmic profile. Then, by analogy with the mean wind profile, the mode profile can be represented as

$$
m(z)=A \ln \left[\left(z-z_{d}\right) / z_{c}\right]
$$

where $m(z)=$ the mode of the extreme wind distribution at height $z$

$\mathrm{A} \quad=\quad \mathrm{is}$ the value of the mode at height $\mathrm{z}$ where $\ln \left[\left(z-z_{d}\right) / z_{c}\right]$

$\mathbf{z}_{\mathbf{c}}=\mathrm{a}$ characteristic height associated with surface roughness, but not necessarily $z_{0}$, the surface roughness length associated with the mean wind profile, and

$z_{\mathbf{d}}=$ a zero-plane displacement.

The coefficient A may be assumed to have a constant value for a site, although this assumption implicitly includes an assumption that any directional variations surface roughness at the site has minimal effect on extreme winds. Thus, the extreme wind adjusted to a standard height of $10 \mathrm{~m}(\mathbf{3 3} \mathrm{ft})$ is estimated using the ratio

$$
m(10) / m(z)=\ln \left(10 / z_{c}\right) / \ln \left[\left(z-z_{d}\right) / z_{c}\right]
$$

The mode profiles for Hanford and Kennedy Space Center annual extreme winds indicate that the characteristic height associated with extreme winds is much smaller than the mean wind profile roughness length. While there are insufficient data for an elaborate evaluation of any potential relationship between $z_{c}$ and $z_{0}, z_{c}$ appears to be several orders of magnitude smaller than $z_{0}$. This result is intuitively reasonable because it means that surface 
roughness has less effect on gust magnitudes than it does on mean winds. For present purposes, it should be acceptable to estimate $z_{c}$ by $z_{0} / 1000$.

There are no theoretical bases for inclusion of a zero-plane displacement for gusts, or for estimating a value of the displacement. However, the effect of $z_{d}$ in Equation (23) is to decrease the change in gust speeds that occurs when speeds are adjusted to a standard height. Consequently, neglecting the zero-plane displacement, if i t exists, would be non-conservative. That is, it could result in a tendency to underestimate the magnitude of extreme winds. For typical, well-exposed, rural wind-measurement sites, $z_{d}$ should be small and can probably be neglected. However, for urban sites its effect may be significant. Citing Simiu and Lozier (1975), Changery (1982a, 1982b) used the following to estimate the zero-plane displacement for urban measurement sites from the anemometer height

$$
z_{d}=0.5625 \mathrm{z}
$$

with the limitation that $z_{d}$ not be permitted to exceed $20 \mathrm{~m}$.

In most cases, the application of the height adjustment factor will reduce wind speeds observed using anemometers located well above $10 \mathrm{~m}$ to lower values that are expected to be more representative of the speeds at $10 \mathrm{~m}$. The proposed height adjustment procedure makes smaller changes in the observed speeds than the procedure used by Siniu et al. (1979) and Changery (1982a, 1982b). As a result, the extreme speeds at a standard height of $10 \mathrm{~m}$ will tend to be higher when the proposed method is used than they would be if the previous method were used. 


\section{SINGLE STATION ANALYSIS}

After completion of the adjustments to the individual wind observations, the data subsets may be combined for analysis of extreme winds. This section discusses the consolidation and analysis of data for a single station. The objective of the consolidation of the data sets is to permit estimation of the parameters of the Fisher-Tippett Type Idistribution. These parameters, along with the tornado strike and intensity probabilities, provide a characterization of the extreme winds at a location. Analysis of data sets from several locations is discussed in the next section.

\section{ANALYSIS OF OBSERVED WINDS}

Prior to consolidation of the data for any location, the extreme winds and any adjustments that may have been made to the data should be examined.

Ultimately, this examination involves subjective judgments as to whether to include or exclude each subset in preparing the data base to be used in the analysis. The following three examples illustrate some of the decisions that must be made.

The extreme wind data for Jacksonville, Florida, compiled and presented by Changery (1982a), are 1isted in Table 6. These data include the year, anemometer location, and the fastest-mile wind speeds for the period from 1873 through 1979. From 1873 through 1949, wind observations were made at the Weather Bureau Office in Jacksonville. During this period, the anemometers were located at heights of 84, 129, 245 and $110 \mathrm{ft}$. It should be noted that the anemometer height given for the years before 1881 is an estimated value. From 1950 through 1979, the observations were made at the Jacksonville Airport. There, the anemometer was located above a building at an elevation of $63 \mathrm{ft}$ through 1970, and at an open-field location at $20 \mathrm{ft}$ from 1971 through 1979.

The anemometers used for wind speed measurements at Jacksonville were generally standard anemometers. However, an experimental anemometer was used from 1941 through 1975. The speeds shown in the first wind speed column are the "true" speeds given by Changery. They have been corrected for anemometer response, but they have not been adjusted to a standard averaging interval or height. The extreme winds prior to about 1900 tend to be clustered around selected values. This may be due to the characteristics of the early Weather Bureau instruments. Otherwise, there do not appear to be any significant problems with the data.

The middle wind speed column (U60) shows the annual extremes after the speeds have been adjusted to a standard $60 \mathrm{~s}$ averaging interval. Recall that standardization of fastest-mile speeds to a 60 s averaging period increases the magnitudes of speeds below $60 \mathrm{mph}$ and decreases magnitudes of speeds above $60 \mathrm{mph}$. Consequently, more speeds were increased than decreased in the standardization process. The third wind speed column (U10) shows the extreme wind time series following adjustment of the data to the standard $10 \mathrm{~m}$ height. 
TABLE 6. Extreme Winds for Jacksonville, Florida. Data from Changery (1982a).

\begin{tabular}{|c|c|c|c|c|c|c|c|c|c|}
\hline lear & $\frac{\text { LoC. }}{\text { FRAB }}$ & $\frac{U}{49}$ & $\frac{\mathrm{U} 60}{500}$ & $\frac{U 10}{\Delta 0}$ & $\frac{\text { Year }}{1027}$ & $\frac{\text { LoC. }}{2 \triangle 1 D R}$ & $\frac{U}{10}$ & $\frac{\mathrm{U} 60}{50}$ & $\frac{\text { U10 }}{127}$ \\
\hline 813 & $504 \mathrm{~K}$ & $\begin{array}{l}49 \\
50 \mathrm{~T}\end{array}$ & 50.9 & $\begin{array}{l}49.4 \\
50.3\end{array}$ & $\begin{array}{l}1927 \\
1928\end{array}$ & 245R & $\begin{array}{l}49 \\
52 T\end{array}$ & $\begin{array}{l}50.0 \\
52.7\end{array}$ & 42.7 \\
\hline 376 & " & $\begin{array}{l}47 \\
63 T\end{array}$ & $\begin{array}{l}48.1 \\
62.7\end{array}$ & $\begin{array}{l}47.6 \\
62.0\end{array}$ & $\begin{array}{l}1929 \\
930\end{array}$ & $"$ & $\begin{array}{l}6 \\
63 \\
43\end{array}$ & $6 \overline{2} \cdot 7$ & 53. \\
\hline 377 & $"$ & 56 & 56.4 & 55.8 & 193 & $"$ & E65 & 64.5 & 55 \\
\hline 379 & " & 38 & 39.7 & 39.3 & 1933 & 1100 & $51 \mathrm{~T}$ & 51.8 & 44 \\
\hline 8 & $84 R$ & 47 & 48 & 47.6 & 1935 & " & $\begin{array}{l}41 \\
49\end{array}$ & $\begin{array}{l}42.5 \\
50.0\end{array}$ & \\
\hline 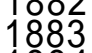 & $"$ & $\begin{array}{l}401 \\
47\end{array}$ & $\begin{array}{l}41 \\
48\end{array}$ & $\begin{array}{l}40.6 \\
47.6\end{array}$ & 1937 & " & $\begin{array}{l}50 \\
35 T\end{array}$ & $\begin{array}{l}50.9 \\
36.9\end{array}$ & \\
\hline & " & $\begin{array}{l}50 \\
47 T\end{array}$ & $\begin{array}{l}50 \\
48\end{array}$ & $\begin{array}{l}50.3 \\
47.6\end{array}$ & 93 & " & $\begin{array}{l}35 \\
40\end{array}$ & 36.9 & \\
\hline 38 & $"$ & $46 \mathrm{~T}$ & 47. & 46.7 & 194 & $n$ * & +37 & 38 & 37 \\
\hline 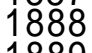 & " & $38 T$ & 39 & 39.3 & 194 & " & $\begin{array}{r}42 \\
+\quad 42\end{array}$ & 43.5 & , \\
\hline 390 & " & 42 & $4 \frac{1}{3}$ & $\begin{array}{l}4 \frac{1}{3} .0 \\
43.0\end{array}$ & 194 & $"$ & $\begin{array}{r}* 46 \\
x^{*} 46\end{array}$ & $\begin{array}{l}43 \\
47\end{array}$ & \\
\hline & 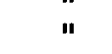 & $\begin{array}{l}4 \prime \\
36\end{array}$ & $\begin{array}{l}48 \\
37\end{array}$ & $\begin{array}{l}47.5 \\
37.5\end{array}$ & $\begin{array}{l}194 \\
194\end{array}$ & $" 1 *$ & $\begin{array}{r}451 \\
\times 44\end{array}$ & $46 \cdot 3$ & \\
\hline & " & $\begin{array}{l}47 \\
58 T\end{array}$ & 48 & 47.6 & 194 & $" 1$ & $\begin{array}{l}381 \\
\times 45 \\
4\end{array}$ & 39.7 & 44 \\
\hline & " & 46 & 47 & 46.7 & 194 & "x & $\begin{array}{l}* \quad 50 \\
+\quad 70\end{array}$ & 50 & 49 \\
\hline & " & 47 & $48^{\circ}$ & 47.6 & 195 & Sint $^{n}$ & $\begin{array}{r}1 \\
+\end{array}$ & 43.5 & 41 \\
\hline & " & 47 & 48 & $\begin{array}{l}47.0 \\
47.6\end{array}$ & 195 & " & $\begin{array}{l}56 \\
52 \\
5\end{array}$ & 52.7 & 50 \\
\hline & " & $\begin{array}{l}46 \\
54\end{array}$ & $\begin{array}{l}4 \prime \\
54 .\end{array}$ & $\begin{array}{l}46 . \% \\
54.0\end{array}$ & 195 & $"$ " & $\begin{array}{r}46 \\
+\quad 46\end{array}$ & $47 \overline{2}$ & 44 \\
\hline & $120 \mathrm{OR}$ & 47 & 48 & 47.6 & 1956 & "1 & $\begin{array}{r}* 49 \\
* 46\end{array}$ & $17 \%$ & $\Delta 4$ \\
\hline & " & 45 & 46 & 43.4 & 195 & $" x$ & $\begin{array}{r}* \\
* \\
*\end{array}$ & 4 & 41 \\
\hline & $"$ & 47 & 48 & $\begin{array}{l}40 \\
45\end{array}$ & 1960 & $11 *$ & * 460 & $47 \cdot 2$ & 44 \\
\hline & " & 60 & $\begin{array}{l}51 \\
60\end{array}$ & $\begin{array}{l}53 \\
56\end{array}$ & 96 & $"$ & $\begin{array}{r}48 \\
\times \quad 54\end{array}$ & $\begin{array}{l}49.0 \\
54.5\end{array}$ & \\
\hline & " & $\begin{array}{l}50 \\
57\end{array}$ & $\begin{array}{l}50 \\
57\end{array}$ & $\begin{array}{l}47.7 \\
53.7\end{array}$ & 1963 & "Ix & $\begin{array}{r}62 \\
\star \\
\star\end{array}$ & 61.8 & 75 \\
\hline & " & $47 \mathrm{~T}$ & 48 & 45.2 & & $" x$ & 571 & 57.3 & 54 \\
\hline & & 51 & & & & $n$ & $\begin{array}{r}48 \mathrm{~T} \\
\times\end{array}$ & & \\
\hline & (20) & 47 & J & 4 & 96 & 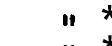 & $\begin{array}{l}10 \\
+52 \mathrm{~T}\end{array}$ & 5 & 50 \\
\hline & $245 \mathrm{R}$ & $\begin{array}{l}53 \\
47\end{array}$ & 53 & 41 & 9 & 111 & $\begin{array}{r}58 \\
\times \quad 44\end{array}$ & $\frac{15}{15} \frac{2}{2}$ & 43 \\
\hline & 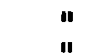 & 50 & 5 & 43 & & $2 Q G *$ & $\begin{array}{r}44 \\
8\end{array}$ & $48^{\circ}$ & \\
\hline & " & 53 & & & $a$ & 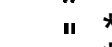 & $\begin{array}{l}44 \\
48 \\
\end{array}$ & & \\
\hline & " & 49 & & $4 \leqslant$. & & $\Delta$ & 44 & & \\
\hline 22 & $n$ & $\begin{array}{l}60 \\
49\end{array}$ & 50 & $51 \cdot 3$ & 87 & ii & $\begin{array}{l}62 \\
42\end{array}$ & $\frac{1}{3} \cdot 8$ & 15 \\
\hline 20 & " & 54 & 54 & 0.6 & & $"$ & 33 & 5.0 & Jy \\
\hline & & & & & & & & & \\
\hline & & & & & & & & & \\
\hline
\end{tabular}

NOTE: $\quad \underset{\star}{E}=$ estimated height, $R$ = roof location, $G$ = ground location, speed. = experimental anemometer, $T$ = tropical storm, $E$ = estimated 
It should be noted that downward adjustment decreases the speeds, while upward adjustment increases them.

Plotting the extreme speeds as a function of time may provide some indication of the general trend of the data in response to changes in anemometer elevation, and the change in anemometer location. However, the scatter of extreme wind data makes it difficult to perceive small effects. A more reliable method of identifying the effects of changes is to compare statistics of the extremes.

The means and standard deviations for the Jacksonville extreme wind data for each height (subset) are presented in Table 7 . The table also contains the modes and scale parameters estimated for each subset using the method of moments (Equations 5 and 6 ). Estimates of the modes are particularly useful in evaluation of potential effects of changes in anemometer location, because they are parameters of the distribution and are more stable measures of central tendency than mean values. That is, the modes are less sensitive to occasional occurrences of extremely large, annual maxima than are means of the annual extremes.

The adjustments have decreased the range of the subset modes. In addition, it should be noted that the large number of annual extremes with speeds of about 47 mph fall near the modes of the adjusted distributions. As a result, they will have little effect on estimates of extremes with a low probability of occurrence.

TABLE 7. Statistics of Jacksonville Extreme Winds at Each Anemometer Location.

$\begin{array}{lrrrrrr}\text { Height } & 84 R & 129 R & 245 R & 110 R & 63 R & 20 G \\ \text { Years } & 30 & 12 & 19 & 16 & 21 & 9\end{array}$

Reported Speeds

$\begin{array}{lcccccc}\text { Mean } & 47.77 & 53.42 & 53.53 & 42.25 & 53.14 & 43.67 \\ \text { St. Dev. } & 7.955 & 8.512 & 6.257 & 5.053 & 11.56 & 8.646 \\ \text { Mode } & 44.19 & 49.59 & 50.71 & 39.98 & 47.94 & 39.78 \\ \text { Scale } & 6.203 & 6.637 & 4.879 & 3.940 & 9.017 & 6.741\end{array}$

Speeds Standardized'to $60 \mathrm{~s}$ Averaging Time

$\begin{array}{lcccccc}\text { Mean } & 48.77 & 53.97 & 54.08 & 43.69 & 53.68 & 44.96 \\ \text { St. Dev. } & 7.283 & 7.705 & 5.696 & 4.720 & 10.50 & 7.997 \\ \text { Mode } & 45.49 & 50.50 & 51.52 & 41.57 & 45.49 & 41.36 \\ \text { Scale } & 5.678 & 6.008 & 4.441 & 3.680 & 8.183 & 6.235\end{array}$

Speeds Standardized to $10 \mathrm{~m}$

$\begin{array}{lcccccc}\text { Mean } & 48.25 & 50.64 & 46.22 & 42.09 & 50.99 & 46.89 \\ \text { St. Dev. } & 7.200 & 7.237 & 4.877 & 4.538 & 9.967 & 8.325 \\ \text { Mode } & 45.01 & 47.38 & 44.02 & 40.05 & 46.50 & 43.14 \\ \text { Scale } & 5.614 & 5.643 & 3.802 & 3.538 & 7.771 & 6.491\end{array}$


Considering the range of the modes and the small variation in the scale parameters in the last set of statistics in Table 7, it seems reasonable to combine the six data subsets into a single set representing Jacksonville, Florida. When the subsets are combined, the method-of-moments estimates of the mode, and scale parameter of the distribution are 44.20 and $5.987 \mathrm{mph}$, respectively. One alternative to combining the data after height adjustment is to combine the subsets without height adjustment. This alternative would result in method-of-moment estimates of the mode and scale parameter of 46.39 and $6.567 \mathrm{mph}$. These larger values of the parameters will result in higher extreme wind speed estimates and a larger uncertainty in the estimates [see Equations (2) and (9)]. When there is significant doubt, it is appropriate to select the option that yields the highest mode and largest scale parameter val ues.

Another alternative to combining all of the subsets is to eliminate one or more subsets from the data base. Elimination of subsets should not be done without clear evidence that the data in the subsets are in error or are not representative of the site for which the extreme wind analysis is to be made. Original data records should be reexamined for a possible explanation of apparent anomalies if elimination of a subset is considered. Again, if there is any doubt about elimination of a subset, the alternative that yields the largest mode and scale parameter should be chosen.

The second example illustrates one type of anomaly that may be encountered. Table 8 lists the extreme wind data presented by Changery (1982b) for the airport at Grand Rapids, Michigan. Statistics for the two data subsets are presented in Table 9. On examination of the statistics for the reported data and the statistics for the data adjusted to a $60 \mathrm{~s}$ averaging period, the two subsets may appear to be consistent. However, on closer examination, it can be seen that the mode estimated for the first subset is slightly lower than the mode estimated for the second subset even though the measurement height for the first subset is higher. This discrepancy is increased when the adjustment to the standard, $10 \mathrm{~m}$ measurement height is made.

A potential cause of this discrepancy can be found in a close examination of the station history. The basic data are presented by Changery (1982b) as though they are for a single location located at $42^{\circ} 54^{\prime}$ north latitude, $85^{\circ}$ $40^{\prime}$ west longitude, although two station identification numbers, WBAN \#14830 and WBAN \#94860 are given. According to Changery (1978), there have been two Grand Rapids,. Michigan Weather Bureau Airport Stations. The first station (MBAN \#14830) was located at the coordinates given above until November 24, 1963. The second station (MBAN \#94860), located at $42^{\circ} 53^{\prime} \mathrm{N}, 85^{\circ} 31^{\prime} \mathrm{W}$, began operation on November 24, 1963, which coincides with the date on which the anemometer height changed. The separation between these stations is about 6 miles, and there is a $37 \mathrm{~m}$ difference in elevations. Consequently, it may be reasonable to assume that the anomaly is due to differences in the topographic settings of the airports. A topographic map of the region may be of assistance in resolving this question. It may also be possible that the difference between the observed extreme winds is due to normal climatological variation, in view of the relatively short period of record at each location. 
TABLE 8. Extreme Winds for Grand Rapids, Michigan. Data from Changery (1982b).

\begin{tabular}{|c|c|c|c|c|c|c|c|c|c|}
\hline Year & Loc. & $U$ & U60 & U10 & Year & LoC. & $\mathrm{U}$ & U60 & U10 \\
\hline 1951 & $64 \mathrm{R}$ & 47 & 48.1 & 45.6 & 1964 & $20 \mathrm{G}$ & 58 & 58.2 & 60.7 \\
\hline 1952 & $"$ & 65 & 64.5 & 61.2 & 1965 & "I & 52 & 52.7 & 55.0 \\
\hline 1953 & " & 46 & 47.2 & 44.8 & 1966 & " & 40 & 41.6 & 43.4 \\
\hline 1954 & " & 57 & 57.3 & 54.3 & 1967 & " & 43 & 44.4 & 46.3 \\
\hline 195 & " & 44 & 45.3 & 43.0 & 1968 & " & 50 & 50.9 & 53.1 \\
\hline 1956 & $"$ & 52 & 52.7 & 50.0 & 1969 & " & 50 & 50.9 & 53.1 \\
\hline 1957 & " & 45 & 46.2 & 43.9 & 1970 & " & 40 & 41.6 & 43.4 \\
\hline 1958 & " & 40 & 41.6 & 39.5 & 1971 & " & 58 & 58.2 & 60.7 \\
\hline 195 & $"$ & 40 & 41.6 & 39.5 & 1972 & " & 56 & 56.4 & 58.8 \\
\hline 196 & $"$ & 43 & 44.4 & 42.1 & 1973 & $\|$ & 37 & 38.8 & 40.4 \\
\hline & $"$ & 40 & 41.6 & 39.5 & 1974 & " & 47 & 48.1 & 50.2 \\
\hline & $"$ & 41 & 42.5 & 40.4 & 1975 & " & 61 & 60.9 & 63.5 \\
\hline & " & 45 & 46.3 & 43.9 & 1976 & " & 61 & 60.9 & 63.5 \\
\hline & & & & & 1977 & " & 39 & 40.7 & .4 \\
\hline & & & & & 1978 & 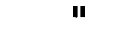 & 51 & 51.8 & 1.0 \\
\hline & & & & & $1 y / y$ & $"$ & 49 & 50.0 & $5<.1$ \\
\hline
\end{tabular}

NOTE: $R=$ roof location, $G=$ ground location

TABLE 9. Statistics of the Grand Rapids Airport

Extreme Winds at Each Anemometer Location.

$\begin{array}{lrr}\text { Height } & 64 R & 20 G \\ \text { Years } & 13 & 16\end{array}$

Reported Speeds

$\begin{array}{lcc}\text { Mean } & 46.54 & 49.50 \\ \text { St. Dev. } & 7.434 & 7.983 \\ \text { Mode } & 43.19 & 45.91 \\ \text { Scale } & 5.797 & 6.225\end{array}$

Speeds Standardized to $60 \mathrm{~s}$ Averaging Time Mean $\quad 47.64 \quad 50.38$

St. Dev. $\quad 6.827 \quad 7.353$

$\begin{array}{lll}\text { Mode } & 44.57 \quad 47.07\end{array}$

Scale $\quad 5.323 \quad 5.733$

Speeds Standardized to $10 \mathrm{~m}$

$\begin{array}{lll}\text { Mean } & 45.21 & 52.54\end{array}$

St. Dev. $\quad 6.458 \quad 7.674$

Mode $\quad 42.30 \quad 49.08$

Scale $\quad 5.036 \quad 5.983$ 
The decision to consolidate the two Grand Rapids airport subsets or not is a subjective one. If one of the airport locations is clearly not representative of the site for which the extreme value analysis is being performed, then it would be necessary to discard the data for that location. If, however, neither airport location can be shown to be unrepresentative, consolidation of the subsets may be more appropriate.

The data for La Crosse, Wisconsin (Changery 1982b) provide the final example. These data are presented in Table 10, and their statistics are summarized in Table 11. From 1874 through 1942 the data were taken at the La Crosse Weather Bureau office. The remaining data were take at the La Crosse airport.

During the 69 years that the wind measurements were made at the Weather Bureau office, the anemometer height increased from 70 to $87 \mathrm{ft}$ and then decreased to $49 \mathrm{ft}$. The summary table shows that the decrease in annual extremes, which coincided with the change in anemometer height, was more than can be accounted for by the height change. In the 35 years that the anemometer was at $49 \mathrm{ft}$, the annual extreme (adjusted to $10 \mathrm{~m}$ ) was less than $35 \mathrm{mph} 28$ times, while in the 34 previous years, the annual extreme (also adjusted to $10 \mathrm{~m}$ ) was less than 35 miles only twice. It is reasonable to assume that the 1908 change in anemometer height was associated with a change in location of the Weather Bureau office. Although Changery (1978, 1982b) does not indicate this change in location, the change is shown in the station history in the Local Climatological Data Annual Summary With Comparative Data for La Crosse (for example in NOAA 1980). In addition, the remarks column contains the following comment on the exposure at $49 \mathrm{ft}$ : "Tops of trees equal or slightly above wind instrument exposure." On this basis, it is reasonable to exclude the $49 \mathrm{ft}$ data from further consideration.

Without exclusion of the $49 \mathrm{ft}$ data from the data set, the mode and scale parameters estimated for $10 \mathrm{~m}$ for La Crosse using a composite data set are 35.03 mph and $8.709 \mathrm{mph}$, respectively. Excluding the $49 \mathrm{ft}$ data, the parameters are $42.10 \mathrm{mph}$ and $8.207 \mathrm{mph}$. These parameters correspond to the estimated $60 \mathrm{~s}$ average extreme winds shown in Table 12. It is evident that the effect of the increase in the mode resulting from excluding the $49 \mathrm{ft}$ data causes an increase in the estimated extremes. However, the decrease in scale parameter tends to offset that increase as lower probability speeds are estimated.

\section{STATISTICAL TESTS}

Statistical comparisons of the data in the subsets may provide insight that can be used in making the decision to consolidate data subsets. Extreme winds have a highly skewed distribution in which there are many relatively small values and a few very large values. As a result, statistical techniques for comparing sample means, such as Student's t test and Duncan's multiple range test (Wine 1964) are not efficient. These tests assume that the samples are drawn from distributions that are normal. There are other tests, including the Kolmogorov-Smirnov two-sample test, the Mann-Whitney (Wi lcoxson), and Kruskal-Wallis tests that do not assume that the distributions from which the 
TABLE 10. Extreme Winds for La Crosse, Wisconsin. Data from Changery (1982b).

\begin{tabular}{|c|c|c|c|c|c|c|c|c|c|}
\hline Year & LoC. & $\underline{U}$ & U60 & U10 & Year & LOC. & U & U60 & U10 \\
\hline 1874 & $7 Q R$ & 61 & 60.9 & 61.4 & 1913 & $49 R$ & 32 & 34.0 & 35.6 \\
\hline 1875 & $\pi$ & 84 & 81.4 & 82.0 & 1914 & & 41 & 42.7 & 44.5 \\
\hline 1876 & " & 43 & 44.4 & 44.7 & 1915 & & 31 & 33.1 & 34.6 \\
\hline 1877 & " & 39 & 40.7 & 41.0 & 1916 & 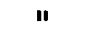 & 30 & 32.1 & 33.6 \\
\hline 1878 & " & 46 & 47.2 & 47.6 & 1917 & 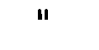 & 25 & 27.3 & 28.5 \\
\hline 1879 & " & 38 & 39.7 & 40.0 & 1918 & $"$ & 25 & 27.3 & 28.5 \\
\hline 1880 & & 42 & 43.5 & 43.8 & 1919 & $"$ & 31 & 33.1 & 34.6 \\
\hline 1881 & $81, R$ & 40 & 41.6 & 41.3 & 1920 & " & 32 & 34.0 & 35.6 \\
\hline 1882 & "I & 60 & 60.0 & 59.6 & 1921 & $"$ & 30 & 32.1 & 33.6 \\
\hline 1883 & II & 38 & 39.7 & 39.4 & 1922 & $"$ & 30 & 32.1 & 33.6 \\
\hline 1884 & $n$ & 62 & 61.8 & 61.4 & 1923 & $"$ & 34 & 35.9 & 37.6 \\
\hline 1885 & " & 48 & 49.0 & 48.7 & 1924 & $"$ & 32 & 34.0 & 35.6 \\
\hline 1886 & & 49 & 50.0 & 49.6 & 1925 & $"$ & 28 & 30.2 & 31.6 \\
\hline 1887 & $8 Q_{n} R$ & 43 & 44.4 & 44.1 & 1926 & $"$ & 24 & 26.3 & 27.5 \\
\hline 1888 & " & 33 & 35.0 & 34.8 & 1927 & $"$ & 21 & 23.3 & 24.4 \\
\hline 1889 & & 50 & 50.9 & 50.6 & 1928 & $"$ & 26 & 28.3 & 29.5 \\
\hline 1890 & $81, R$ & 47 & 48.1 & 47.8 & 1929 & $"$ & 25 & 27.3 & 28.5 \\
\hline 1891 & "1 & 28 & 30.2 & 30.0 & 1930 & $"$ & 23 & 25.3 & 26.5 \\
\hline 1892 & " & 38 & 39.7 & 39.4 & 1931 & $"$ & 37 & 38.8 & 40.5 \\
\hline 1893 & " & 40 & 41.6 & 41.3 & 1932 & $"$ & 22 & 24.3 & 25.4 \\
\hline 1894 & "1 & 35 & 36.9 & 36.6 & 1933 & $"$ & 27 & 29.2 & 30.6 \\
\hline 1895 & " & 43 & 44.4 & 44.1 & 1934 & $"$ & 30 & 32.1 & 33.6 \\
\hline 1896 & " & 40 & 41.6 & 41.3 & 1935 & $"$ & 26 & 28.3 & 29.5 \\
\hline 1897 & " & 47 & 48.1 & 47.8 & 1936 & $"$ & 32 & 34.0 & 35.6 \\
\hline 1898 & " & 40 & 41.6 & 41.3 & 1937 & $"$ & 24 & 26.3 & 27.5 \\
\hline 1899 & " & 43 & 44.4 & 44.1 & 1938 & $"$ & 23 & 25.3 & 26.5 \\
\hline 1900 & " & 35 & 36.9 & 36.6 & 1939 & $"$ & 24 & 26.3 & 27.5 \\
\hline 190 & & 36 & 37.8 & 37.6 & 1940 & " & 31 & .1 & \\
\hline 1902 & $87, R$ & 40 & 41.6 & 41.0 & 1941 & " & 28 & 32.0 & 31.6 \\
\hline 1903 & "I & 36 & 37.8 & 37.3 & 1942 & $"$ & 25 & 27.3 & 28 \\
\hline 1904 & " & 38 & 39.7 & 39.2 & 1943 & $29 R$ & 53 & 53.6 & 54. \\
\hline 190 & $"$ & 34 & 35.9 & 35.4 & 1944 & $"$ & 65 & 64.5 & 65.2 \\
\hline 190 & $"$ & 37 & 38.8 & 38.2 & 1945 & $"$ & 40 & 41.6 & 42.1 \\
\hline & & 49 & $50 . Q$ & 49.3 & 1946 & $"$ & 52 & 52.7 & \\
\hline 1908 & $49 \mathrm{R}$ & 25 & 27.3 & 28.5 & 1947 & " & 47 & 48.1 & 48. \\
\hline 19 & " & 30 & 32.1 & 33.6 & 1948 & $"$ & 54 & 54.5 & \\
\hline & 11 & 25 & 27.3 & 28.5 & 1949 & $"$ & 69 & 68.1 & 68.8 \\
\hline & " & 30 & 32.1 & 33.6 & 1950 & $"$ & 61 & 60.9 & 1.6 \\
\hline & & 34 & 35.9 & 37.6 & & & & & \\
\hline
\end{tabular}

NOTE: $\quad R=$ roof location 
TABLE 11. Statistics of La Crosse Extreme Winds at Each Anemometer Location.

\begin{tabular}{|c|c|c|c|c|c|c|c|}
\hline $\begin{array}{l}\text { Height } \\
\text { Years }\end{array}$ & $\begin{array}{r}70 \mathrm{R} \\
7\end{array}$ & $\begin{array}{r}81 R \\
6\end{array}$ & $\begin{array}{r}80 \mathrm{R} \\
3\end{array}$ & $\begin{array}{r}81 R \\
12\end{array}$ & $\begin{array}{r}87 R \\
6\end{array}$ & $\begin{array}{r}49 R \\
35\end{array}$ & $\begin{array}{r}29 R \\
8\end{array}$ \\
\hline $\begin{array}{l}\text { Reported } \\
\text { Mean } \\
\text { St. Dev. } \\
\text { Mode } \\
\text { Scale }\end{array}$ & $\begin{array}{l}\text { peeds } \\
50.43 \\
16.68 \\
42.92 \\
13.01\end{array}$ & $\begin{array}{c}49.50 \\
9.915 \\
45.04 \\
7.730\end{array}$ & $\begin{array}{c}42.00 \\
8.544 \\
38.15 \\
6.662\end{array}$ & $\begin{array}{c}39.33 \\
5.433 \\
36.89 \\
4.236\end{array}$ & $\begin{array}{c}39.00 \\
5.292 \\
36.62 \\
4.126\end{array}$ & $\begin{array}{c}28.37 \\
4.466 \\
26.36 \\
3.482\end{array}$ & $\begin{array}{c}55.13 \\
9.524 \\
50.84 \\
7.425\end{array}$ \\
\hline $\begin{array}{l}\text { Speeds S } \\
\text { Mean } \\
\text { St. Dev. } \\
\text { Mode } \\
\text { Scale }\end{array}$ & $\begin{array}{l}\text { odardiz } \\
51.11 \\
15.12 \\
44.31 \\
11.79\end{array}$ & $\begin{array}{c}d \text { to } 60 \\
50.36 \\
9.116 \\
46.52 \\
7.108\end{array}$ & $\begin{array}{c}\text { s Avera } \\
43.43 \\
7.988 \\
39.82 \\
6.228\end{array}$ & $\begin{array}{c}\text { ing Time } \\
40.95 \\
5.113 \\
38.65 \\
3.986\end{array}$ & $\begin{array}{c}40.65 \\
4.938 \\
38.42 \\
3.850\end{array}$ & $\begin{array}{c}30.53 \\
4.300 \\
28.59 \\
3.353\end{array}$ & $\begin{array}{c}55.52 \\
8.692 \\
51.60 \\
6.777\end{array}$ \\
\hline $\begin{array}{l}\text { Speeds S } \\
\text { Mean } \\
\text { St. Dev. } \\
\text { Mode } \\
\text { Scale }\end{array}$ & $\begin{array}{c}\text { odardiz } \\
51.50 \\
15.23 \\
44.64 \\
11.88\end{array}$ & $\begin{array}{c}\text { d to } 10 \\
50.00 \\
9.051 \\
45.93 \\
7.057\end{array}$ & $\begin{array}{c}43.17 \\
7.941 \\
39.60 \\
6.192\end{array}$ & $\begin{array}{c}40.66 \\
5.076 \\
38.38 \\
3.958\end{array}$ & $\begin{array}{c}40.07 \\
4.868 \\
37.88 \\
3.796\end{array}$ & $\begin{array}{c}31.19 \\
4.495 \\
29.89 \\
3.505\end{array}$ & $\begin{array}{c}56.11 \\
8.784 \\
52.16 \\
6.849\end{array}$ \\
\hline
\end{tabular}

TABLE 12. Effect of Excluding the $49 \mathrm{ft}$ Data From the La Crosse, Wisconsin, Extreme Wind Data Base.

$\begin{array}{cccc}\begin{array}{c}\text { Probability } \\ \left(y r^{-1}\right)\end{array} & \begin{array}{c}\text { with } \\ \mathrm{ft} \text { data } \\ \text { (rnph) }\end{array} & & \begin{array}{c}\text { without } \\ \begin{array}{c}\text { wt data } \\ \text { (mph) }\end{array}\end{array} \\ & & & 61 \\ 10-2 & 55 & 80 \\ 10-3 & 95 & 99 \\ 10-4 & 115 & 118\end{array}$

samples are drawn are normal. These tests are called nonparametric tests and are described.in various statistics texts including Hollander and Wolfe (1973) and Daniel (1978).

The Mann-Whitney and Kruskal-Walli s tests, which may be used to compare the location parameters (modes) of distributions, are based on order statistics of the observations in the subsets. The data are arranged in order of ascending value. Each value is assigned a rank according to its position, with the lowest value having the rank of one. The sums of the ranks of the data in each subset are computed and are used in comparing the samples. The Mann-Whitney test is used when two samples are compared, and the Kruskal-Wallis test is used to compare more than two samples. 
The Kruskal-Wallis test was used to compare the estimated modes of data subsets for Jacksonville standardized to the $60 \mathrm{~s}$ averaging period before and after adjustment to the standard $10 \mathrm{~m}$ measurement height. Prior to adjusting the data to the $10 \mathrm{~m}$ height, 6 of the 15 differences were statistically different at confidence level of $90 \%$ or greater, and four of them were significant at the $99 \%$ confidence level. After the height adjustment was applied, only three of the differences were significant. All three of the significant differences involved the fourth measurement period. The annual maximum wind speeds during the fourth measurement period (1934 through 1949) were relatively low but not outside of the range of the speeds during the other periods. Thus, the tests tend to support the adjustment of the speeds to the standard $10 \mathrm{~m}$ height. Although the tests indicate that the distribution of extreme winds during the fourth period was significantly different than those of winds during the other periods, further examination of the data does not indicate that consolidation of the subsets would be improper. When attempting to interpret the results of these statistical tests, it is well to remember that the locations for which data are available are not likely to be the location for which the probabilistic risk assessment is to be performed.

When the Mann-Whitney test was used to compare modes of the Grand Rapids data, the difference prior to adjustment to $10 \mathrm{~m}$ was not significant at even the $75 \%$ confidence level. However, after the height adjustment, the difference in the modes of the subsets was significant at the $95 \%$ confidence level. Depending on the situation in which the Grand Rapids were to be used, any one of several courses of action might be appropriate. If one of the Grand Rapids airport locations is clearly not representative of the site for which extreme winds are being estimated, the data for that site could be excluded from further analysis. If neither data subset can be excluded, the data may be consolidated with or without height adjustment.

Consolidation of the data subsets prior to height adjustment could be justified by arguing that the standard measurement height lies between the two actual measurement heights and that the statistical test does not indicate that the distributions are different. An argument can be made for combining the subsets after the height adjustment on the basis of estimates of the modes and scale parameters. If the data are combined prior to height adjustment, the estimates of the mode and scale parameter are 45.95 and 5.558, respectively, while if the subsets are combined after the height adjustment, the parameter values are 45.67 and 6.197. When modes are approximately the same, the larger scale parameter value will yield the higher (more conservative) extreme wind estimates. This may be confirmed by considering Equation (2).

A third alternative might be to assume that the subsets are from different locations and treat them as such. However, this alternative is only a variation on the previous alternatives. If the extreme wind analysis is to be based on data for a single station, this alternative results in discarding one of the subsets with a reduction in the scale parameter that may not be warranted. If the extreme wind analysis is to be based on data for many stations and neither of the subsets will be discarded in consolidation of the multiple station data base, the issue of a combination of the data subsets is only a matter of timing. 
The observed extreme wind speeds available from the standard climatological data sources do not properly account for the probability of winds due to tornadoes. Equations (11) through (13) provide a means of assigning a probability to tornado winds. Parameters for the tornado intensity distribution are given in Table $\mathbf{3}$, and the corresponding distributions for the eastern and western United States are shown in Figure 1. Given these probabilities, tornado wind speeds can be estimated if the tornado strike probability is known.

The National Severe Storms Forecast Center (NSSFC) operated by the National Weather Service in Kansas City, Missouri, maintains a data base that lists tornadoes reported in the contiguous United States since 1950. Tornadoes are tabulated by states and are described by position (latitude and longitude of the beginning and end), length, width, and intensity. A similar data base, called the DAPPL data base, is maintained by Fujita at the University of Chicago. Grazul is (1984) reevaluated the intensity ratings of tornadoes listed as F4 and F5 in the NSSFC and DAPPL tornado data bases and reconciled the differences in the ratings of these tornadoes.

Ramsdell and Andrews (1986) used the NSSFC data base, containing the results of the reconciliation, to prepare a climatology of tornado occurrences in the contiguous United States from 1954 through 1983. Their estimates of the tornado point-strike probability estimates $\left(\mathrm{yr}^{-1}\right)$ for five latitude and longitude boxes covering the contiguous United States are shown in Figure 2. The probabilities in the figure have been multiplied by $10^{6}$. Thus, the probabilities range from a low of about $10^{-7}$ in western Oregon to a high of almost $4 \times 10^{-3}$ in the vicinity of Kansas and Oklahoma.

\section{FNAL ANALYSIS}

At this point, the extreme winds at a location are characterized by three numbers--the mode and scale parameter of the Fisher-Tippett Type I distribution, and the tornado strike probability. With these numbers, and the number of annual extreme winds used to estimate the Type I distribution parameters, it is a simple matter to compute the probabilities $\left(y r^{-1}\right)$ associated with extreme winds. Appendix $\mathbf{D}$ contains a listing of a short computer program for this purpose.

Parameters for the extreme wind characteristics for the three locations discussed in the examples earlier in this section are summarized in Table 13. These parameters and the program in Appendix $D$ have been used to estimate extreme wind probabilities for each of the sites. The results are shown in Tables 14, 15 and Figure 3.

The wind speeds given in the tables and figure are fastest-mile wind speeds. They were converted to $60 \mathrm{~s}$ averages in the program for evaluation of the probability of occurrence and estimation of the wind speeds at the upper and lower ends of the $90 \%$ confidence interval. The wind speeds associated with the confidence interval were adjusted to fastest-mile values at the end of the 


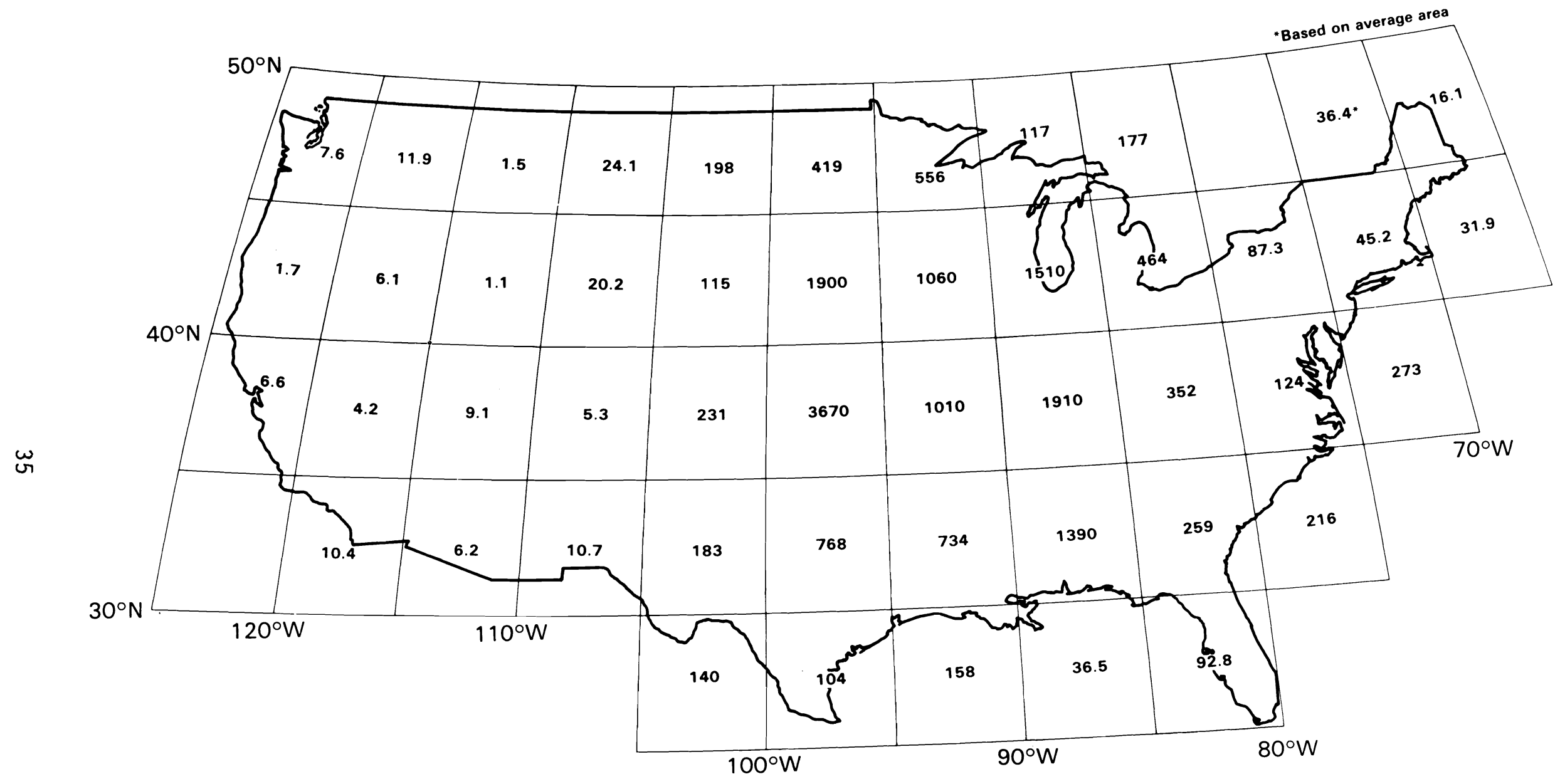

FIGURE 2 Tornado Point-Strike Probabilities $\left(y r^{-1}\right)$ for the Contiguous United States Based on Tornadoes Reported from 1954 Through 1983.

Probabilities shown have been multiplied by $10^{6}$. From Ramsdell and Andrews (1986). 


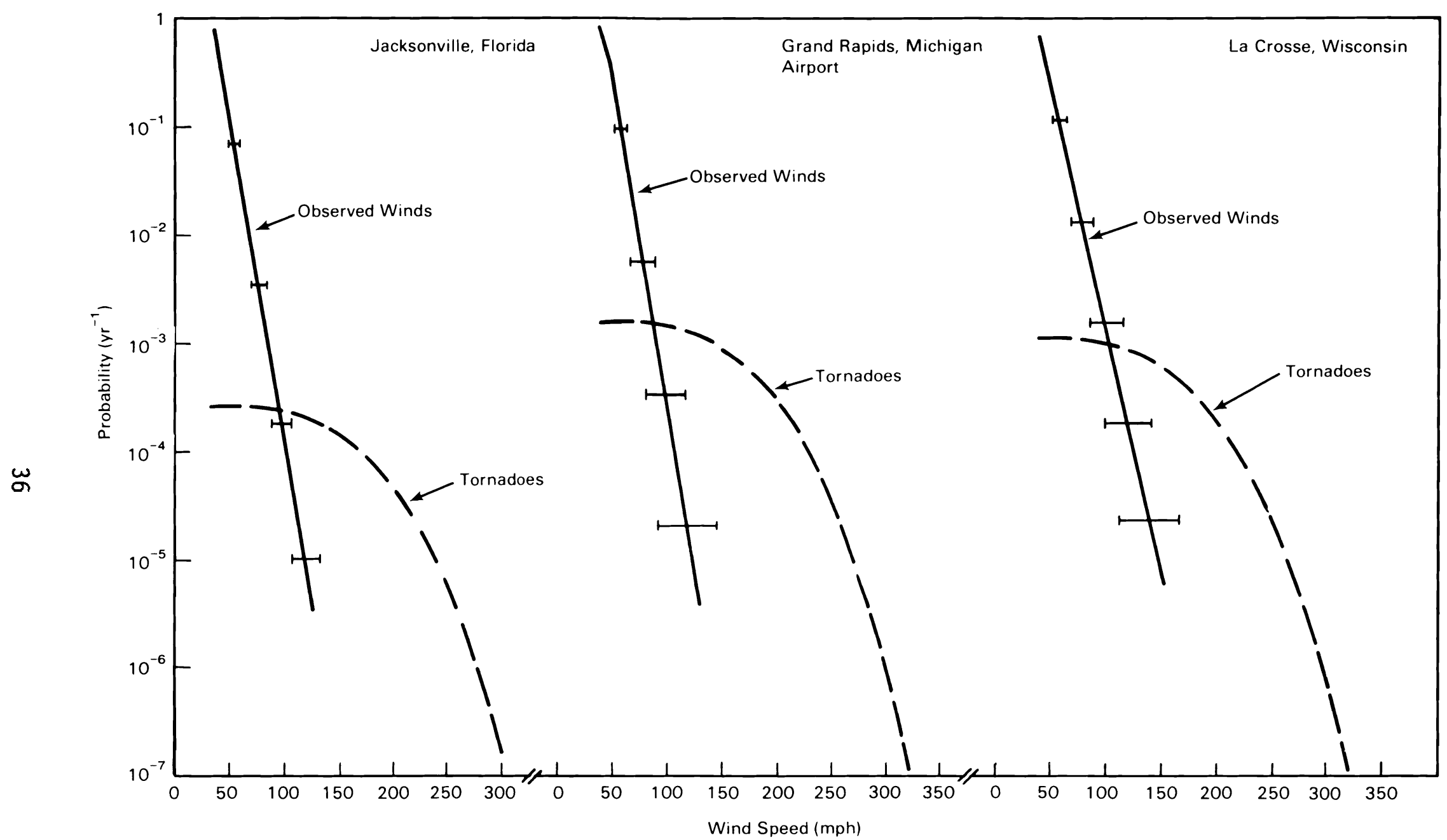

FIGURE 3. Final Extreme Wind Analysis for Jacksonville, Grand Rapids, and La Crosss. Error Bands Indicate $90 \%$ Confidence Interval. 
TABLE 13. Extreme Wind Parameter Estimates for Jacksonville, Florida; the Grand Rapids, Michigan Airport; and La Crosse, Wisconsin.

Location
Jacksonville
Grand Rapids La Crosse

$\begin{array}{cccc}\mathrm{N} & 107 & 29 & 42 \\ \mathrm{~m} & 44.02 & 45.67 & 42.10 \\ \mathrm{~s} & 5.987 & 6.197 & 8.207 \\ \mathrm{P}_{\text {s }} & 2.59 \mathrm{E}-4 & 1.51 \mathrm{E}-3 & 1.06 \mathrm{E}-3\end{array}$

TABLE 14. Extreme Wind Estimates for Jacksonville, Florida; the Grand Rapids, Michigan Airport; and La Crosse, Wisconsin Based on Observed Wind Data. All wind speeds are fastest-mile speeds.

\begin{tabular}{|c|c|c|c|c|c|c|c|c|c|}
\hline \multirow{2}{*}{$\begin{array}{l}\text { Speed } \\
\text { (mph) }\end{array}$} & \multicolumn{3}{|c|}{ Jacksonville } & \multicolumn{3}{|c|}{ Grand Rapids } & \multicolumn{3}{|c|}{ La Crosse } \\
\hline & $\begin{array}{l}\text { Prob. } \\
\left(y r^{-1}\right)\end{array}$ & $90 \%$ & Conf. & $\begin{array}{l}\text { Prob. } \\
\left(y r^{-1}\right)\end{array}$ & $\begin{array}{r}90 \% \\
\mathrm{In}\end{array}$ & & $\begin{array}{l}\text { Prob. } \\
\left(y r^{-1}\right)\end{array}$ & $\begin{array}{r}90 \% \\
\text { In }\end{array}$ & Conf \\
\hline & $7.8 \mathrm{E}-1$ & 39 & 41 & $8.5 \mathrm{E}-1$ & 37 & 43 & $6.5 \mathrm{E}-1$ & 38 & 42 \\
\hline 50 & $2.7 \mathrm{E}-1$ & 48 & 52 & $3.5 \mathrm{E}-1$ & 47 & 53 & $2.9 \mathrm{E}-1$ & 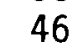 & \\
\hline 60 & $6.7 \mathrm{E}-2$ & 57 & 63 & $9.4 \mathrm{E}-2$ & 54 & 66 & $1.1 \mathrm{E}-1$ & 54 & 66 \\
\hline 70 & $1.5 \mathrm{E}-2$ & 65 & 75 & $2.3 \mathrm{E}-2$ & 61 & 79 & $3.7 \mathrm{E}-2$ & 61 & 79 \\
\hline 8 & $3.5 \mathrm{E}-3$ & 73 & 87 & $5.5 \mathrm{E}-3$ & 68 & 92 & 1.3 & 69 & 91 \\
\hline 0 & $8.0 \mathrm{E}-4$ & 82 & 98 & $1.3 \mathrm{E}-3$ & 74 & 106 & $4.4 \mathrm{E}-3$ & 76 & 104 \\
\hline 0 & $1.9 \mathrm{E}-4$ & 90 & 110 & 3.3 & 81 & 119 & 1. & 83 & 117 \\
\hline 110 & $4.4 E-5$ & 98 & 122 & $8.1 \mathrm{E}-5$ & 88 & 133 & $5.3 \mathrm{E}-4$ & 90 & 130 \\
\hline 120 & $1.0 \mathrm{E}-5$ & 107 & 134 & $2 .(1-2)$ & 94 & 146 & $1.8 \mathrm{E}-4$ & 98 & 143 \\
\hline
\end{tabular}

program. Fastest-mile speeds cannot be determined directly from the $60 \mathrm{~s}$ average speeds, therefore the method of successive substitutions (e.g., Carnahan et al. 1969) is used to obtain approximate fastest-mile speeds. Convergence is assumed when the difference between consecutive approximations is less than $0.001 \mathrm{mph}$.

The first column in Table 14 lists the nominal wind speed for which the estimates are made, and the three columns for each location give the probability $\left(\mathrm{yr}^{-1}\right)$ of observing the nominal speed, and the upper and lower speeds of the $90 \%$ confidence interval associated with the probability. For example, the probability of occurrence of a $60 \mathrm{mph}$ wind at Jacksonvi 1le is $6.7 \mathrm{E}-2 \mathrm{yr}^{-1}$ (return period of about 15 years), and the $90 \%$ confidence interval for wind speeds at the $6.7 \mathrm{E}-2 \mathrm{yr}^{-1}$ probability level is 57 to $63 \mathrm{mph}$. 
TABLE 15. Tornado Wind Speed Estimates for Jacksonville, Florida; the Grand Rapids, Michigan Airport; and La Crosse, Wisconsin.

\begin{tabular}{|c|c|c|c|}
\hline $\begin{array}{l}\text { Speed } \\
(\mathrm{mph})\end{array}$ & $\begin{array}{c}\text { Jacksonville } \\
\text { Prob. } \\
\left(v r^{-1}\right) \\
\end{array}$ & $\begin{array}{c}\text { Grand Rapids } \\
\text { Prob. } \\
\left(v r^{-1}\right)\end{array}$ & $\begin{array}{l}\text { La Crosse } \\
\text { Prob. } \\
\left(v r^{-1}\right)\end{array}$ \\
\hline $\begin{array}{r}50 \\
100 \\
150 \\
200 \\
250 \\
300\end{array}$ & $\begin{array}{l}2.6 \mathrm{E}-4 \\
2.4 \mathrm{E}-4 \\
1.5 \mathrm{E}-4 \\
5.0 \mathrm{E}-5 \\
5.8 \mathrm{E}-6 \\
1.7 \mathrm{E}-7\end{array}$ & $\begin{array}{l}1.5 \mathrm{E}-3 \\
1.4 \mathrm{E}-3 \\
9.0 \mathrm{E}-4 \\
2.9 \mathrm{E}-4 \\
3.4 \mathrm{E}-5 \\
1.0 \mathrm{E}-6\end{array}$ & $\begin{array}{l}1.1 \mathrm{E}-3 \\
9.8 \mathrm{E}-4 \\
6.3 \mathrm{E}-4 \\
2.0 \mathrm{E}-4 \\
2.4 \mathrm{E}-5 \\
7.0 \mathrm{E}-7\end{array}$ \\
\hline
\end{tabular}

The effects of the differences in parameter values and the number of observations can be seen by comparing the data for the three locations in Table 14. The parameters for Jacksonville and the Grand Rapids airport are approximately the same. Therefore, the ratio of width of the confidence interval for the Grand Rapids airport to the width of the interval for Jacksonville should be about 1.9 based on the square root of the ratio of number of observations, which is the case. The modal speed for La Crosse is lower than the modal speeds for either of the other locations. However, the probability of occurrence of an extreme wind of $100 \mathrm{mph}$ at La Crosse is an order of magnitude greater than it is at Jacksonville and about five times as great as it is at Grand Rapids. These differences are the result of relatively large scale parameter for La Crosse. 


\section{MULTIPLE STATION ANALYSIS}

Extreme winds tend to be associated with small-scale meteorological phenomena (e.g., thunderstorms and tornadoes) or to occur in small areas associated with larger phenomena (e.g., near the eye of a hurricane). As a result, estimates of the probability of given extreme wind at specific location on the basis of observed winds depend on both the intensities of storms during the observation'period and the proximity of the high wind regions of the storms to the location. The NCDC publishes 30-year climatological "normals" for winds and temperatures that are measured routinely. Certainly, the data used to estimate extreme values should cover at least as long a period as is used for means. Some locations in the United States have extreme wind data records that cover more than 100 years. However, these locations are the exception rather than the rule. Multiple-station analysis provides a method for estimating extreme winds on the basis of data for several stations.

The conceptual basis for multiple-station analysis is the double nature of the randomness associated with extreme winds--the randomness of storm intensity and the randomness of storm position. If a topographically and meteorologically homogeneous region can be defined that includes the site for which extreme winds are to be estimated and several stations that have extreme wind observations, then combining the extreme wind data as if they were for a single station may provide better extreme wind estimates than would be obtained otherwise. The period of record for the combined data base would be at least as long as that for any of the individual data sets within the data base, and the individual station observations for years in which the individual station records overlap will provide some representation of the effects of position of the storm relative to the station.

In selecting extreme wind data for use in a multiple-station analysis, it is necessary to consider the characteristics of the storms that produce high winds in an area as well as topographical and meteorological homogeneity. For example, winds in hurricanes decrease as the hurricanes move inland. Therefore, observed extreme winds at stations 25 to 50 miles from the Atlantic coast are not likely to adequately reflect the hurricane winds for coastal sites. However, in the situation, it may be reasonable to use data from coastal stations a hundred miles away. Similar conditions may exist along the shores of the Great Lakes. On the other hand, for much of the great plains, the midwest, and the eastern Unitęd States (excluding hurricane areas), the extreme wind climate is largely determined by extreme winds associated with thunderstorms and extratropical cyclones. In these regions, the variability of extreme wind climates over distances of a few hundred miles should be relatively small.

Multiple-station analysis is an option that can be chosen following completion of the analysis of data from individual stations. If topographical and climatological evaluation of a region indicates that there are several stations that may be representative of the conditions at a location the data for the stations can be combined and reanalyzed. However, if the results of individual station analyses of the available extreme wind data indicate that 
local topographic conditions are a dominate factor in extreme winds at one or more of the stations, then the data for those sites should be excluded from the analysis.

The objective of the multiple-station analysis is identical to that of the single-station analysis discussed in the last section. It is to obtain estimates of the parameters for the extreme wind distribution. Therefore, the multiple-station analysis involves the same steps as the single-station analysis, except that the decision to include or exclude is applied to stations rather than data subsets at a station.

The following two examples demonstrate multiple-station analysis. More data are available for these regions than are discussed, and should be used in an actual extreme value analysis. In addition, many of the decisions in the examples are arbitrary and are open to question. However, the point of the example is to demonstrate the procedure. If the procedure is followed and identical decisions are made by different analysts, a common result should be obtained. If different decisions are made and each decision is documented, the points of difference can easily be identified and resolved. Neither example involves or is in any way related to an existing or proposed nuclear facility.

\section{ATLANTIC COAST EXAMPLE}

Changery (1982a) contains extreme wind data for 14 locations along the Atlantic coast between Jacksonville, Florida, and Cape Henry, Virginia. Figure 4 summarizes the data for these stations. The order of the stations in the figure corresponds to their location along the coast from north to south. The period of record for each station is represented by a horizontal line, and changes in anemometer elevation are marked by tick marks on the line. Estimates of the mode and scale parameter (in parentheses) for the data subsets, adjusted to $10 \mathrm{~m}$, are shown above each line, and the mode and scale parameters for the combined data for each site are shown at the end of the site's time line.

Examining this figure, it appears that it would be reasonable to treat this portion of the Atlantic coast as two separate regions. The northern region would include the stretch of coast from Cape Henry through Cape Lookout and Fort Macon, North Carolina, and the southern region would include the coast from Wilmington, North Carolina, through Jacksonville. Manteo and Smithville/ Southport are exceptions in their respective groups. Both locations have relatively short periods of record. In addition, the period of record at Manteo occurred during a period in which other stations had relatively low extremes, while the period of record at Smithville/Southport occurred when many of the other stations had relatively high extremes. Thus, the deviations of the extreme wind characteristics for these sites from characteristics of the other stations in their groups is not reason to drop the sites from further consideration.

The nature of the coastline is shown in Figure 5 along with the extreme value parameters for each location. The stations north of the dividing line 
Cape Henry, VA

Kitty Hawk, NC

Manteo, NC

Hatteras. NC

Portsmouth. NC

Cape Lookout/Fort Macon, NC

Wilmington, NC WBO

Wilmington, NC APT

Smithville/Southport, NC

Charleston, SC

Savannah, GA WBO

Savannah. GA APT

Jacksonville, FL WBO

Jacksonville, FL APT

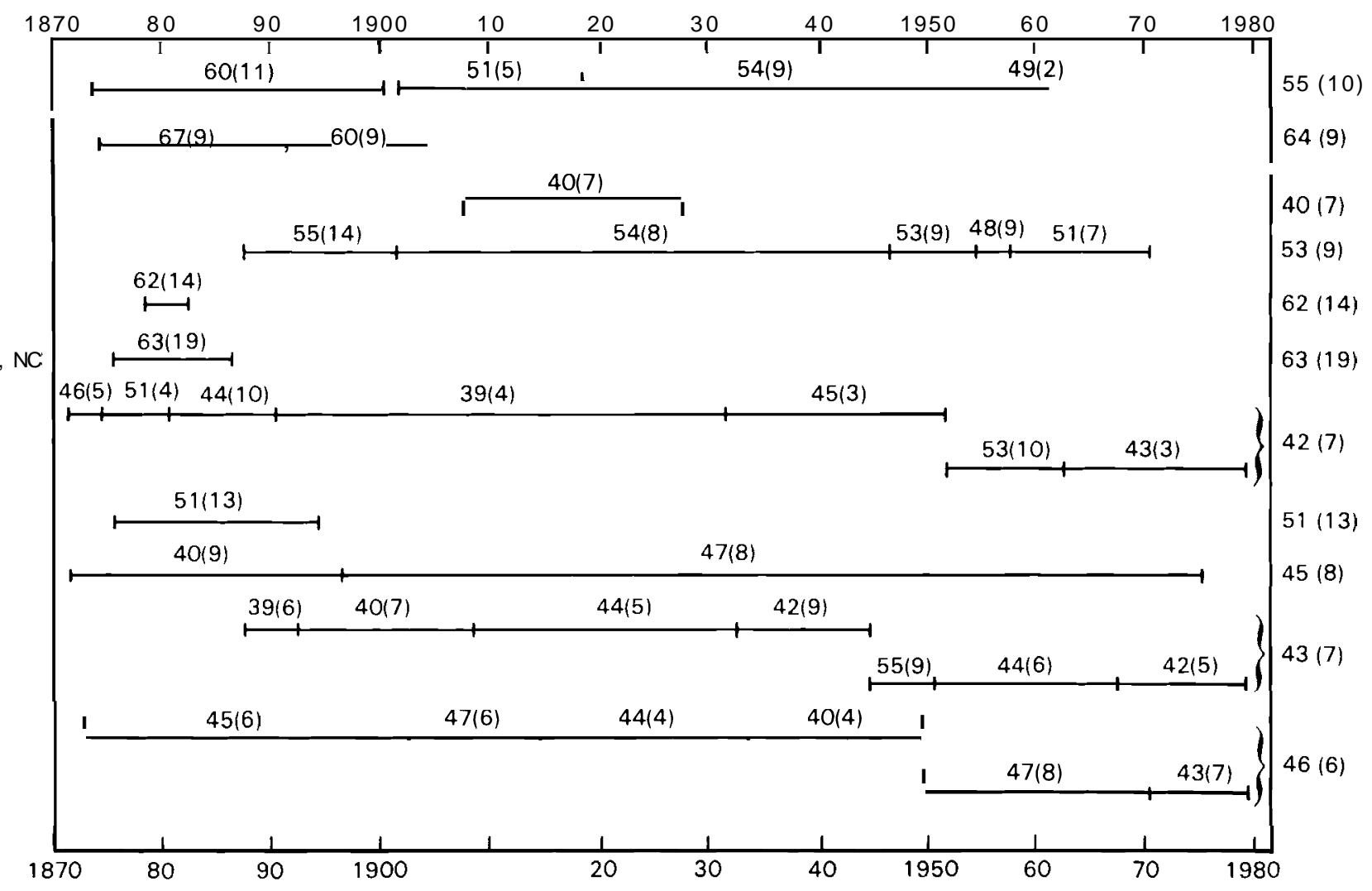

FIGURE 4. Synopsis of Coastal Extreme Wind Data Between Jacksonville and Cape Henry. The Mode and Scale Parameter (In Parentheses) for Each Data Subset, Following Adjustment to $10 \mathrm{~m}$, are Shown Above the Time Line and the Composite Parameters are on the Right. 


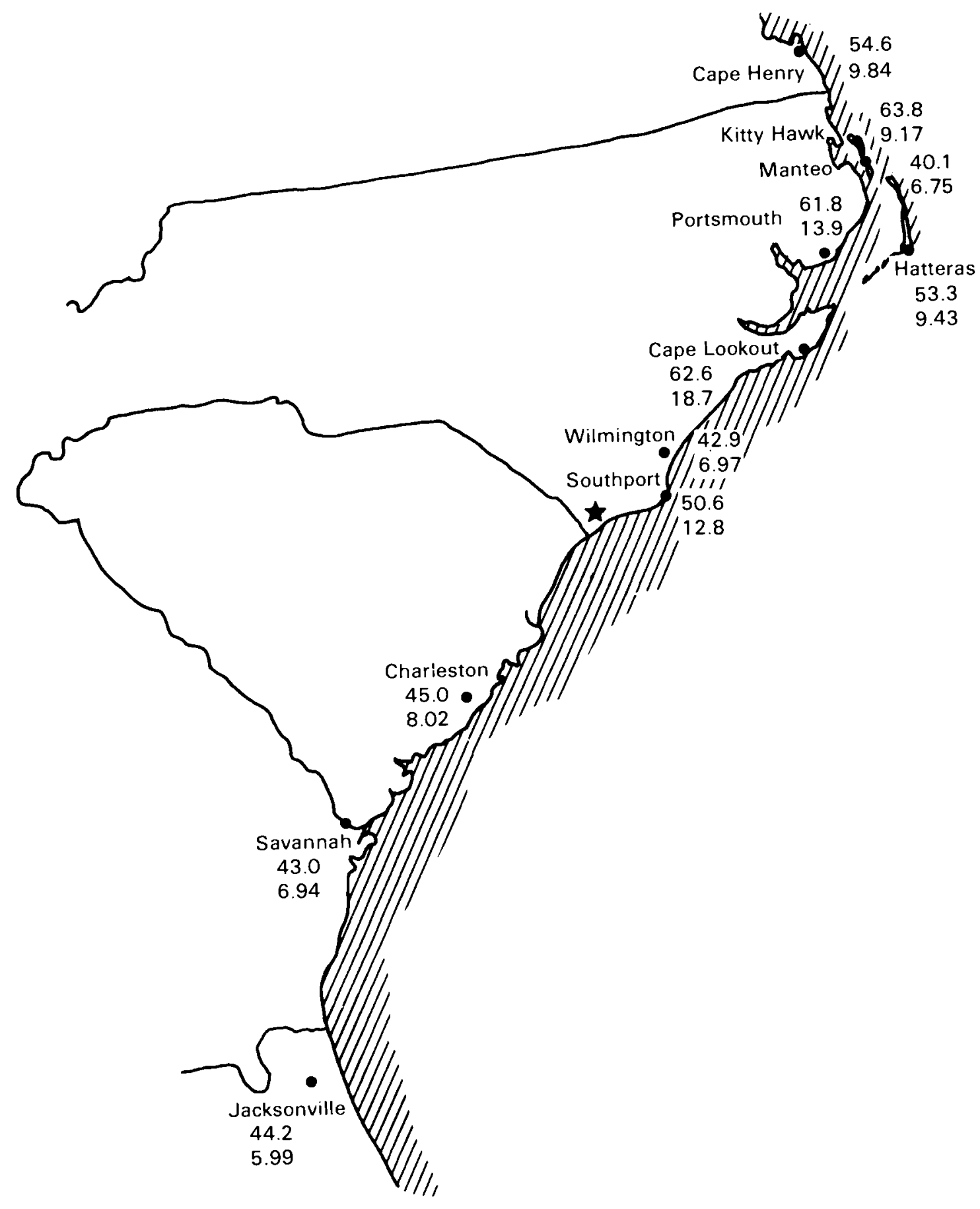

FIGURE 5. Map of the Coastal Region Between Jacksonville and Cape Henry Showing Extreme Wind Distribution Parameters and Location for Which Extreme Winds are to be Estimated. The Location is Indicated by a Star. 
are generally located on barrier islands several miles off the coast, while none of the stations south of line are located on a barrier island.

Assuming that an extreme wind assessment is to be made for a site at the approximate location of the star in Figure 5. The northern stations may be dropped from consideration. Thus, the data base for further consideration is reduced to the data from five locations: Jacksonville, Florida; Savannah, Georgia; Charleston, South Carolina; Smithville/Southport, North Carolina, and Wilmington, North Carolina. The individual station data for these stations are summarized in Table 16, and the bottom line of the table gives parameter estimates based on the composite data set. The cumulative distribution of the observed extreme wind speeds in the composite data base is shown in Figure 6 along with the expected cumulative distribution (straight line) for a Type I distribution. The Type I distribution fits the main portion of the observed distribution quite well. However, the magnitudes of the lower probability extremes appears to be somewhat underestimated.

The analytical results presented in Table 16 and Figure 6 are for extreme winds for the standard $60 \mathrm{~s}$ averaging interval at a measurement height of 33 $\mathrm{ft}(10 \mathrm{~m})$. An extreme wind analysis for the hypothetical location giving fastest-mile speeds is shown in Figure 7. The figure also shows the 90\% confidence interval associated with the observed extremes and the probabilities associated with extreme winds due to tornadoes.

TABLE 16. Data Base For The Atlantic Coast MultipleStation Extreme Wind Analysis Example

\begin{tabular}{|c|c|c|c|c|c|}
\hline \multirow[b]{2}{*}{ Location } & Years of & \multicolumn{3}{|c|}{ Parameter Estimates } & \multirow[b]{2}{*}{ St. Dev. } \\
\hline & Record & Mode & St. Dev. & Scale & \\
\hline Wilmington, $\mathrm{NC}$ & 108 & 42.09 & 0.7246 & 6.986 & 0.7032 \\
\hline $\begin{array}{l}\text { Smithville/ } \\
\text { Southport, NC }\end{array}$ & 19 & 50.55 & 3.161 & 12.75 & 3.068 \\
\hline Charleston, SC & 103 & 45.01 & 0.8539 & 8.019 & 0.8287 \\
\hline Savannah, GA & 92 & 43.00 & 0.7818 & 6.939 & 0.7588 \\
\hline Jacksonvi 1le, FL & 107 & 44.20 & 0.6254 & 5.986 & 0.6069 \\
\hline Composit e & 429 & 43.69 & 0.3944 & 7.559 & 0.3828 \\
\hline
\end{tabular}

The analysis was made with the computer program listed in Appendix D using a tornado strike probability of $2.16 \times 10^{-4}$, which was obtained from Figure 2. 


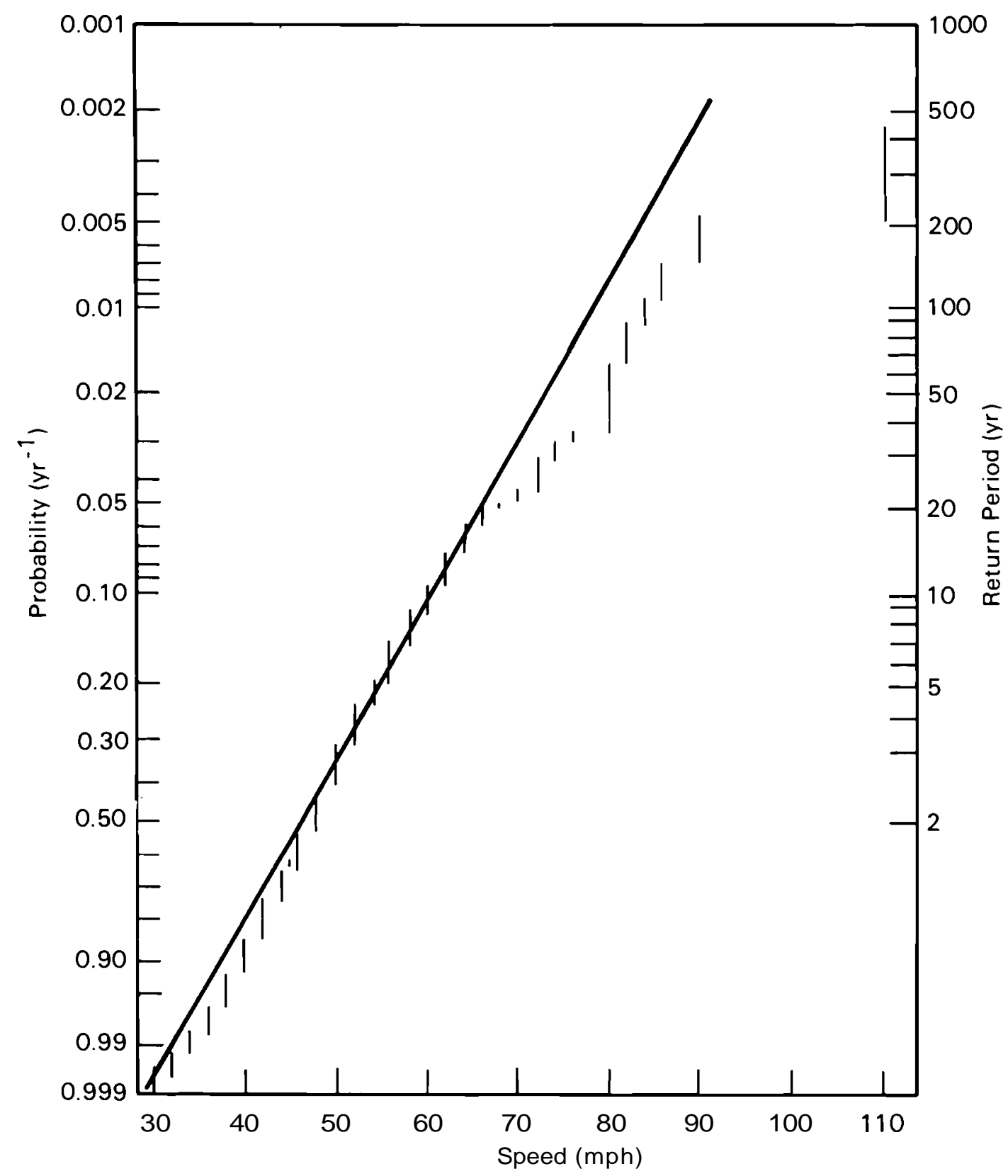

FIGURE 6. Distribution of Coastal Extreme Winds for Stations From Jacksonville Through Wilmington. 


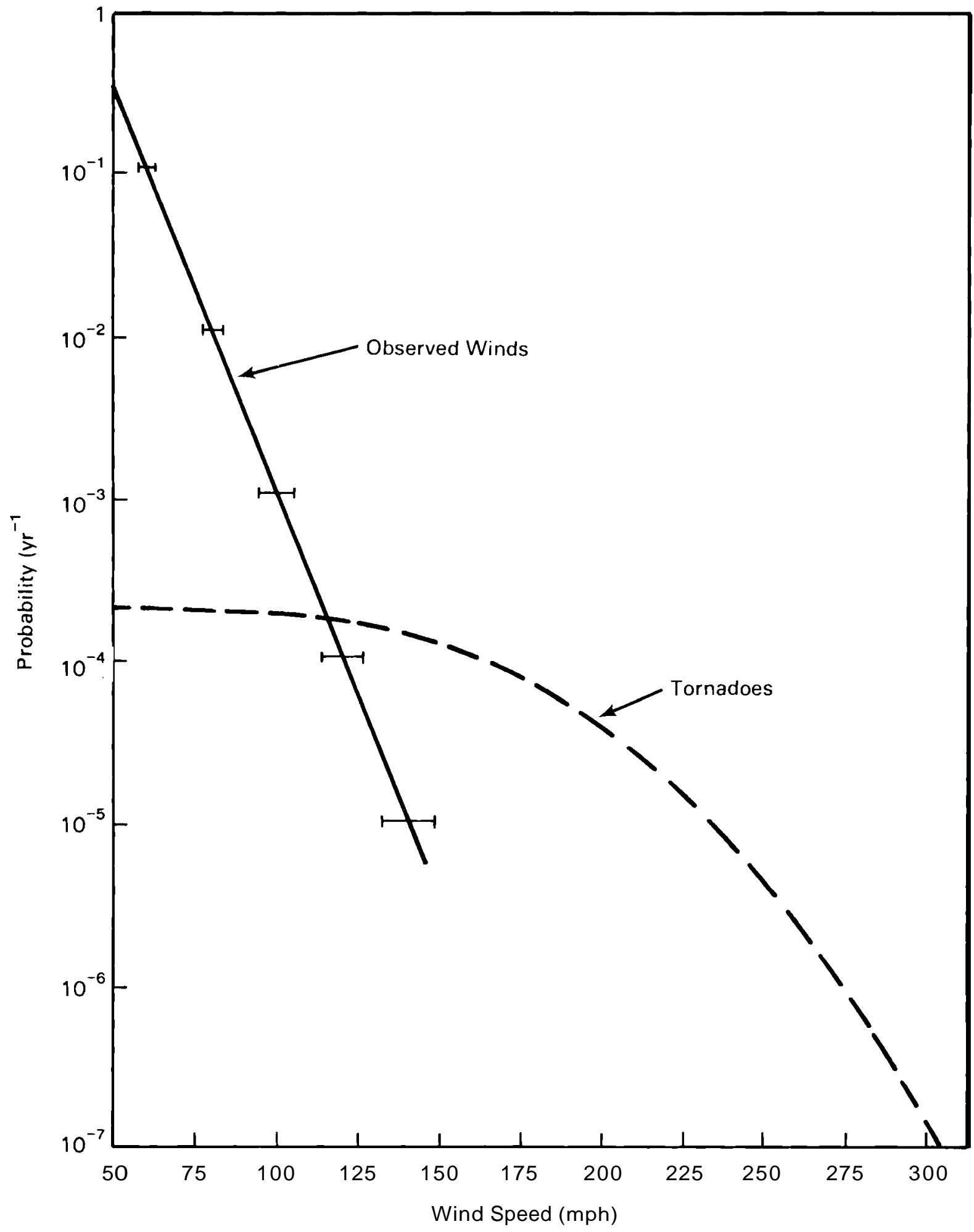

FIGURE 7. Final Extreme Wind Analysis for the Hypothetical Atlantic Coast Location. Error Bands Indicate the $90 \%$ Confidence Interval. 


\section{MIDWEST EXAMPLE}

As a second example of a multiple-station analysis, consider a site on the western shore of Green Bay on Lake Michigan. A map of the general area is shown in Figure 8 with the hypothetical site indicated by a star. Locations in the region for which Changery (1982b) provides extreme wind data are shown on the map along with their extreme wind distribution parameters. The data for Beaver Island, Michigan, and Plum Island, Wisconsin, are not likely to be representative of conditions at the hypothetical site because of relatively long, openwater fetches in all directions. Similarly, the data for Marquette, Michigan and Wausau, La Crosse, and Madison, Wisconsin are probably not representative of the site. Consequently, the extreme wind analysis is based on data for Escanaba, Michigan, Green Bay, Wisconsin, and Milwaukee, Wisconsin.

Parameter estimates for single-station analyses of extreme winds for these stations are given in Table 17. The range of parameter values appears to be consistent with consolidation of the data. Parameter estimates for the multiple-station analysis are given at the bottom of the table. Figure 9 compares the distribution of the observed extreme winds in the combined data set with a Type I distribution having the composite data base parameters given in Table 17. The completed analysis for the site is shown in Figure 10, where the speeds have been converted to fastest-miles from $60 \mathrm{~s}$ averages.

Two tornado wind curves are shown in Figure 10. These curves are based on tornado strike probabilities given in Figure 2. The two curves are shown because the hypothetical site lies in a region in which the tornado strike probability changes significantly. The lower tornado curve represents conditions to the south of the site, while the upper curve represents conditions to the north. It is likely that an intermediate curve would represent the actual conditions at the site. These conditions can be estimated if site specific tornado strike probability is computed from tornado data. A less rigorous method of estimating the tornado wind probabilities would be to arithmetically average the probabilities at each speed.

TABLE 17. Data Base For The Midwest Multiple-Station Extreme Wind Analysis Example

\begin{tabular}{|c|c|c|c|c|c|}
\hline \multirow[b]{2}{*}{ Location } & \multirow{2}{*}{$\begin{array}{l}\text { Years of } \\
\text { Record }\end{array}$} & \multicolumn{3}{|c|}{ Parameter Estimates } & \multirow[b]{2}{*}{ St. Dev. } \\
\hline & & Mode & St. Dev. & Scale & \\
\hline Escanaba, M I & 79 & 43.24 & 0.6489 & 5.337 & 0.6298 \\
\hline Green Bay, WI & 93 & 46.29 & 0.6707 & 5.985 & 0.6509 \\
\hline Milwaukee, WI & 107 & 46.36 & 0.5822 & 5.573 & 0.5651 \\
\hline Composite & 429 & 45.39 & 0.3720 & 5.750 & 0.3611 \\
\hline
\end{tabular}




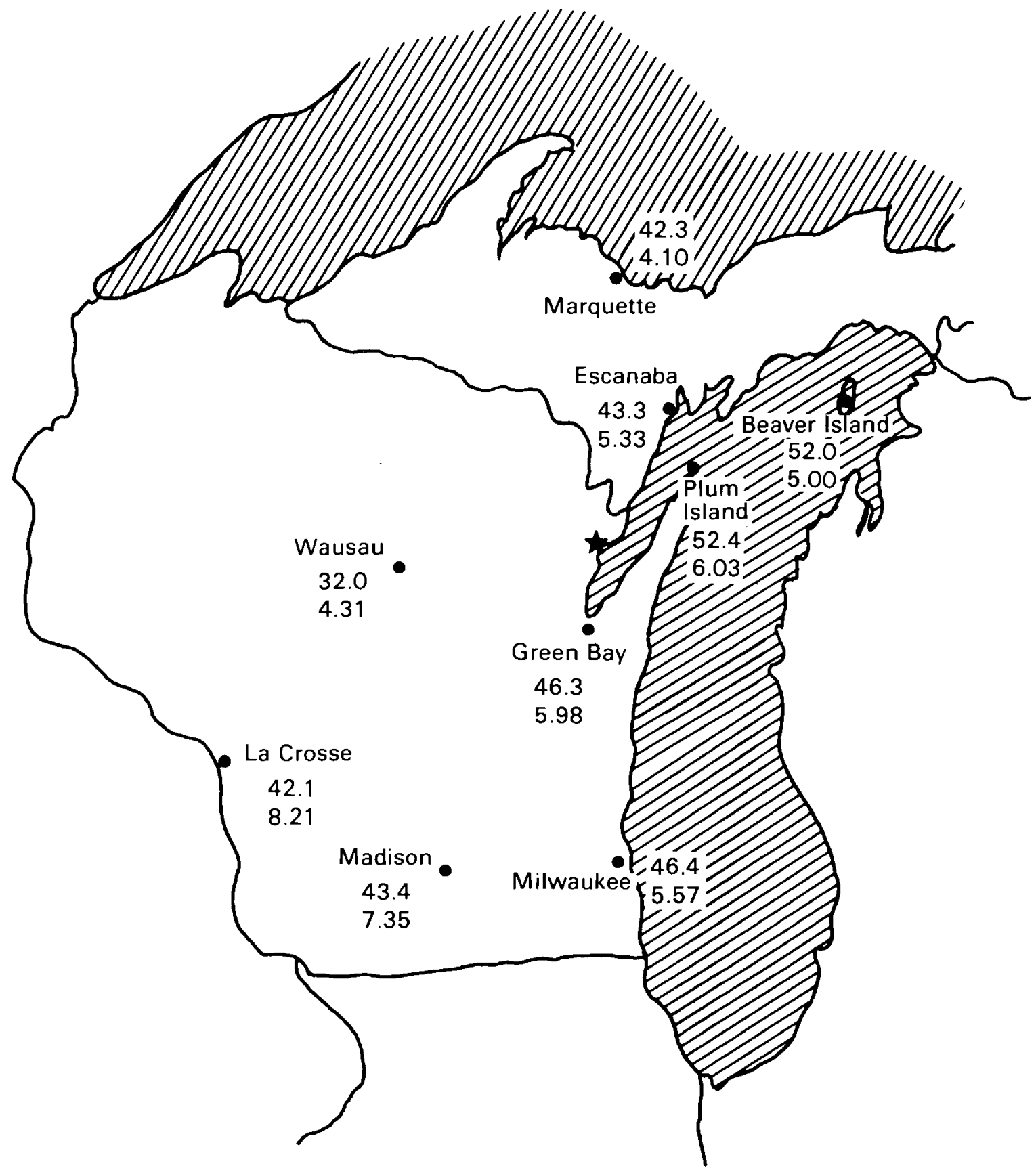

FIGURE 8. Map of the Region for the Midwest Example Showing Extreme Wind Distribution Parameters and Location for Which Extreme Winds are to be Estimated. The Location is Indicated by a Star. 


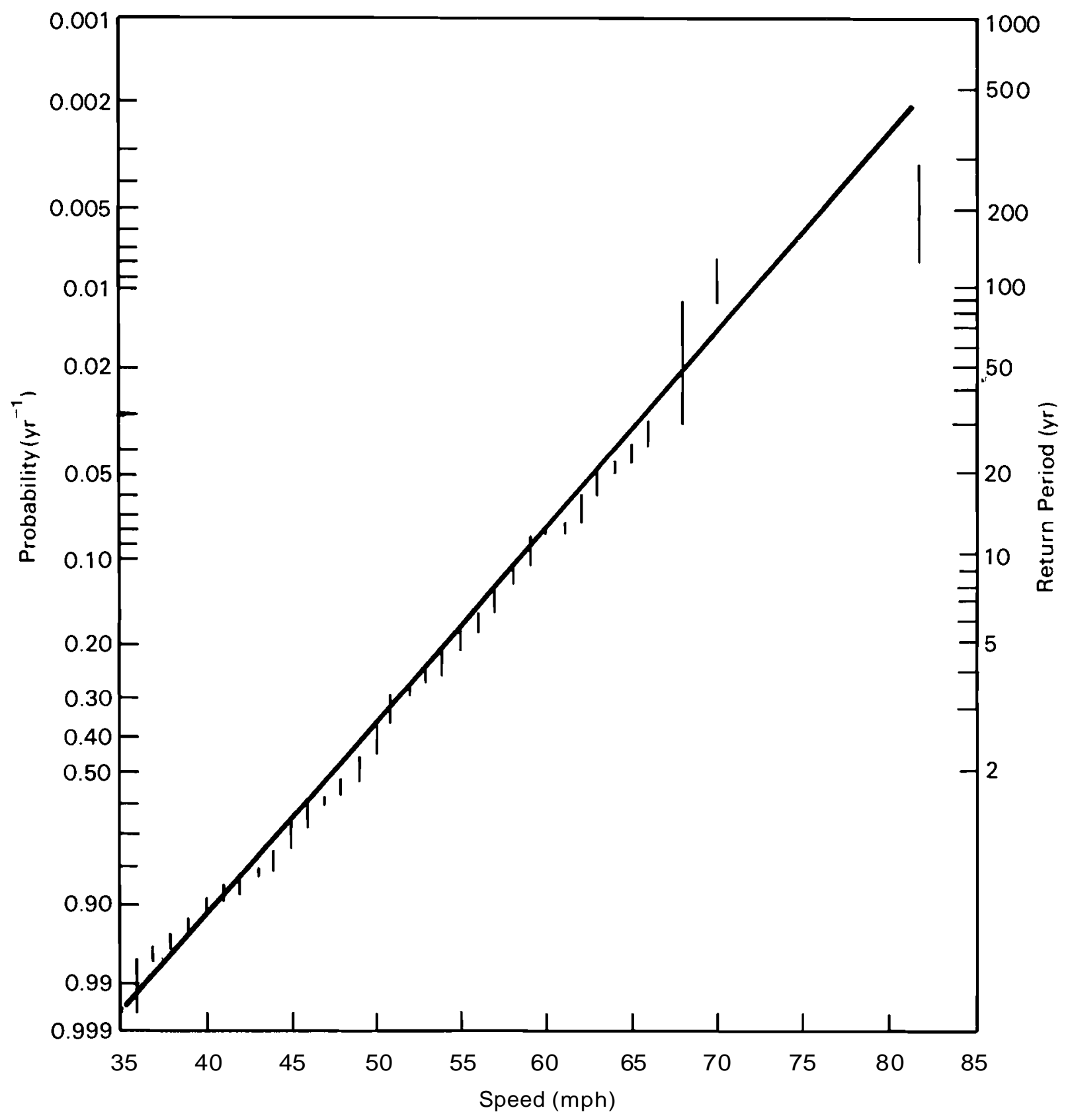

FIGURE 9. Distribution of Combined Extreme Winds from Escanaba, Green Bay, and Milwaukee. 


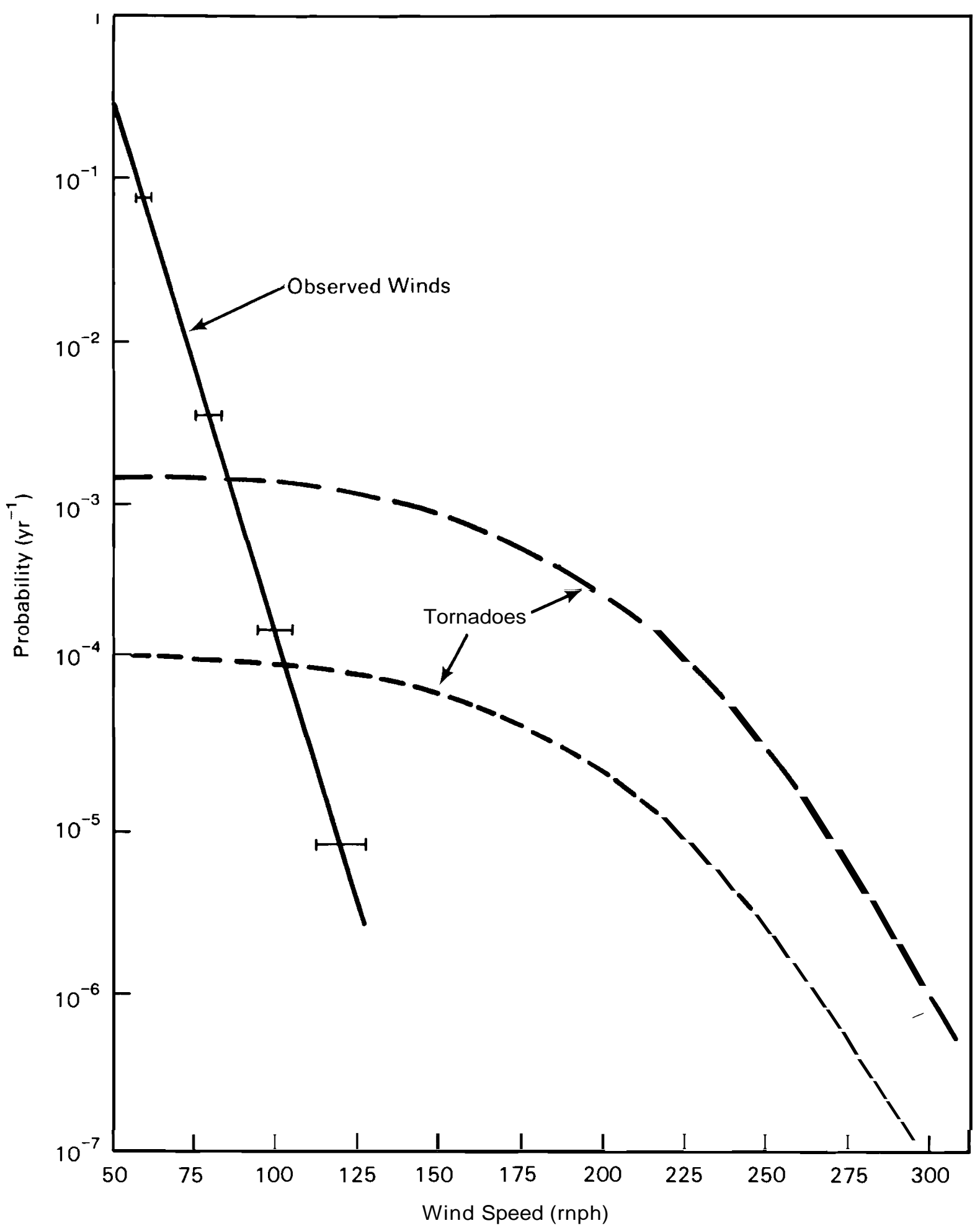

FIGURE 10. Final Extreme Wind Analysis for the Hypothetical Midwest Location. Error Bands Indicate the $90 \%$ Confidence Limit. The Upper Tornado Line Assumes a Strike Probability of $1.51 \times 10^{-3} \mathrm{yr}^{-1}$. While the Lower Tornado Line Assumes a Strike Probability of $1.17 \times 10^{-3} \mathrm{yr}^{-1}$. 


\section{DISCUSSION}

The staff of the NRC is required to estimate probabilities associated with extreme winds for use in Probabilistic Risk Assessments. These estimates must be made within time and cost constraints that preclude wind measurements or prolonged analysis of available data. This report describes a procedure that can be used by the NRC staff. The procedure minimizes, but does not avoid, subjective decisions in the analysis of extreme wind data. The subjective decisions that remain are generally to include or exclude specific data or to make or not make adjustments to the data. By making the same choices in these matters, different staff members given identical data sets should arrive at a common result. The procedure provides a framework for identifying when a subjective decision is made and the nature of the decision. If staff members document their choices during an analysis and arrive at different results, it should be easy to isolate the points of disagreement that need resolution.

There is a good deal of uncertainty associated with estimation of extreme winds, even when following the proposed procedure. A portion of the uncertainty may be evaluated quantitatively using available data and statistical techniques. However, there are factors that contribute to the uncertainty that are not directly quantifiable and may not be properly reflected in the usual statistical techniques for establishing confidence intervals. These factors include:

1) the amount, type, and quality of the extreme wind data

2) the nature of the extreme wind climate(s), and

3) the complexity of the terrain.

The uncertainties associated with these factors may well be larger than the uncertainties estimated from the data. As a result, it is suggested that confidence be expressed in two parts. The first part should be an objective rating that qualitatively reflects the overall adequacy and quality of the data used to determine parameter values for the extreme wind model, and the second part is a confidence band for the extreme wind estimates that is based on the uncertainty in the estimates of the parameters of the model.

A three-level qualitative confidence categorization scheme was developed for wind power estimates for various regions of the United States (PNL 1981). A similar categorization could be used for extreme wind estimates. Determination of a confidence rating involves a subjective integration of information based of general criteria established for use in the making this determination.

The adequacy of the data is evaluated by considering the distribution and number of stations, and the number of years and useful periods of record. The quality of the data refers to the representativeness of the data with respect to open terrain exposure and the usefulness of the data. Airfield stations at open terrain sites with good anemometer exposures for 30 or more years are considered to have good quality data. Extreme wind estimates based primarily 
on fastest-mile and peak gust data from representative airfield locations would receive higher confidence ratings than those based on other types of extreme wind data. Estimates based primarily on fastest 1-min observed data would have higher confidence ratings than those for areas with little or no representative data.

The nature of the extreme wind climate is evaluated by considering the types of extreme winds (e.g., hurricanes, thunderstorms, orographic, extratropical) that affect an area and the extent to which these winds are represented in the available data. A longer period of record is required for reliable extreme wind estimates in a hurricane area than is required in an area in which severe thunderstorm-related winds are predominant. For example, 20 stations that have 10 years of data from the same period would not be as useful in a hurricane wind climate as in the severe thunderstorm wind climate. In areas where different extreme wind climates overlap or where the prevailing extreme wind climate is unknown, the confidence rating in the extreme wind estimates would be low.

The complexity of the terrain can be determined from surface landform maps or shaded relief maps. In complex terrain areas without abundant data, the local variability in extreme winds may be difficult to estimate; thus, the confidence rating in the extreme wind estimates may be low. Where there is relatively little relief and a similar extreme wind climate over large regions, the confidence rating would depend largely on the amount, type, and quality of the data and the reliability of the extreme wind model being used.

Clearly both the quantitative and qualitative evaluations of uncertainties in extreme wind analyses are functions of the availability of extreme wind data. These data can be found in many locations. However, there is no single source of information for the available data. A national index to extreme wind data is needed. Such an index would facilitate the identification and selection of suitable data for use in extreme wind PRA analysis. It should list every location in the United States for which extreme wind data have been recorded and provide information on the types of extreme wind data that are available, periods of record for each type, anemometer heights and locations, and formats in which these data are available. An index to extreme wind data would also be useful in documenting problems associated with extreme winds reported in existing publications, tabulations, or data tapes. 


\section{REFERENCES}

ANSI. 1982. "American National Standard Minimum Design Loads for Buildings and Other Structures." ANSI A58.1-1982, American National Standards Institute, New York, 100 pp.

ANS. 1983. "Standard of Estimating Tornado and Extreme Wind Characteristics at Nuclear Power Plant Sites." ANSIIANS-2.3-1983. American Nuclear Society, La Grange Park, Illinois, 23 pp.

Batts, M. E., M. R. Corder, L. R. Russell, J. R. Shaver and E. Simiu. 1980. Hurricane Wind Speeds in the United states. NBS Building Science Series 124. U.S. Department of Commerce, Washington, D.C.

Brownlee, K. A 1965. Statistical Theory and Methodology in Science and Engineering. 2nd Ed., John Wiley \& Sons, New York, 590 pp.

Carnahan, B., H. A. Luther and J. 0. Wilkes'. 1969. Applied Numerical Methods. John Wiley \& Sons, New York, $604 \mathrm{pp}$.

Changery, M. J. 1978. National Wind Data Index. HCO/T1041-01, National Climatic Data Center, Asheville, North Carolina.

Changery, M. J. 1982a. Historical Extreme Winds for the United States Atlantic and Gulf of Mexico Coastlines. NUREG/CR-2639, U.S. Nuclear Regulatory Commission, Washington, D.C.

Changery, M. J. 1982b. Historical Extreme Winds for the United States - Great Lakes and Adjacent Regions. NUREG/CR-2890, U.S. Nuclear Regul atory Commission, Washington, D.C.

Daniel, W. W. 1978. Applied Nonparametric Statistics. Houghton Mifflin, Boston, Massachusetts, $503 \mathrm{pp}$.

Davenport, A. G. 1960. "Rational for Determining Design Wind Velocities." J. Struc. Div., ASCE 86(5):39-68.

Deacon, E. L. 1965. "Wind Gust Speed: Averaging Time Relationship." Australian Meteorological Magazine 51:11-14.

Downton, F. 1966. "Linear Estimation of Parameters in the Extreme Value Distribution." Technometrics 8(1):3-17.

Fisher, R. A., and L. H. C. Tippett. 1928. "Limiting Forms of the Frequency Distribution of the Largest or Smallest Member of a Sample." Proc. Cambridge Phi 1. Soc. 24(2):180-190.

Fujita, T. T. 1970. "A Proposed Characterization of Tornadoes and Hurricanes by Area and Intensity." Research Paper No. 91, Satellite and Mesometeorology Research Project, University of Chicago, Chicago, Illinois. 
Galambos, J. 1978. The Asymptotic Theory of Extreme Order Statistics. John Wiley \& Sons, New York, 352 pp.

Grazulis, T. P. 1984. Violent Tornado Climatography, 1880-1982.

NUREG/CR-3670, U.S. Nuclear Regulatory Commission, Washington, D.C.

Gumbel, E. J. 1958. Statistics of Extremes. Columbia University Press, New York.

Harrison, L. P. 1963. "Key to Meteorological Records Documentation No. 3.151." U.S. Weather Bureau, Washington, D.C., 68 pp.

Hatch, W. L. 1983. Selective Guide to Climatic Data Sources. Key to Meteorological Records Documentation No. 4.11. National Climatic Data Center, Asheville, North Carolina.

Hollander, M., and D. A. Wolfe. 1973. Nonparametric Statistical Methods. John Wiley \& Sons, New York, 503 pp.

IAEA. 1981. "Extreme Meteorological Events in Nuclear Power Plant Siting, Excluding Tropical Cyclones." Safety Series No. 50-SG-S11A, Vienna, Austria, $77 \mathrm{pp}$.

Johnson, N L., and S. Kotz. 1970. Continuous Univariate Distributions - I Houghton Mifflin, Boston, Massachusetts.

Kinnison, R. R. 1985. Applied Extreme Value Statistics. Macmillan Inc., New York, 149 pp.

Lieblein, J. 1954. "A New Method of Analyzing Extreme Value Data." Technical Note 3053, National Advisory Committee for Aeronautics, Washington, D.C.

Lieblein, J. 1974a. "Efficient Methods on Extreme Value Methodology." NBSIR 74-602, National Bureau of Standards, Washington, D.C.

Lieblein, J. 1974b. "Note on Simplified Estimators for the Type I Extreme Value Distribution." NBSIR 75-637, National Bureau of Standards, Washington, D.C.

Markee, E. H. Jr., J. G. Beckerly and K. E. Sanders. 1974. Technical Basis for Interim Regional Tornado Criteria. WASH-1300, U.S. Atomic Energy Commission, Washington, D.C.

Meyer, S. L. 1975. Data Analysis for Scientists and Engineers. John Wiley \& Sons, New York.

NOAA. 1980. "Local Climatological Data, Annual Summary with Comparative Data, La Crosse, Wisconsin." In Local Climatological Data, Annual Summaries for 1979, Part II - Nebraska-Wyoming. National Oceanic and Atmospheric Administration, National Climatic Center, Asheville, North Carolina. 
PNL 1981. Wind Energy Resource Atlas: Volumes 1 to 12. PNL-3195 WERA-1 to 12, Pacific Northwest Laboratory, Richland, Washington.

Ramsdell, J. V., and G. L. Andrews. 1986. Tornado Climatology of the Contiguous United States. NUREG/CR-5697, U.S. Nuclear Regulatory Commission, Washington, D.C.

Schreck, R. I _ , and W. F. Sandusky. 1982. TORNADO, A Program to Compute Tornado Strike and Intensity Probabilities with Associated Wind Speeds and Pressure Drops at Nuclear Power Stations. PNL-4483, Pacific Northwest Laboratory, Richland, Washington.

Simiu, E., and D. W. Lozier. 1975. "The Buffeting of Tall Structures by Strong Winds." NBS Building Science Series 74, National Bureau of Standards, Washington, D.C.

Simiu, E., and J. J. Filliben. 1976. "Probability Distributions of Extreme Wind Speeds." J. Struc. Div., ASCE 102:1861-1877.

Simiu, E., J. Bietry and J. J. Filliben. 1978. "Sampling Errors in Estimation of Extreme Winds." J. Struc. Div., ASCE 104:491-501.

Simiu, E., and R. H. Scanlan. 1978. Wind Effects on Structures: An Introduction to Wind Engineering. Wiley-Interscience, New York, 458 pp.

Simiu, E., M. J. Changery and J. J. Filliben. 1979. Extreme Wind Speeds at 129 Stations in the Contiguous United States. NBS Building; Science Series 118, National Bureau of Standards, Washington, D.C.

Simiu, E., and J. J. Filliben. 1980. "Weibull Distributions and Extreme Wind Speeds." J. Struc. Div., ASCE 106:2365-2374.

Tabony, R. C. 1983. "Extreme Value Analysis in Meteorology." Meteorol. Mag. 112:77-98.

Thom, H. C. S. 1963. "Tornado Probabilities." Mon. Wea Rev. 91:730-736.

Thom, H. C. S. 1964. "Prediction of Design and Operating Velocities for Large Steerable Radio Antennas." Large Steerable Radio Antennas - Climatological and Aerodynamic Considerations. Annuals of the New York Academy of Sciences $116: 90-100$.

Thom, H. C. S. 1968. "New Distributions of Extreme Winds in the United States." J. Struc. Div., ASCE 94:1787-1801.

Wantz, J. W., and R. E Sinclair. 1981. "Distribution of Extreme Winds in the Bonneville Power Administration Service Area." J. Appl. Meteorol. $20: 1400-1411$.

Wine, R. L. 1964. Statistics for Scientists and Engineers. Prentice-Hall, Englewood Cliffs, $671 \mathrm{pp}$. 
APPENDIX A

MAXIMUM-LIKELIHOOD ESTIMATION OF EXTREME VALUE DISTRIBUTION PARAMETERS 
MAXIMUM-LIKELIHOOD ESTIMATION OF

EXIREME VALUE DISTRIBUTION PARAMETERS

Kinnison (1985) discusses several methods for estimating the parameters of a Fisher-Tippett Type I distribution. Among these methods, linear regression gives biased estimates of the parameters. The method-of-moments is preferred when simplicity is desired, but it is inefficient in estimating the scale parameter. Maximum-likelihood methods are judged to be best overall, although they are not as easy to use as other methods. This appendix describes the estimation of parameter values for a Type I distribution from a consistent set of extreme wind observations using maximum-likelihood and a simplex algorithm.

The conceptual basis for maximum-likelihood estimation is that a probability can be assigned to a given set of random samples (observations) if the form of the distribution from which the samples are drawn is known. The random observations are treated as known values, and the distribution parameters are treated as unknowns. The parameters are adjusted until a maximum is found for the probability of obtaining the set of observations. According to Brownlee (1965), for large samples, maximum likelihood estimates are consistent, asymptotically normal, and asymptotically efficient under general conditions.

The likelihood estimator, $L$, is given by

$$
L=\prod\left[P\left(x_{i} \mid m, s\right)\right]
$$

where $P()$ is the probability of observing $x_{i}$ from the hypothesized distribution given location and scale parameter values, $m$ and $s$, respectively. For the Fisher-Tippett Type Idistribution, the probability for each observation is

$$
P\left(x_{i} \mid m, s\right)=s^{-1} \exp \left\{-y_{i}-\exp \left(-y_{i}\right)\right\}
$$

where $y_{i}$ is the standardized extreme value.

As the number of observations increases, there are numerical problems in computation of the likelihood function using Equation (A. 1). However, the values of parameters that maximize the likelihood function will also maximize the logarithm of the likelihood function. Further, the value of the likelihood function is constrained to be between zero and one; the logarithm of the likelihood function will be negative, and the logarithm will approach zero as the likelihood function approaches one. Therefore, maximization of the likelihood function can be achieved by minimizing the absolute value of the logarithm of the likelihood function. This function can be computed as

$$
L=n \ln (1 / s)-\sum_{1}\left[y_{i}+\exp \left(-y_{i}\right)\right]
$$

where $n$ is the number of observations. 
There are several methods for finding maximum-likelihood estimates. One of these methods, referred to as the Nelder-Mead Simplex algorithm (0'Neill 1971), is a systematic trial and error procedure that does not require evaluation of function derivatives. According to $0^{\prime} \mathrm{Ne} \mathbf{1 1 1}$, the only assumptions required are that the likelihood function is continuous and that it is single-valued. The simplex algorithm is also described by Olsson and Nelson (1975) and has been extended to grouped data by 0lsson (1979). If the assumptions are correct, the algorithm will converge for any reasonable combination of initial values, but the large errors in the initial values will increase the number iterations required for convergence.

A simplex consists of a set of $\mathrm{N}+\mathrm{l}$ points in $\mathrm{N}$-dimensional space, where $\mathrm{N}$ is the number of parameters to be estimated. The first simplex is determined using the initial parameter estimates and steps. The three initial points are $A$, located at coordinates $\left(m_{0}, s_{0}\right) ; B$, located at $\left(m_{0}+\Delta m, s_{0}\right)$ and $C$, located at $\left(m_{0}, s_{0}+A s\right)$ where $m_{0}$ and $s_{0}$ are the initial-parameter estimates and $A m$ and As are the initial step sizes. Figure A.l shows. the points plotted as functions of the location and scale parameters.

Initial estimates of parameter values may be obtained from the observed extreme winds using any of the methods discussed previously, including the method of moments. Initial values are also needed for step sizes for each parameter to be used in the search for the function maximum. Initial step sizes equal to $5 \%$ of the parameter values can be used as defaults.

The negative log-likelihood function is computed for each point. Assume, for illustration, that the values of the functions are $L(A), L(B)$, and $L(C)$, respectively, and that $L(A)$ is greater than $L(B)$, which in turn is greater than $L(C)$. After the function values have been computed, the largest value is selected and the vertex of the simplex associated with that value is moved to a new location. The new location lies on a line extending from the vertex being replaced through the centroid of the remaining points, with the position being determined by a fixed search pattern.

In Figure A.1, the centroid is marked $A^{\prime}$ and one of the four points $D, E$, $F$, or $G$ is the new position of the vertex. The new position is selected in the following manner. Initially, the negative log-likelihood function is computed for position $F$, which is located so that the distance $A^{\prime} F$ is equal to the distance $A A^{\prime}$. The next step in the search depends on the value of $L(F)$ relative to the $L(A), L(B)$, and $L(C)$. There are four alternatives for the next step.

1. If $L(F)$ is less than $L(C)$, the simplex is extended to point $G$ which is twice as far from $A^{\prime}$ as $F$, and $L(G)$ is computed. The new simplex becomes BCG.

2. If $L(F)$ is greater than or equal to $L(C)$ and less than or equal to $L(B)$ then the search stops, and the new simplex becomes BCF. This is called a reflection of the simplex. 


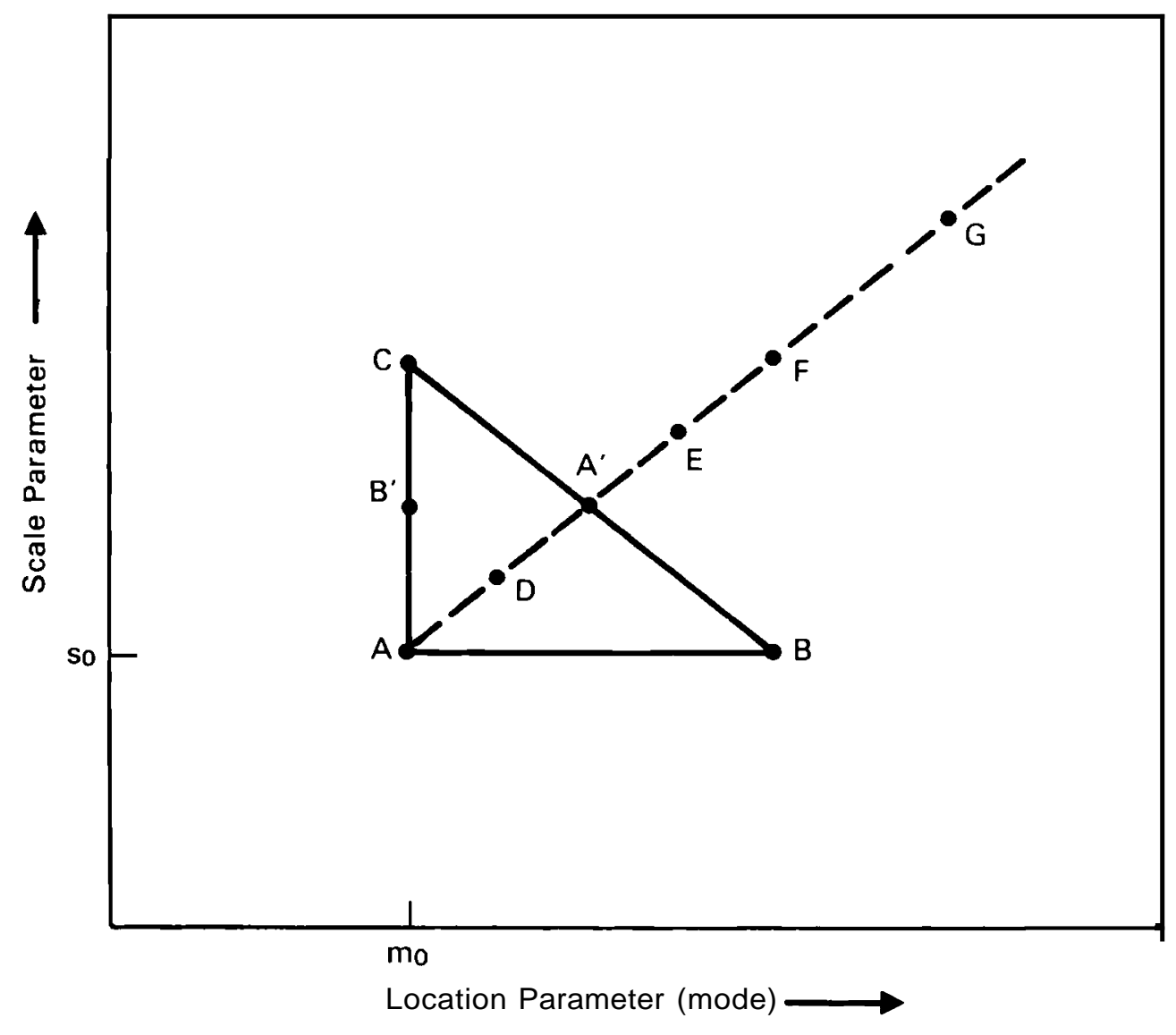

FIGURE A.1. A Simplex Used in Maximum-Likelihood Estimation.

A. 3 
- If $L(F)$ is equal to or less than $L(A)$ but equal to or greater than $L(B)$, then the negative log-1ikelihood function is computed for $E$, which is half way between $A^{\prime}$ and $F$. If $L(E)$ is less than $L(F)$, the simplex is contracted to BCE. Otherwise, the simplex shrinks to $A^{\prime} B^{\prime} C$, where $B^{\prime}$ is the centroid of the points remaining when $B$ is excluded.

4. Finally, if in the initial reflection $L(F)$ is greater than $L(A)$, the negative log-likelihood function is computed for $D$, which is halfway between $A$ and $A^{\prime}$. If $L(D)<L(A)$, the simplex is contracted, and the new simplex becomes $B C D$. Otherwise the new simplex is shrunk to $A^{\prime} B^{\prime} C$.

After the new simplex has been determined, the function values at the vertices are compared and the process starts over. As this iterative process is followed, the simplex is reoriented and distorted to conform to the slope of the function.

The number of iterations completed is counted as the procedure is followed. Convergence of the procedure is determined by computing the variance of the negative log-likelihood function at the $\mathrm{N}+\mathrm{l}$ vertices. When this variance falls below a predetermined convergence criterion, the algorithm is terminated. When the algorithm terminates due to convergence, a check is made to ensure that the point found is a local minimum. If it is not, the algorithm is restarted using the point with the lowest function values. The algorithm will terminate without convergence if the number of function evaluations exceeds a preset limit.

After final convergence is achieved, a quadratic surface is fit to the parameters using the parameter values in the final simplex. The quadratic fit can be used to obtain additional estimates of the function minimum- and bestparameter values. It may also be used to estimate variances of the parameter estimates and the covariances between the parameters (Nelder and Mead 1965).

Maximum likelihood has been used to refine the Type I distribution parameter estimates for the Atlantic Coast and Midwest multiple-station analysis examples. Table A.1 compares the method-of-moment and maximum-likelihood parameter estimates and their standard deviations. In both cases, the maximum-likelihood method gives somewhat larger parameter estimates and significantly larger estimates of the standard deviations of the estimates of the parameters. These changes increase the probability of extremes and the uncertainty in extreme wind speed estimates given a probability of occurrence. Figure A.2 shows the observed extreme wind distribution for the Atlantic Coast example and a Type I distribution having the maximum-likelihood parameters given in Table A.1. The Type I distribution with the maximum-likelihood parameters clearly fits the higher speed of the observed distribution better than the Type I distribution show in Figure 6, which was based on the method-of-moment parameter estimates. 


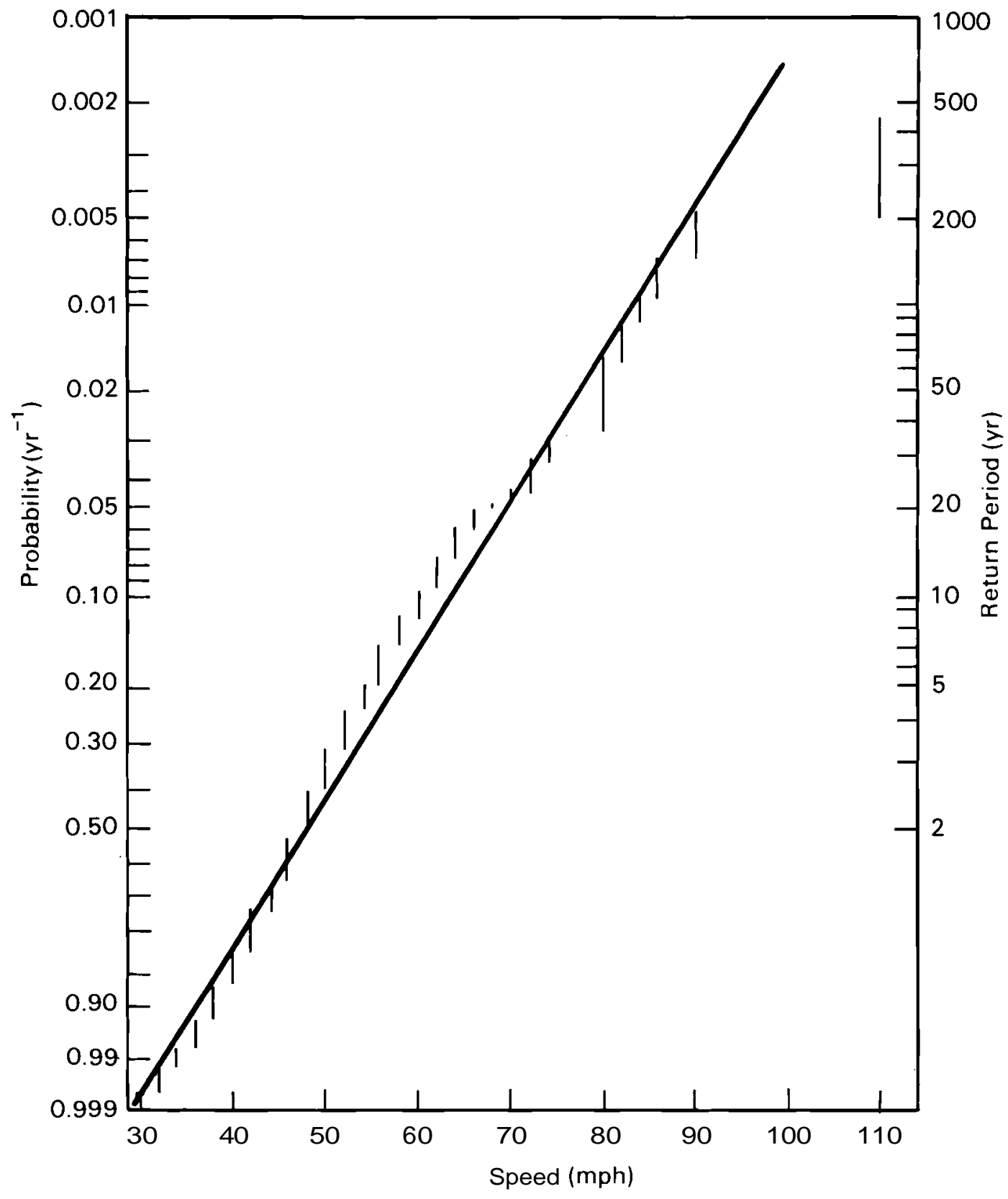

FIGURE A.2. Distribution of Observed Coastal Extreme Winds for Stations From Jacksonville Through Wilmington Showing a Type I Distribution with Maximum-Likelihood Parameter Estimates. 
TABLE A. 1. Compari son of Method-of-Moments and Maximum-Likelihood Estimates of Extreme Wind Distribution Parameters and Their Standard Deviations

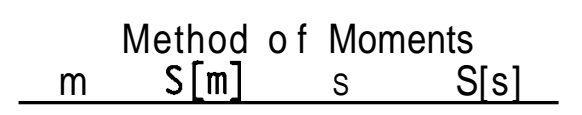

Atlantic

Coast

Midwest
43.690 .3944

7.5590 .3828

$45.39 \quad 0.3720$

$5.750 \quad 0,3611$

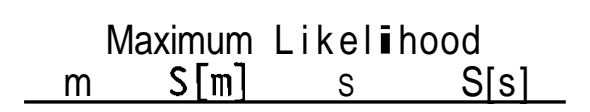

$\begin{array}{llll}44.54 & 0.6006 & 8.533 & 0.4782\end{array}$

$45.91 \quad 0.6821 \quad 7.825 \quad 0.5380$

\section{REFERENCES}

Brownlee, K. A. 1965. Statistical Theory and Methodology in Science and Engineering, J. Wiley \& Sons, New York, 590 pp.

Kinnison, R. R. 1985. Extreme Value Statistics. Macmillan Inc., New York, $149 \mathrm{pp}$.

Nelder, J. A., and R. Mead. 1965. "A Simplex Method for Function Minimization." Computer Journal 7:308-313.

O'Neill, R. 1971, "Algorithm AS47 - Function Minimization Using a Simplex Procedure." Applied Statistics 20:338-345.

Olsson, D. M., and L. S. Nelson. 1975. "The Nelder-Mead Simplex Procedure for Function Minimization." Technometrics 17:45-51.

Olsson, D. M. 1979. "Estimation for Mixtures of Distributions by Direct Maximization of the Likelihood Function." J. Quality Technology 11:153-159. 
APPENDIX B

VARIATION OF EXTREME WINDS WITH AVERAGING INTERVAL 


\section{VARIATION OF EXTREME WNDS WIH AVERAGING INIERVAL}

Several types of extreme wind data are generally available--peak gusts, fastest miles, and fastest 1 - and 5-min averages. To assemble an adequate data base for use in parameter estimation it may be necessary to combine data of two or more these types. However, gust magnitudes are related to the duration over which the speed is averaged. Therefore, before extreme wind data of various types are combined, the speeds should be adjusted to a standard averaging interval.

Gust factors are frequently used to describe the relationship between wind speed and averaging interval. For example, if $U(T)$ is a wind speed averaged for time $T, U(t)$ is the maximum speed averaged for time $t$, and $t$ is less than and contained within $T$, then the gust factor, $G(t: T)$, is

$$
G(t: T)=U(t) / U(T)
$$

For peak gusts measured with conventional anemometers, the minimum averaging interval is generally assumed to be about $2 \mathrm{~s}$ (e.g., Deacon 1965, Tattelman 1975, Wantz and Sinclair 1981). This minimum accounts for the response characteristics of the instruments and recording systems.

Deacon (1965) proposed that the ratio of a $\mathrm{T}$ second average to the maximum $2 \mathrm{~s}$ average within at a height of about $10 \mathrm{~m}$ be modeled as

$$
R(T: 2)=a-b \log _{16}(T+1.5)
$$

for $\mathrm{T}$ between about 1 and $100 \mathrm{~s}$, where $\mathrm{a}$ and $\mathrm{b}$ depend on the underlying terrain. This ratio is the reciprocal of the usual gust factor defined by Equation (B.1). Deacon's suggested values for $\mathrm{a}$ and $\mathrm{b}$ are given in Table B.1. For extremely flat terrain and over water, slightly smaller values of $a$ and $b$ might be appropriate. However, small changes in parameter values do not make consequential changes in standardized gust speeds.

\section{TABLE B. 1. Coefficient Values for Deacon's

\begin{tabular}{|c|c|c|}
\hline $\begin{array}{l}\text { Terrain } \\
\text { Type }\end{array}$ & $\mathrm{a}$ & $\mathrm{b}$ \\
\hline Open, treeless & 1.085 & 0.156 \\
\hline $\begin{array}{l}\text { Hedges, scattered } \\
\text { trees and buildings }\end{array}$ & 1.095 & 0.175 \\
\hline $\begin{array}{l}\text { Numerous trees and } \\
\text { buildings, suburban } \\
\text { areas }\end{array}$ & 1.12 & 0.220 \\
\hline
\end{tabular} Wind Speed Ratio Model}


Equation (B.2) provides a basis for adjusting gust speeds to an arbitrary averaging period. Letting $\mathbf{t}$ denote the desired averaging period and $\mathrm{T}$ the actual averaging interval, then

$$
G(t: T)=R(t: 2) / R(T: 2)
$$

where both the numerator and denominator of the right-hand expression are evaluated using Equation (B.2). $\quad G(t: T)$ in Equation (B.3) is equivalent to $G(t: T)$ in Equation (B.I).

The data on which Deacon based his relationship and the readily available gust factor data are for strong winds, but not necessarily for annual maximum gusts. Therefore, although extreme wind data should be adjusted to a common averaging time, the magnitude of adjustment of extreme wind data should be minimized. The most common extreme wind data are fastest miles. These averages are based on wind passage rather than time. Typical annual maximum fastest mile speeds are near $60 \mathrm{mph}$. At $60 \mathrm{mph}$ the one mile of wind passage takes $60 \mathrm{~s}$, and the averaging intervals for fastest mile speeds between 30 and $120 \mathrm{mph}$ are within a factor of two of $60 \mathrm{~s}$. Thus, it is reasonable to select $60 \mathrm{~s}$ as a reference averaging interval. by

Given a fastest mile speed $u$ in miles per hour, the adjusted speed is given

$$
U(60)=v(t)\left[\begin{array}{l}
a+b \log (61,5)] \\
{[a+b \log (t+1: 5)}
\end{array}\right]
$$

where the averaging interval is $\mathbf{t}=3600 / \mathbf{u}$ seconds. Similar equations can be derived for adjusting other extreme wind data. Appropriate coefficient values for use with Equation (B.4) for typical nuclear power plants are given in the second row of Table B.1.

The ratio of $\mathrm{t}$-s gust speeds to $60 \mathrm{~s}$ speeds implicit in Equation (B.4) is shown by the curve in Figure B.I along with observed gust factors. The point attributed to Wantz and Sinclair (1981) is the average gust factor for 94 stations in the Pacific Northwest. The standard deviation of the gust factors was 0.11. Tattelman's (1975) gust factors are based on empirical fits to 100 hours of data from the Mount Washington Observatory. The remaining data points shown in the figure are based on extreme wind data available from the NCDC. The data shown in the figure support Deacon's relationship.

\section{REFERENCES}

Deacon, E. L. 1965. "Wind Gust Speed: Averaging Time Relationship." Australian Meteorological Magazine 51:11-14.

Tattelman, P. 1975. "Surface Gustiness and Wind Speed Range as a Function of Time Interval and Mean Wind Speed." J. Appl. Meteorol. 14:1271-1276.

Wantz, J. W., and R. E Sinclair. 1981. "Distribution of Extreme Winds in the Bonneville Power Administration Service Area." J. Appl. Meteorol.

$20: 1400-1411$. 


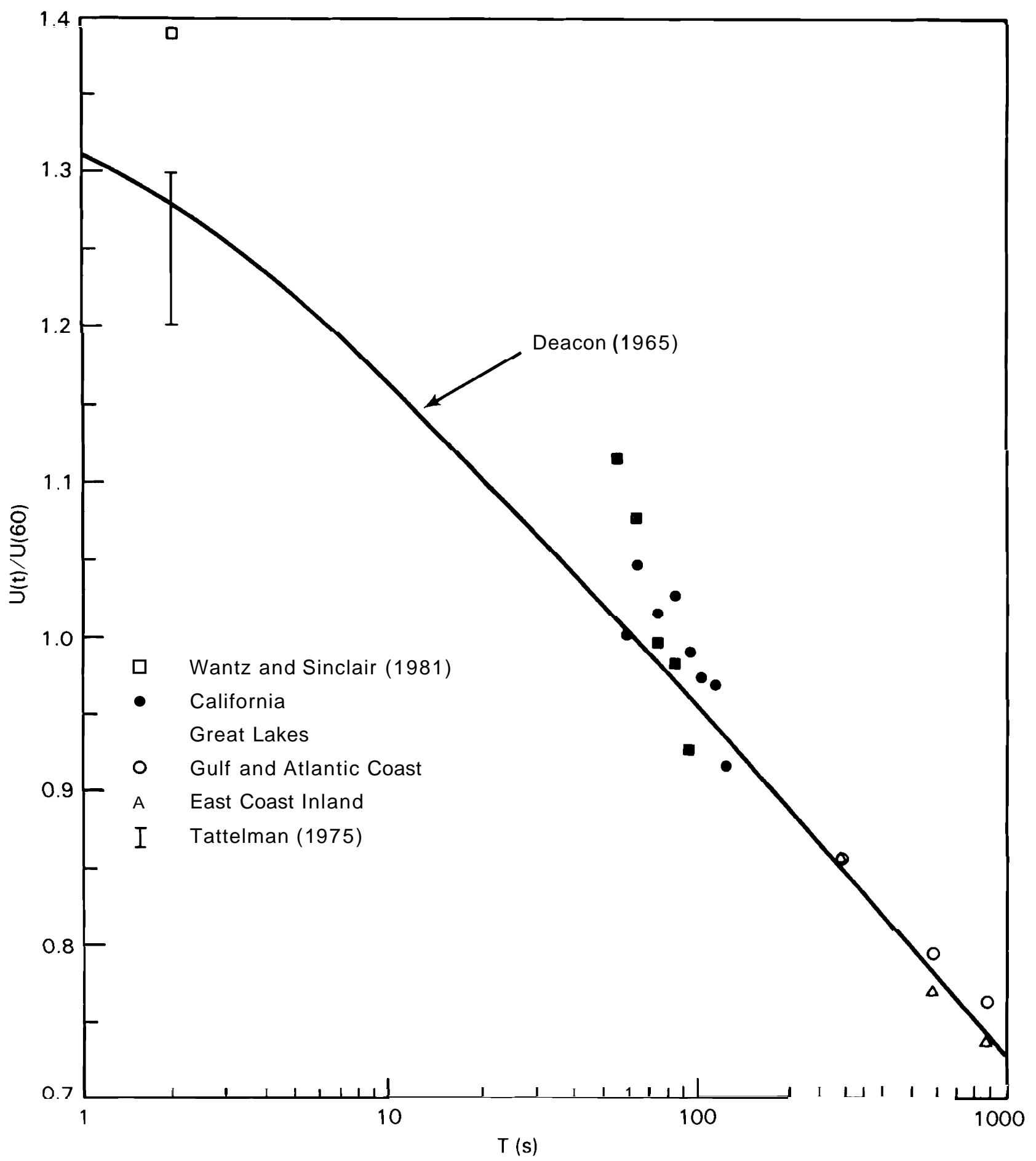

FIGURE B.1. Ratio of a T-s Gust to a $60 \mathrm{~s}$ Gust. 


\section{APPENDIX C}

VARIATION OF EXTREME WINDS WITH HEIGHT 


\section{VARIATION OF EXTREME WINDS WITH HEIGHT}

High winds tend to be associated with periods of neutral atmospheric stability. The wind profile in the lowest $100 \mathrm{~m}$ of the atmosphere during these conditions is described by a logarithmic relationship

$$
U(z)=\left(u^{*} / k\right) \ln \left[\left(z-z_{d}\right) / z_{0}\right]
$$

wh'ere $U(z)$ is the wind speed at height $z, z_{d}$ is a zero-plane displacement, $u^{*}$ is a characteristic wind speed called the friction velocity, $k$ is von Karman's constant $(\sim 0.4)$, and $z_{0}$ is a characteristic length that is generally associated with surface roughness.

It is reasonable to assume that extreme-gust magnitudes also vary with height. Therefore, if observed gust magnitudes are to be compared or used to estimate extreme gusts, the observed speeds should be adjusted to a standard reference height. However, the manner in which extreme gusts vary with height has not been established on the basis of observation.

The relationship used to adjust annual maximum wind speeds to a common measurement height used by Simiu et al. (1979), and Changery (1982a, 1982b) is

$$
U(10)=U(z) \frac{\ln \left(10 / z_{0}\right)}{\ln \left[\left(z-z_{d}\right) / z_{0}\right]}\{1.0+0.02[(z-10) / 10]\}
$$

where $U(10)$ is annual maximum observed speed adjusted to a standard height of $10 \mathrm{~m}$, and $U(z)$ is the observed maximum. The portion of the right term in front of the braces can be obtained directly from Equation (C.1), and the term in braces is a modification to the logarithmic profile to make the relationship appropriate for fastest mile speeds. This modification is based on turbulence observations made under steady-state atmospheric conditions.

This appendix suggests an alternative adjustment technique based on the assumptions: 1) that annual maximum winds are random samples drawn from an extreme value distribution, and 2) that the parameters of the distribution may be a function of location and height above the surface. The proposed technique tends to make smaller changes in speeds than result from Equation (C.2). As a result, it yields greater speeds at the standard level for wind that were observed at anemometer heights above the standard level. Consequently, the proposed procedure is more conservative than Equation (C.2) because most available extreme wind data were measured at heights above $10 \mathrm{~m}$.

Although the form of the extreme wind distribution is not known with certainty, extreme winds are frequently assumed to have a Fisher-Tippett Type I distribution. The Type I distribution will be assumed as a basis for evaluation of the vertical variation of distribution parameters. The Type I distribution has two parameters, a location parameter and a scale parameter. The location 
parameter of Type I distribution, and other extreme value distributions is the mode.

Data for use in evaluating the vertical variation of the Type I distribution parameters were obtained from measurements made on towers at Hanford, Washington and the Kennedy Space Center in Florida. Data for other locations (e.g., the NOAA tower near Boulder, Colorado) were sought, but were either nonexistent or not readily available.

The meteorological characteristics of both sites are well established. The Hanford tower is located on relatively flat terrain covered by grass and short shrubs and for most of the period of record was instrumented with aerovanes. Wind data are continuously recorded on strip charts. The roughness length is about $0.03 \mathrm{~m}(0.098 \mathrm{ft})$. Stone et al. (1983) describe the Hanford climate and instrumentation. The Kennedy Space Center tower is located about $5 \mathrm{~km}$ from the Atlantic Ocean and is instrumented with Climet CI-14 series anemometers. The tower site and instrumentation are described by Fichtl and McVehil (1970). The tower site is well exposed; the predominant upwind surface (175 degrees of azimuth) is covered with 1- to 2-m-high vegetation, sectors covering about $135^{\circ}$ of azimuth are covered with 10 - to 15 -m-high trees, and the remaining $50^{\circ}$ sector has a water surface. The surface roughness length is a function of direction. For most wind directions it is between 0.2 and $0.3 \mathrm{~m}$. However, for south-southeast winds, it is about $0.5 \mathrm{~m}$, and for westerly winds i t is between 0.5 and $0.8 \mathrm{~m}$.

The Hanford extreme wind data consist of 40 years of peak gust observations at 15.2, 60.9, and $122 \mathrm{~m}(50,200$, and $400 \mathrm{ft})$. These data, which have not been published previously, are presented in Table C.1. The Kennedy Space Center data consist of 4 years of peak gust data for three levels on a short tower $(3,10$, and $18 \mathrm{~m})$ and six levels on a tall tower $(18,30,60,90,120$, and $150 \mathrm{~m}$ ). The Kennedy data, which were abstracted from Alexander (1978), are presented in Table C.2.

The mean and standard deviations of the annual maximum wind speeds for each measurement level were computed. These values were used to estimate the mode and scale parameter of the distribution using the method of moments. The Hanford parameter estimates were refined using the maximum-likelihood techniques described in Appendix A. The parameter estimates for both sites are presented in Table C.3.

Figures C.1 and C.2 show the computed vertical variations of the modal annual maximum gust (location parameter) and scale parameter for Type I extreme value distributions at Hanford and the Kennedy Space Center, respectively. Both parameters tend to increase with increasing height, although the relationship between the scale parameter and height is not well defined. The mode clearly increases with the logarithm of height.

Coefficients for the model

$$
U(z)=A+B \ln (z)
$$

were estimated using linear regression, and a characteristic length $\mathrm{z}$, 
TABLE C.1. Hanford, Washington, Extreme Winds. Peak gusts in meters/second. A + in a date column indicates the first of two occurrences, and an $m$ indicates missing.

$15.2 \mathrm{M}$

$60.9 \mathrm{M}$

YEAR DATE DIR SPD

DATE DIR SPD

1945

1946

1947

1948

1949

1950

1951

1952

1953

1954

1955

1956

1957

1958

1959

1960

1961

1962

1963

1964

1965

1966

1967

1968

1969

1970

1971

1972

1973

1974

1975

1976

1977

1978

1979

1980

1981

1982

1983

1984

\begin{tabular}{|c|c|}
\hline 17 & USN \\
\hline $13+$ & $\mathbb{N V} 2$ \\
\hline $2 / 18$ & \\
\hline $5 / 26$ & SSN 31.7 \\
\hline $1 / 27$ & \\
\hline$/ 27$ & $\operatorname{SS} N$ \\
\hline$/ 15$ & SSN 27 \\
\hline $12 / 4$ & SSE 2 \\
\hline $9 / 28$ & $\operatorname{SSN} 2$ \\
\hline & $\mathbb{N}$ \\
\hline $\begin{array}{l}2 / 22 \\
2 / 1\end{array}$ & \\
\hline $3 / 1$ & 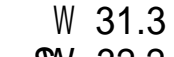 \\
\hline & $\underset{S N}{\mathbb{S}}$ \\
\hline $\begin{array}{l}11 / 3 \\
2 / 15\end{array}$ & S \\
\hline $11 / 24$ & ssw \\
\hline $8 / 1$ & sw \\
\hline $11 / 19$ & SSN \\
\hline $3 / 2$ & \\
\hline $3 / 14$ & UEN \\
\hline 5 & \\
\hline 120 & SSM \\
\hline $7 / 11+$ & $\begin{array}{l}5 \mathrm{~W}, \\
\text { VEN }\end{array}$ \\
\hline $4 / 12$ & WSW \\
\hline $7 / 3$ & SSN \\
\hline $2 / 24$ & \\
\hline $1 / 11$ & $\mathbb{S N}$ \\
\hline $11 / 16$ & \\
\hline $12 / 21$ & $\$ N$ \\
\hline $12 / 3$ & SS \\
\hline $3 / 24$ & \\
\hline $\begin{array}{l}11 / 1 \\
4 / 19\end{array}$ & \\
\hline+11 & \\
\hline $1 / 12$ & \\
\hline $11 / 1$ & \\
\hline $12 /$ & \\
\hline & \\
\hline & \\
\hline
\end{tabular}

$1 / 7+$ VIN 26.8

$6 / 13$ SW 30.4

$7 / 10$ S 31.3

$5 / 26 \quad$ SSN 36.6

$11 / 27$

$10 / 27$

$\mathrm{m}$

$1 / 9$

$11 / 26$

$12 / 22$

$3 / 2$

$6 / 5$

$11 / 3$

$12 / 15$

$11 / 24+$

SSN 32.2

SSW 31.7

m $\mathrm{m}$

$m$ m

\$V 32.6,

\$V 27.7

SV 33.5

\$N 33.1

SW39.8

U\$N 29.9

$8 / 15$

$11 / 19$

$3 / 28$

$1 / 19$

$2 / 5$

$1 / 1$

$1 / 29+$ SSW 30.8

$7 / 11+$ W 25.9

$4 / 12$ WSN 29.1

$7 / 3$

$2 / 24$

$4 / 5$

$11 / 16$

$12 / 21$

$12 / 3$

$3 / 24$

$11 / 1$

$12 / 22$

$7 / 9$

$1 / 12$

$11 / 14$

$12 / 16$

$3 / 13$

$12 / 14$
S26.4

SV 31.7

W38.4

SN 25.9

SV 32.6

\$N 32.6

SN 33.1

SSN 29.9

W 29.1

UN 32.2

SSN 29.1

SSN 32.2

SSN 32.6

W 32.6

S 30.8
$122 M$

DATE DIR SPD

$1 / 7+$ V\&N 26.8

$6 / 13 \quad$ SN 32.2

$7 / 10$ S 32.6

$6 / 9$ S 37.5

$11 / 27 \quad$ SSN 38.0

$10 / 27$ SSN 35.8

$1 / 15$ SV 32.6

$4 / 6 \quad$ NW 26.8

$1 / 9 \quad$ SN 34.9

$11 / 26$ \$V 30.4

$12 / 22$ SN 39.3

$3 / 2 \quad$ SN 36.3

$6 / 5$ SV 41.6

$11 / 3$ USN 32.2

$12 / 15 \quad$ SSN 27.7

$11 / 24$ S 29.9

$8 / 15$ \$V 34.0

$11 / 19$ SV 30.4

$3 / 28 \quad$ SN 34.9

$1 / 19$ SSW 29.1

$2 / 5 \quad$ SSN 37.1

$1 / 1 \quad$ SSN 31.3

$1 / 29$ SV 34.4

$7 / 11$ USN 26.8

$4 / 12$ WAV 29.9

$7 / 3$ S 26.8

$3 / 26$ SSN 33.5

$1 / 11$ U\&V 37.5

$11 / 16$ SV 25.5

$12 / 21 \quad$ SV 33.1

$12 / 3 \quad$ SN 35.3

$3 / 24$ SV 35.8

$11 / 1 \quad$ SSN 33.1

$12 / 22$ USN 34.4

$7 / 9$ V\$N 34.9

$1 / 12 \quad \mathbb{S N} 33.5$

$11 / 14 \quad$ SSN 35.3

$12 / 16 \quad$ SSN 36.2

$1 / 8$ W 32.2

$12 / 14$ S 29.5 
TABLE C.2. Peak Gusts at the Kennedy Space Center. Speeds are in meters/second. $m$ indicates missing data.

\begin{tabular}{|c|c|c|c|c|c|c|c|c|c|c|}
\hline $\begin{array}{l}\text { Short } \\
\text { Tower }\end{array}$ & $\begin{array}{r}1966 \\
\text { Date Dir }\end{array}$ & Spd & Date & $\begin{array}{l}1967 \\
\text { Dir }\end{array}$ & Spd & $\begin{array}{r}1968 \\
\text { Date Dir }\end{array}$ & Spd & $\begin{array}{r}19 \\
\text { Date } \mathrm{C}\end{array}$ & & Spd \\
\hline $\begin{array}{r}3 \mathrm{~m} \\
10 \mathrm{~m} \\
18 \mathrm{~m}\end{array}$ & $\begin{array}{cc}6 / 9 & 135 \\
\mathrm{~m} & \mathrm{~m} \\
6 / 9 & 128\end{array}$ & $\begin{array}{c}27.4 \\
\mathrm{~m} \\
30.3\end{array}$ & $\begin{array}{c}7 / 30 \\
\mathrm{~m} \\
7 / 30\end{array}$ & $\begin{array}{c}\text { m } \\
\text { m } \\
269\end{array}$ & $\begin{array}{c}22.9 \\
\mathrm{~m} \\
26.2\end{array}$ & $\begin{array}{ll}6 / 5 & 018 \\
6 / 5 & 028 \\
6 / 5 & 011\end{array}$ & & $\begin{array}{l}2 / 15 \\
7 / 25 \\
7 / 25\end{array}$ & $\begin{array}{l}151 \\
270 \\
270\end{array}$ & \\
\hline \multicolumn{11}{|l|}{$\begin{array}{r}\text { Tall } \\
\text { Tower } \\
\end{array}$} \\
\hline $\begin{array}{r}18 \mathrm{~m} \\
30 \mathrm{~m} \\
60 \mathrm{~m} \\
90 \mathrm{~m} \\
120 \mathrm{~m} \\
150 \mathrm{~m}\end{array}$ & $\begin{array}{rr}6 / 9 & 118 \\
6 / 9 & 127 \\
6 / 9 & 133 \\
6 / 9 & 131 \\
6 / 9 & 130 \\
1 / 22 & 190\end{array}$ & $\begin{array}{l}29.9 \\
30.3 \\
37.6 \\
40.7 \\
38.1 \\
32.6\end{array}$ & $\begin{array}{l}7 / 30 \\
7 / 30 \\
2 / 13 \\
2 / 13 \\
2 / 13 \\
2 / 13\end{array}$ & $\begin{array}{c}\mathrm{m} \\
280 \\
344 \\
346 \\
351 \\
345\end{array}$ & $\begin{array}{l}25.4 \\
28.2 \\
27.9 \\
28.8 \\
28.7 \\
29.7\end{array}$ & $\begin{array}{ll}6 / 5 & 015 \\
6 / 5 & 001 \\
6 / 5 & \mathrm{~m} \\
6 / 5 & 014 \\
6 / 5 & 014 \\
6 / 5 & 011\end{array}$ & $\begin{array}{l}32.0 \\
37.3 \\
35.5 \\
33.9 \\
38.2 \\
38.8\end{array}$ & $\begin{array}{r}10 / 3 \\
11 / 4 \\
10 / 3 \\
12 / 10 \\
10 / 3 \\
2 / 15\end{array}$ & $\begin{array}{c}153 \\
312 \\
159 \\
m \\
168 \\
137\end{array}$ & $\begin{array}{l}25.0 \\
26.8 \\
25.5 \\
25.8 \\
27.4 \\
30.8\end{array}$ \\
\hline
\end{tabular}

Table C.3. Parameter Estimates for Extreme Wind Distributions at Hanford and the Kennedy Space Center Based on Peak Gust Data.

\begin{tabular}{|c|c|c|}
\hline Location & $\begin{array}{c}\text { Height } \\
\text { (m) }\end{array}$ & $\begin{array}{r}\text { Mode } \\
(\mathrm{m} / \mathrm{s}) \\
\end{array}$ \\
\hline Hanford & $\begin{array}{r}15.2 \\
60.9 \\
121.9\end{array}$ & $\begin{array}{l}26.3 \\
29.6 \\
31.0\end{array}$ \\
\hline $\begin{array}{l}\text { Kennedy } \\
\text { Short } \\
\text { Tower }\end{array}$ & $\begin{array}{r}3 \\
10 \\
18\end{array}$ & $\begin{array}{l}23.9 \\
23.9 \\
26.2\end{array}$ \\
\hline $\begin{array}{l}\text { Kennedy } \\
\text { Tall } \\
\text { Tower }\end{array}$ & $\begin{array}{r}18 \\
30 \\
60 \\
90 \\
120 \\
150\end{array}$ & $\begin{array}{l}26.5 \\
28.6 \\
29.0 \\
29.4 \\
30.5 \\
31.1\end{array}$ \\
\hline
\end{tabular}

analogous to $z_{0}$ was estimated for each location from

$$
Z_{c}=\exp (-A / B)
$$

The estimated characteristic lengths are shown on Figures C.I and C.2. In each case, the characteristic length is significantly smaller than the typical roughness length. For Hanford, the ratio of the characteristic length for the 


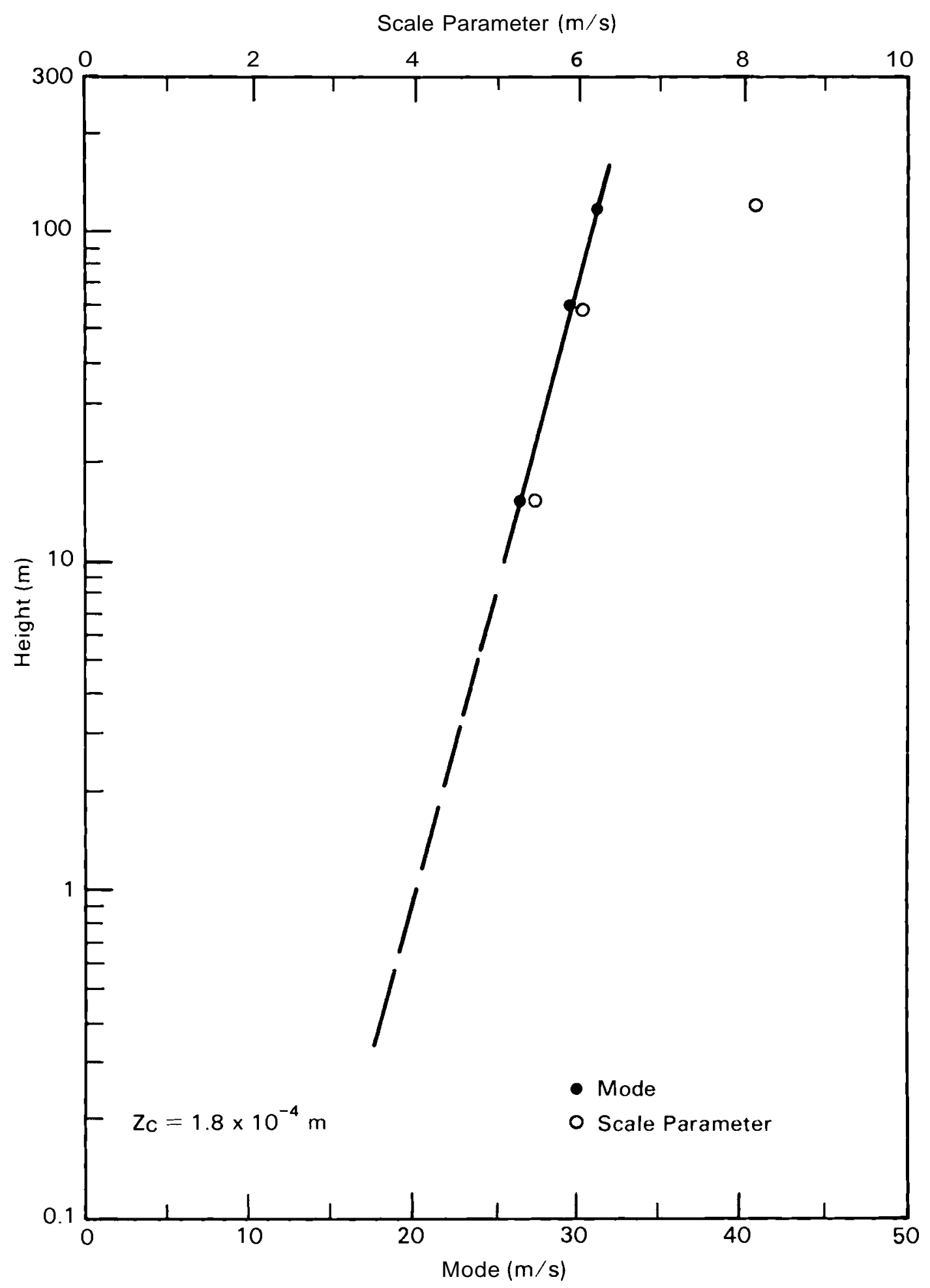

Hanford (1945-1984)

FIGURE C.1. Vertical Variation of Extreme Wind Distribution Parameters at Hanford, Washington.

$$
\text { C. } 5
$$




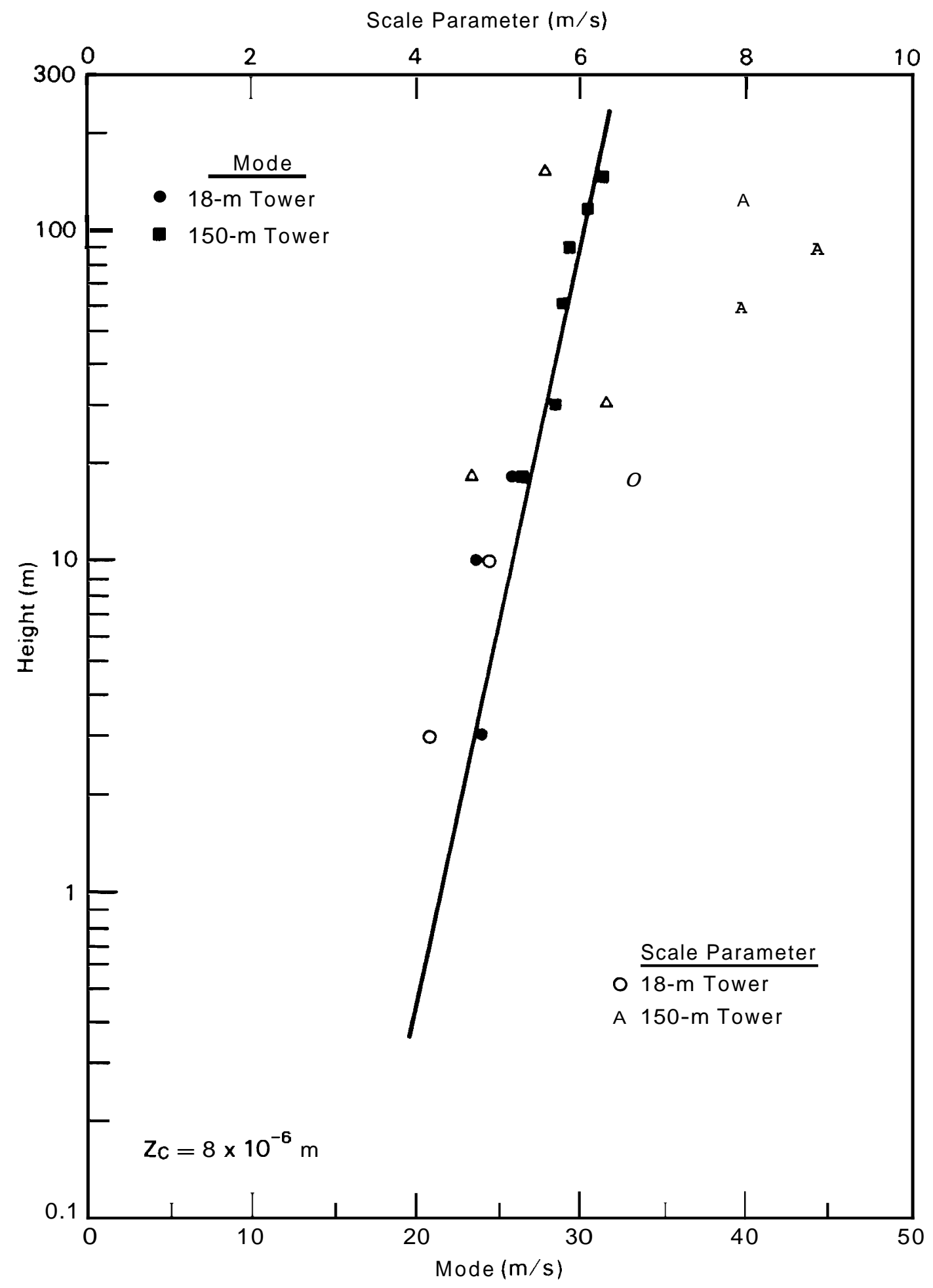

Kennedy Space Center (1966-1969)

FIGURE C.2. Vertical Variation of Extreme Wind Distribution Parameters at the Kennedy Space Center, Florida. 
extreme wind location parameter profile to that for the mean wind profile is about $6 \times 10^{-3}$. The ratio for the Kennedy Space Center is about $3 \times 10^{-5}$.

From the perspective of adjusting wind extreme winds, it is clear that the extreme winds at these sites do not decrease as rapidly with decreasing height as do the mean winds. On this basis, it is recommended that extreme winds at $10 \mathrm{~m}(33 \mathrm{ft})$ be estimated using

$$
U(10)=U(z) \frac{\ln \left(10 / z_{0}\right)}{\ln \left[\left(z-z_{d}\right) / z_{c}\right]}
$$

where $z_{c}=a z_{0}$, with $a=10^{-3}$.

There is no theoretical basis for estimation of a zero-plane displacement for gusts. However, the effect the zero-plane displacement in Equation (C.8) is to reduce the magnitude of the adjustment in gust speeds. Therefore, if there is a zero-plane displacement for gusts, assuming a value of zero for $\mathbf{z}_{d}$ for all locations would be non-conservative. Changery (1982a, 1982b) provides a reasonable method for estimating $z_{d}$ on the basis of typical surface conditions at stations. He grouped wind measurement locations into four categories. For airport and some coastal stations, $\mathbf{z}_{\mathbf{d}}$ was assumed to be zero. For measurement stations in urban areas, the zero-plane displacement was computed from the instrument height. The building height was assumed to be $75 \%$ of the measurement height, and the zero-plane displacement was assumed to be $75 \%$ of the building height, with the restriction that $z_{d}$ was not allowed to exceed $20 \mathrm{~m}$.

The ratio between the wind speed at $10 \mathrm{~m}$ and that at height $\mathrm{z}$ can be defined as an adjustment factor and can be used to compare the effects of Equations (C.2) and (C.8). The reduction factors for the two equations (assuming $\mathbf{z}_{0}=0.05 \mathrm{~m}$ and $\mathbf{z}_{\mathrm{d}}=0$ ) are shown in Table C.4 for measurements at four levels. For each of these levels, Equation (C.8) gives higher reduced speeds. When the reduction factors are applied to a $60 \mathrm{mph}$ wind at each level, the difference in reduced speeds ranges from 1.6 mph for speeds measured at $91.4 \mathrm{~m}(300 \mathrm{ft})$ to $3.6 \mathrm{mph}$ for speeds measured at $30.5 \mathrm{~m}(100 \mathrm{ft})$. Thus, Equation (C.8) is a more conservative method for adjusting for measurement height than Equation (C.2). Therefore, Equation (C.8) is the recommended method for adjusting heights.

TABLE C.4. Comparison of Factors for Use in Reducing Extreme Wind Speed Measurements Made at Height $z$ to Speeds at $10 \mathrm{~m}$ (33 $\mathrm{ft})$.

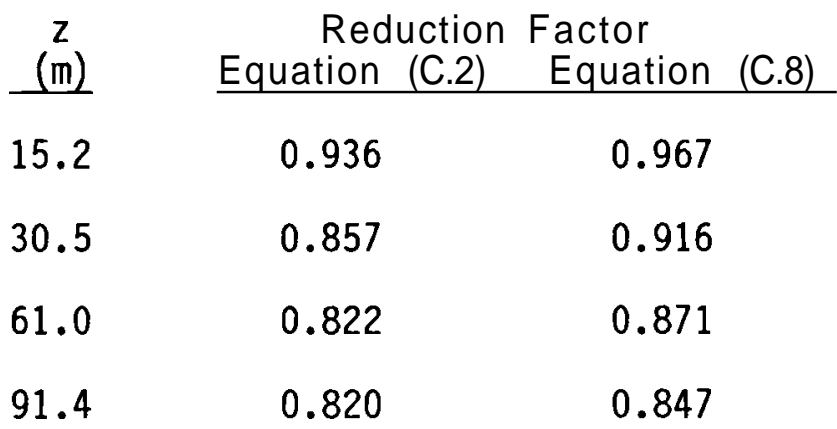




\section{REFERENCES}

Alexander, M. B. 1978. An Analysis of Maximum Horizontal Wind Speeds Recorded Since 1961 at Kennedy Space Center, Florida. NASA TM-78177. George C. Marshall Space Flight Center, Marshall Space Flight Center, Alabama.

Changery, M. J. 1982a. Historical Extreme Winds for the United States Atlantic and Gulf of Mexico Coastlines. NUREG/CR-2639, U.S. Nuclear Regulatory Commission, Washington, D.C.

Changery, M. J. 1982b. Historical Extreme Winds for the United States - Great Lakes and Adjacent Regions. NUREG/CR-2890, U.S. Nuclear Regulatory Commission, Washington, D.C.

Fichtl, G. H., and G. E. McVehil. 1970. "Longitudinal and Lateral Spectra of Turbulence in the Atmospheric Boundary Layer and the Kennedy Space Center." J. Appl. Meteor. 9:51-63.

Simiu, E., M. J. Changery and J. J. Filliben. 1979. .Extreme Wind Speeds at 129 Stations in the Contiguous United States. NBS Building; Science Series 118, National Bureau of Standards, Washington, D.C.

Stone, W. A., J. M. Thorp, 0. P. Gifford and D. J. Hoitink. 1983. Climatological Summary for the Hanford Area. PNL-4622, Pacific Northwest Laboratory, Richland, Washington. 
APPENDIX D

BASIC PROGRAM FOR EVALUATING EXTREME WIND PROBABILITIES 


\section{BASIC PROGRAM FOR EVALUATING EXTREME WIND PROBABILITIES}

The following program provides estimates of the probability associated with specific extreme winds and a $90 \%$ confidence band for wind speeds at that probability. The wind speeds given are fastest-mile speeds.

The program, as presented, assumes the method-of-moments relationships between the scale parameter and the variances of the mode and scale parameter. If the parameter estimates have been obtained using a method that provides estimates of the parameter variances, the code should be modified to accept those variances. This can be done by replacing lines 310 and 320 with input statements.

The program is written in BASICA and should run on most personal computers without major modifications. The computations in the program are keyed to equations in the body of the report by equation numbers given in the remarks. Remarks are indicated by an apostrophe at the beginning of a line. Several lines of the code contain more than one statement; in these lines the statements are separated by colons.

10 PROGRAM TO ESTIMATE THE PROBABILITY OF EXTREME WINDS

20 'ON THE BASIS OF METHOD-OF-MOMENTS ESTIMATES OF THE

30 MODE AND SCALE PARAMEIER OF A FISHER-TIPPETT TYPE-I

40 'DISTRIBUTION AND AN ESTIMATE OF THE TORNADO STRIKE

50 'PROBABILITY

60 I

70 PRINT "THIS PROGRAM COMPUTES THE PROBABILITIES ASSOCIATED"

80 PRINT "WITH EXTREME FASTEST MILE WINDS BETWEEN 40 AND 400 MPH."

90 PRINT : PRINT "INPUT DATA REQUIRED ARE THE NUMBE OF EXTREME WIND"

100 PRINT "OBSERVATIONS, THE MODE AND SCALE PARAMEIER FOR THE DISTRIBUTION,"

110 PRINT "AND THE TORNADO STRIKE PROBABILITY":PRINT

120 '

130 DIM ST(25)

140 FOR I = 1 TO 25: READ ST(I) : NEXT I

150 '

160 't STATISTICS FOR 90\% CONFIDENCE INTERVAL

170 DATA $6.314, \quad 2.920, \quad 2.353, \quad 2.132, \quad 2.015, \quad 1.943, \quad 1.895, \quad 1.860,1.833$

180 DATA $1.812,1.753,1.725,1.708,1.697,1.690,1.684,1.680,1.676$

190 DATA 1.671, 1.667, 1.665, 1.662, 1.661, 1.658, 1.645

200 '

210 LPRINT "EXTREME WIND ESTIMATION -- PROCRAM DATED 9/5/86

220

230 PRINT: INPUT "ENTER LOCATION ", LOCATION\$

240 LPRINT: LPRINT LOCATION\$ :LPRINT

250 '

260 PRINT: INPUT "ENTER THE TOTAL NUMBE OF OBSERVATIONS ", NOBS

270 PRINT: INPUT "ENTER THE MODE OF THE DISTRIBUTION ", M1

280 PRINT: INPUT "ENTER SCALE PARAMETER ",S1

290 ' 
300 'COMPUTE VARIANCES OF MODE AND SCALE PARAMETER (eqnS 7 \& 8)

310 VM1 $=1.1678 * S 1 \wedge 2 /$ NOBS

320 VS1 $=1.1 * \mathrm{~S} 1 \wedge 2 /$ NOBS

330 '

340 LPRINT "OBSERVED EXTREME WINDS"

350 LPRINT USING "\#\#\# OBSERVATIONS, MODE = \#\#.\#\#\#, SCALE = \#\#.\#\#\#";

360 NOBS, M1 , S1

370 PRINT: INPUT "ENTER THE TORNADO STRIKE PROBABILITY ",PS

380 PRINT:PRINT "TORNADO REGIONS: $1=$ EASTERN UNITED STATES"

390 PRINT " 2 = WESTERN UNITED STATES"

400 PRINT" 3 = CONTIGUOUS UNITED STATES"

410 PRINT: INPUT "ENTER REGION NUMBER ", REGION

420 '

430 'SELECT PARAMETERS FOR TORNADO INTENSITY DISTRIBUTION

440 I $F$ REGION=1 THEN $A=136.1: B=3.076:$ LPRINT "EASTERN UNITED STATES"

450 I $F$ REGION=2 THEN $A=78.29: B=2.357:$ LPRINT "WESTERN UNITED STATES"

460 I F REGION 1 OR REGION $>2$ THEN $A=135.6: B=3.033: L P R I N T$ "CONTIGUOUS UNITED STATES"

470 LPRINT USING "TORNADO STRIKE PROBABILITY = \#.\#\#\#^^^^";PS

480 PRINT

490 '

500 'PICK t STATISTIC

510 LPRINT:NDF = NOBS - 2

520 I F NDF $<11$ THEN STI = NDF: GOTO 560

530 I F NDF $<55$ THEN STI $=$ NDF $\backslash 5+8:$ GOTO 560

540 I F NDF $<110$ THEN STI $=$ NDF $\backslash 11+13:$ GOTO 560

550 I F NDF $<150$ THEN STI $=24$ ELSE STI $=25$

560 '

570 LPRINT "SPD $\quad Y \quad$ PROB. $\quad$ CONF LIM. $\quad$ T. PROB."

580 FOR I $=40$ TO 400 STEP 10

590 '

600 'CONVERT FASTEST MILE TO 60-S AVERAGE (eqns 17, 19 \& 20)

$610 \mathrm{~T}=3600 / \mathbf{I}$

$620, \mathrm{U} 60=(.7819 * \mathbf{I}) /(1.095-.076 * \operatorname{LOG}(\mathrm{T}+1.5))$

640 'COMPUTE STANDARDIZED SPEED (eqn 2)

$650 \quad Y_{1}=(U 60-M 1) / S 1$

660

670 'COMPUTE PROBABILITY (eqn 3)

$680 \quad P S L=1 !-\operatorname{EXP}(-\operatorname{EXP}(-Y 1))$

690

700 'COMPUTE UPPER AND LOWER CONFIDENCE LIMITS FOR 60-S AVERAGE SPEED (eqn 10)

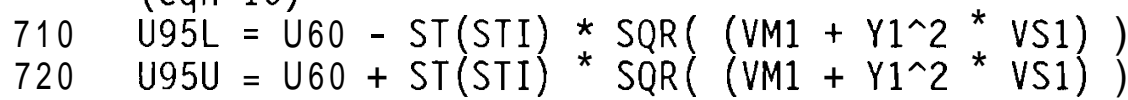

730 '

740 'COMPUTE TORNADO PROBABILITY (eqns $11 \& 13$ )

$750 \quad$ PTOR $=0$

$760 \mid \mathrm{F} \mathbf{I} \Rightarrow 40$ THEN PTOR $=$ PS ${ }^{*} \operatorname{EXP}\left(-((I-40) / A)^{\wedge} B\right)$ 
780 'STOP COMPUTATIONS I F TORNADO PROBABILITY $<1.0 \mathrm{E}-7$

790 IF PTOR <.0000001 THEN GOTO 980

800 '

810 'CONVERT CONFIDENCE LIMITS TO FASTEST-MILE SPEEDS

820 TFO $=3600 /$ U95L

830 UFLO $=$ U95L * $(1.4004-.0972 * \operatorname{LOG}($ TFO + 1.5) $)$
840 TFL $=3600 \%$ UFLO

$850 \mathrm{UFL}=\mathrm{U95L} *(1.4004-.0972 * \operatorname{LOG}(\mathrm{TFL}+1.5))$

860 IF ABS (UFL-UFLO) <.001 THEN GOTO 870 ELSE UFLO = UFL: GOTO 840

870 TFO $=3600 /$ U95U

880 UFUO $=$ U95U * $\left(1.4004-.0972{ }^{*} \operatorname{LOG}(\right.$ TFO +1.5$\left.)\right)$

890 TFU $=3600 /$ UFUO

900 UFU $=$ U95U * $(1.4004-.0972 * \operatorname{LOG}(\mathrm{TFU}+1.5))$ 910 IF ABS(UFL-UFLO) $<.001$ THEN GOTO 920 ELSE UPU = UFU: GOTO 890

930 'PRINT RESULTS

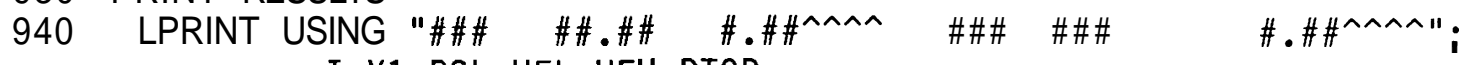

950 NEXT

I, Y1 , PSL, UFL, UFU, PTOR

960 '

970 'SK IP TO TOP OF PAGE (SEND ASC II FORM FEED TO PR INTER)

980 LPRINT CHR\$(12)

990 GOTO 230

1000 END 


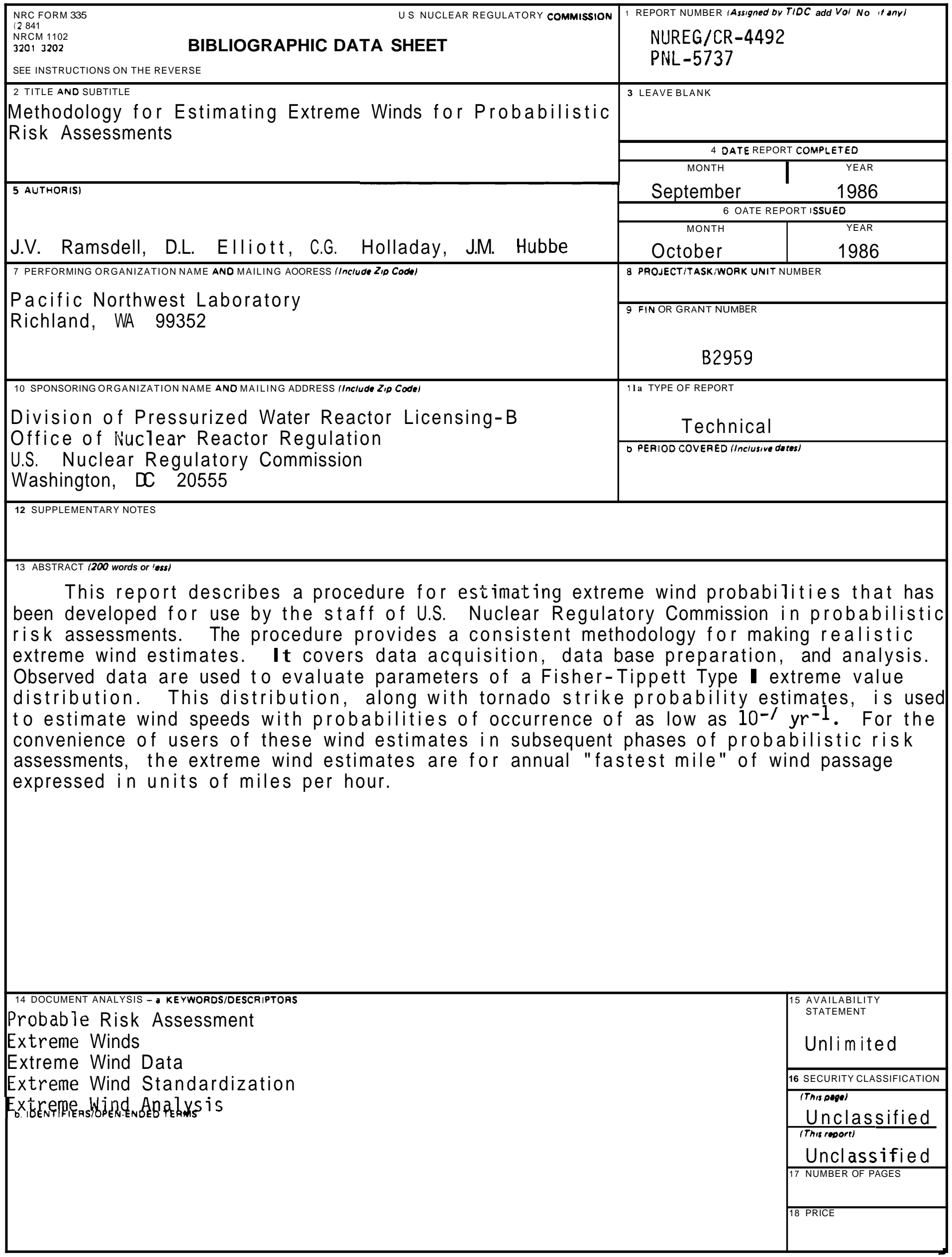

